San Jose State University

SJSU ScholarWorks

Master's Theses

Master's Theses and Graduate Research

1998

\title{
The effect of plasma gas flow rate on adhesion of copper to acrylonitrile-butadiene-styrene plastics
}

\author{
Rajesh Arjun Ashrani \\ San Jose State University
}

Follow this and additional works at: https://scholarworks.sjsu.edu/etd_theses

\section{Recommended Citation}

Ashrani, Rajesh Arjun, "The effect of plasma gas flow rate on adhesion of copper to acrylonitrilebutadiene-styrene plastics" (1998). Master's Theses. 1686.

DOI: https://doi.org/10.31979/etd.j78r-v8wa

https://scholarworks.sjsu.edu/etd_theses/1686

This Thesis is brought to you for free and open access by the Master's Theses and Graduate Research at SJSU ScholarWorks. It has been accepted for inclusion in Master's Theses by an authorized administrator of SJSU ScholarWorks. For more information, please contact scholarworks@sjsu.edu. 


\section{INFORMATION TO USERS}

This manuscript has been reproduced from the microfilm master. UMI films the text directly from the original or copy submitted. Thus, some thesis and dissertation copies are in typewriter face, while others may be from any type of computer printer.

The quality of this reproduction is dependent upon the quality of the copy submitted. Broken or indistinct print, colored or poor quality illustrations and photographs, print bleedthrough, substandard margins, and improper alignment can adversely affect reproduction.

In the unlikely event that the author did not send UMI a complete manuscript and there are missing pages, these will be noted. Also, if unauthorized copyright material had to be removed, a note will indicate the deletion.

Oversize materials (e.g., maps, drawings, charts) are reproduced by sectioning the original, beginning at the upper left-hand comer and continuing from left to right in equal sections with small overlaps. Each original is also photographed in one exposure and is included in reduced form at the back of the book.

Photographs included in the original manuscript have been reproduced xerographically in this copy. Higher quality 6" $\times 9$ " black and white photographic prints are available for any photographs or illustrations appearing in this copy for an additional charge. Contact UMI directly to order.

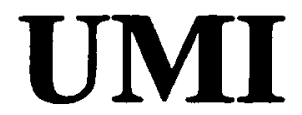

A Bell \& Howell Information Company 



\section{NOTE TO USERS}

The original manuscript received by UMI contains pages with light and slanted print. Pages were microfilmed as received.

This reproduction is the best copy available

\section{UMI}



THE EFFECT OF PLASMA GAS FLOW RATE ON ADHESION OF COPPER TO ACRYLONITRILE-BUTADIENE-STYRENE PLASTICS

\author{
A Thesis \\ Presented to \\ The Faculty of the Department of Chemical Engineering \\ San Jose State University
}

In Partial Fulfillment

of the Requirements for the Degree

Master of Science

by

Rajesh Arjun Ashrani

August 1998 
OMI Number: 1391509

UMI Microform 1391509

Copyright 1998, by UMI Company. All rights reserved.

This microform edition is protected against unauthorized copying under Title 17, United States Code.

\author{
UMI \\ 300 North Zeeb Road \\ Ann Arbor, MI 48103
}


(c) 1998

Rajesh Arjun Ashrani

ALL RIGHTS RESERVED 
APPROVED FOR THE DEPARTMENT OF CHEMICAL ENGINEERING

Melanie me nil

Dr. Melanie McNeil

(Chairperson and Thesis Advisor)

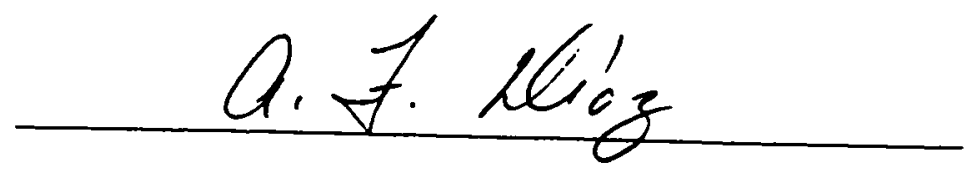

Dr. Arthur Diaz

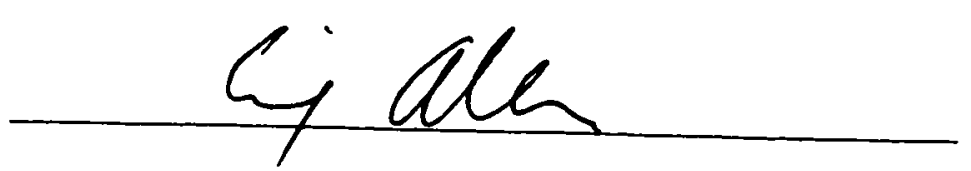

Dr. Emily Allen

APPROVED FOR THE UNIVERSITY

William Bis 


\begin{abstract}
THE EFFECT OF PLASMA GAS FLOW RATE ON ADHESION OF COPPER TO

ACRYLONITRILE-BUTADIENE-STYRENE PLASTICS

by Rajesh Arjun Ashrani
\end{abstract}

This thesis addresses the effect of varying the flow rate of oxygen and helium during plasma etching of acrylonitrile-butadiene-styrene(ABS) substrate and the resulting adhesion strength obtained after electroplating the substrate with copper. Coupons were etched at $25 \mathrm{ml} / \mathrm{min}$, $50 \mathrm{ml} / \mathrm{min}$., $75 \mathrm{ml} / \mathrm{min}$. and $92\left(\mathrm{O}_{2}\right)$ or $100(\mathrm{He}) \mathrm{ml} / \mathrm{min}$. Etch time(te), RF Power(E), and Chamber Pressure(P) were maintained constant at $10 \mathrm{~min}$., 50 Watts, and $380 \mathrm{mtorr}$, respectively.

Peel strength analysis reveled that average peel strength decreased linearly as the flow rate was increased for both gases. The range of peel strength was between 2.54 to $4.27 \mathrm{~kg} / \mathrm{cm}$ for oxygen and 1.13 to $2.42 \mathrm{~kg} / \mathrm{cm}$ for helium. Oxygen etched ABS revealed that an increase in flow rate reduced the number of pores, increased the average pore diameter and reduced the average fractional etch area. Helium etched ABS showed that an increase in flow rate increased the number of pores, reduced the average pore diameter and reduced the average fractional etch area. The average pore diameter distribution for oxygen etched substrate showed the maximum number of pores to be between $0.1-0.4 \mu \mathrm{m}$ for $25 \mathrm{ml} / \mathrm{min}$. and $92 \mathrm{ml} / \mathrm{min}$, respectively and for helium etched ABS it was between $0-0.3 \mu \mathrm{m}$ and $0-0.2 \mu \mathrm{m}$. for $25 \mathrm{ml} / \mathrm{min}$. and $100 \mathrm{ml} / \mathrm{min}$, respectively. 


\section{ACKNOWLEDGMENTS}

I would like to thank the following people for their help and support:

Dr. Melanie McNeil

Dr. Peter Gwordz

Dr. Arthur Diaz

Dr. Emily Allen

Dr. Patrick Pizzo

Mr. John Hanel

Mr. Raynaldo Aguilar

Mrs. Fe Aguilar

Dr. Suparna Ashrani

Mr. Gene Smith of Research Devices, Inc.

Mr. Harsh Kacchi of Atotech U.S.A

Mr. Peter Halden of 3M Corporation

Mr. Mike Ahlman and Mr. Doug Kinsey of March Instruments

Mr. Mick Barber and Mr. Richard of Quard Group

Mr. Arthur W. Schmell of Porter Instrument Company, Inc.

My Parents: Mr. Arjun Ashrani and Mrs. Kiran Ashrani

Mr. Gurmeet Naroola 


\section{$1.0 \quad$ INTRODUCTION}

1.1 General background 1

1.2 Description of the plating process 5

1.3 Available etching methods 7

2.0 LITERATURE REVIEW

2.1 Theory of mechanical or chemical bond formation 13

2.2 Effect of different parameters on adhesion 15

$\begin{array}{lll}2.3 & \text { Effect of different plasmas on adhesion }\end{array}$

$\begin{array}{lll}2.4 & \text { Summary } & 24\end{array}$

3.0 RESEARCH HYPOTHESIS AND OBJECTIVE

$\begin{array}{llr}3.1 & \text { Hypotheses } & 29\end{array}$

$\begin{array}{lll}3.2 & \text { Objective } & 30\end{array}$

4.0 EXPERIMENTAL PROCEDURE AND APPARATUS

4.1 Plasma Etching 31

$\begin{array}{lll}4.2 & \text { Copper plating } & 32\end{array}$

$\begin{array}{lll}4.3 & \text { Peel test analysis } & 36\end{array}$

4.4 Scanning electron microscope (SEM) analysis 36

4.5 Copper thickness measurement and analysis 37

4.6 Data analysis 38

$\begin{array}{lll}4.7 & \text { Graphical analysis } & 40\end{array}$ 


\subsection{RESULTS}

5.1 Introduction 41

5.2 Peel strength results 41

$\begin{array}{lll}5.3 & \text { Repeatability and reproducibility } & 47\end{array}$

$\begin{array}{lll}5.4 & \text { SEM results } & 48\end{array}$

6.0 DISCUSSION

6.1 Effect of flow rate on peel strength 61

6.2 Effect of flow rate on etching 65

$\begin{array}{lll}7.0 & \text { CONCLUSION } & 70\end{array}$

$\begin{array}{ll}\text { REFERENCES } & 73\end{array}$

APPENDICES

APPENDIX A: Description of Apparatus $\quad 77$

APPENDIX B: Description of procedure $\quad 86$

APPENDIX C: SEM traces of etched coupons $\quad 112$

APPENDIX D: SEM data for etched coupons 115 


\section{LIST OF TABLES}

TABLE 1: Comparison of different etching methods 3

TABLE 2: Plasma etching experimental procedure 33

TABLE 3: Plating experimental procedure $\quad 34$

TABLE 4: Peel strength for oxygen etched ABS substrate 42

TABLE 5: Peel strength for helium etched ABS substrate 45

TABLE 6: Plating bath make up and analysis frequency 94

TABLE 7: Analysis tests for PD-Pre catalyst bath 95

TABLE 8: Analysis tests for PD and PTC catalyst bath 96

TABLE 9: Analysis tests for AA Accelerator bath 97

TABLE 10: Analysis tests for MR-A and MR-B bath 99

TABLE 11: Analysis test for AT-C Anti-tarnish bath 100

TABLE 12: Analysis tests for electrolytic copper plating bath 101

TABLE 13: Electroless and acid copper plating time schedule 102

TABLE 14: Copper film thickness measurement 105 


\section{LIST OF FIGURES}

FIGURE 1: Plasma etching effect on wetablity 2

FIGURE 2: Steps in conventional ABS plating process 6

FIGURE 3: Schematic of surface modification in plasma reactor 9

FIGURE 4: One variable testing: Varied flow rate 25

FIGURE 5: One variable testing: Varied chamber pressure 26

FIGURE 6: Cohesive failures $\quad 35$

FIGURE 7: Peel strength versus varying flow rate for oxygen 43

FIGURE 8: Peel strength versus varying flow rate for helium 46

FIGURE 9: SEM micrograph for unetched ABS substrate 50

FIGURE 10: SEM micrograph of oxygen etched substrate @25 ml/min. 51

FIGURE 11: SEM micrograph of oxygen etched substrate @92 ml/min. 52

FIGURE 12: SEM micrograph of helium etched substrate @25 ml/min. 53

FIGURE 13: SEM micrograph of helium etched substrate @100 ml/min. 54

FIGURE 14: Average pore diameter distribution for oxygen 55

FIGURE 15: Average pore diameter distribution for helium 56

FIGURE 16: Number of pores versus gas flow rate 58

FIGURE 17: Average pore diameter versus gas flow rate 59

FIGURE 18: Average fractional etch area versus gas flow rate 60

FIGURE 19: March plasma etcher CS-1701 78

FIGURE 20: Sample preparation for peel test 81 
FIGURE 21: March Plasma etcher CS-1701; Back side view

FIGURE 22: Front panel display of etcher

FIGURE 23: Conversion factor chart

89

FIGURE 24: SEM magnification controls

FIGURE 25: SEM trace of coupon etched with oxygen

113

FIGURE 26: SEM trace of coupon etched with helium

114 


\subsection{INTRODUCTION}

\subsection{GENERAL BACKGROUND}

Over the past four decades industries have been eliminating metal parts and replacing them with metal - plated plastics. Metal - plated plastics have helped various industries to lower their production cost without hampering the quality of their products. In fact, the metal - plated parts have more and better chemical and physical properties, such as better corrosion resistance, conductivity, metallic strength, metallic luster and is much lighter, than their metal counterparts (Heymann et. al., 1970; Villamizar et. al., 1981). These parts are used in the printed circuit board industries, automobile industries, home furnishings, artistic jewelry, coating industries, aircraft industries, space industries and kitchen wares.

Plastic substrates are usually hydrophobic and are not naturally wetable. Oxidation and surface roughening are necessary to increase adhesion and improve bond strength during electroplating. A common method of determining wetability is by measuring the contact angle between a liquid drop and the surface. Figure 1 shows a comparison between the contact angle of untreated plastic and plasma treated plastic. Plasma etch reduces the contact angle and increases the surface energy for better bonding characteristics. The roughness of the surface provides greater adhesion of subsequent top coats. Some common etching methods are: 


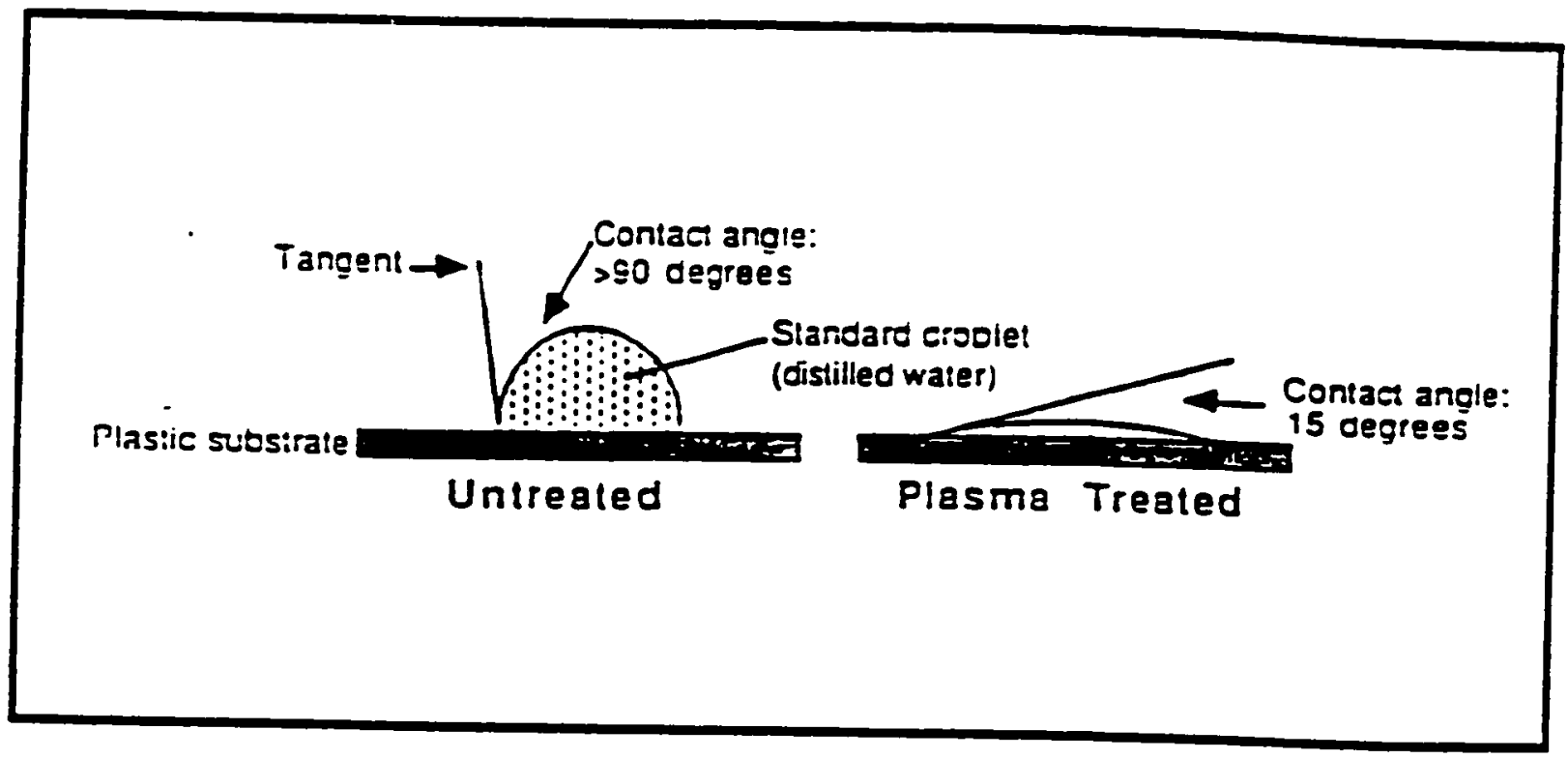

FIGLRE 1: Plasma Etching effect on plastic surface wetability characteristics as measured by contact angle

Source: Kaplan and Holland (1987) 


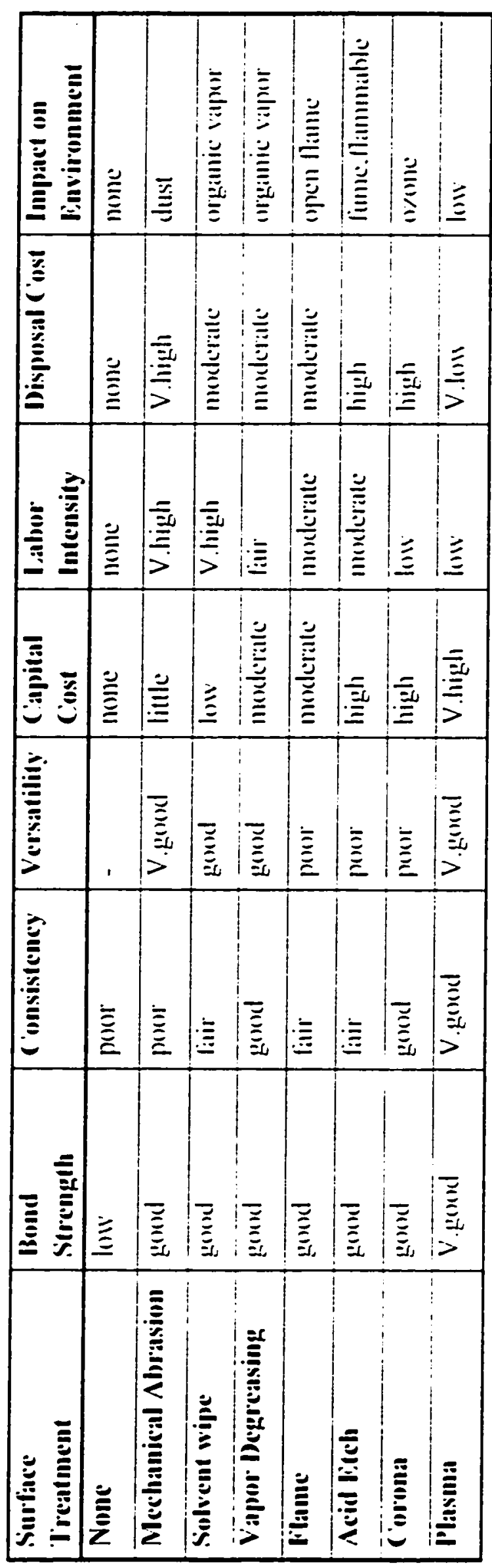

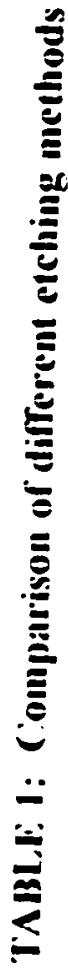


mechanical abrasion, solvent degreasing, vapor degreasing, flaming, acid chemical etching, corona and plasma discharge (Kaplan and Holland, 1987). A comparison of factors associated with various etching methods is shown in Table 1.

The surface preparation in the plating of plastic (POP) industry is predominantly done by acid etching. The etchant is a mixture of sulfuric and chromic acid. The amount of plastics plated each year is over million square feet (Peng, 1994), so the volume of waste generated is enormous. Due to the environmental concerns for disposal of toxic wastes, plasma etching has been proposed as an alternative to eliminate the hazard and the cost associated with acid etching. Plasma etching is an advanced technology that is dry, clean, cost effective and environmentally friendly, but the capital cost associated is very high.

Adhesion to the low surface free energy plastics, which is the ground state of the plastic before any treatment, can also be attained through the use of adhesion promoters. The adhesion promoter most commonly used consists of chlorinated poly(olefin) dissolved in a nonpolar solvent. When applied to the low surface free energy plastic, the solvent swells and diffuses into the surface thereby mechanically interlocking with the substrate domains below the surface and accounting for better adhesion (Ryntz, 1994).

Acrylonitrile-butadiene-styrene (ABS) is the most commonly used plastic substrate for electroplated plastic parts (Lindsay and LaSala, 1985, Krulik, 1978). ABS is the easiest plastic to process and has been reported to have high performance in the end use products as a result of establishing strong and durable 
bonds with electroplated metals (Abuelazaim, 1994). The highest volume of ABS is used in the automobile industry. Examples are: car interior, bumpers, wheel covers, radiator grilles and brakes.

\subsection{DESCRIPTION OF THE PLATING PROCESS}

Etching makes the surface of the plastic hydrophilic and more susceptible to improved bonding. To prevent delamination, blistering, burnoff or flaking of the plated plastics adequate etching is necessary before electroplating (Krulik, 1978). The etched plastic is first activated to catalyze the chemical deposition of metal. This makes the plastic conductive and prevents it from damage by ultraviolet radiation. After activation, a thin film of metal is deposited by electroless plating. After the plastic has been made conductive, the metal film of copper can be built by electro-deposition from a sulfuric acid electrolytic bath (Heymann, et. al. 1970).

In general, electroplating of plastics consists of five steps: (1) Surface pretreatment by mechanical roughing or etching and conditioning, (2) Activating the substrate by colloidal $\mathrm{Pd} / \mathrm{Sn}$ catalyst, (3) Electroless metal deposition over thetreated surface, (4) Electroplating the substrate by conventional procedures (Villamizar et. al., 1981). Refer to Figure 2 for the outline. 


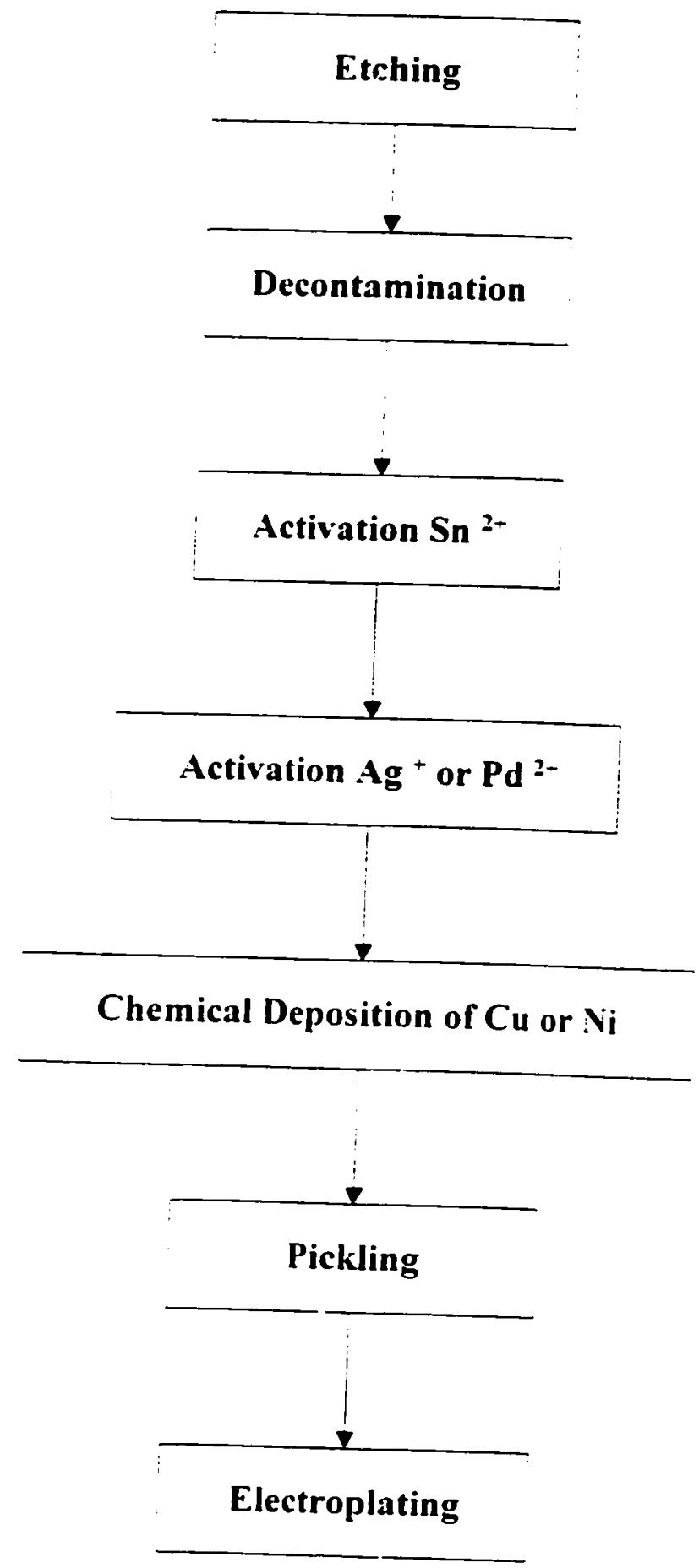

FIGLRE 2: Sequence of steps in conventional ABS plating process (Rinsing occurs between each stage)

Source: Heymann et. al. (1970) 


\subsection{AVAILABLE ETCHING METHODS}

As shown in Table 1 , there are various ways of etching the substrate. Chromic acid etching is the most commonly used process. Chromic acid is a mixture of potassium dichromate, distilled water and sulfuric acid. It is the most popular method for preparing ABS for electroplating (Villamizar et. al., 1981). However, acid etching is being replaced by an alternative due to its negative impact on the environment.

One promising alternate to the acid etching process is plasma etching. The mechanism of this phenomena includes: (a) Surface oxidation (b) Ionic bombardment (c) Polymer cross linkage and, (d) Chemical reaction or surface grafting (Herb, 1989). A plasma can be initiated by a DC voltage or radio frequency (RF) in the range of $1 \mathrm{KHz}$ to $100 \mathrm{GHz}$ with almost any gas. Most commercial systems utilize $\mathrm{RF}$ power of $13.56 \mathrm{MHz}$ range. A plasma is a collection of positive, negative and neutral particles in which the density of the negatively charged particles is the same as that of the positively charged particles. When an energetic electron strikes a neutral gas molecule, it forms free radicals, ions and excited species. The free radicals are responsible for the reactions while the excited species produce the glow. The electron energy required for ionization is much greater than the energy required for dissociation. Very few electrons have the necessary energy to ionize gas molecules, yet many electrons have sufficient energy to dissociate them. This is reflected in the relative concentrations of free 
radicals and ions. Roughly, one out of every $10^{6}$ gas molecules ionizes $\left(\approx 10^{4}\right.$ form free radicals). This is good because it is the free radicals which are responsible for changing the surface. The most important species in the plasma process are the electrons and free radicals. The physical and the chemical properties of the plasma depend on the gas(es) used, RF power, residence time, gas flow rates, reactor geometry, chamber pressure and temperature. In order for the plasma etching to take place all of the following should occur (Coburn, 1989):

Reactive species must be generated, (2) Reactive species must diffuse to the sample surface, (3) Plasma gas should adsorb on the substrate surface, (4) Sufficient energy should be available for the reaction to occur, (5) Volatile compounds formed should be exhausted into the vacuum pump, (6) Pump speed should be adequate to remove the volatile compound and replenish the reactive species. Refer to Figure 3 for schematic of a gas plasma reactor. 


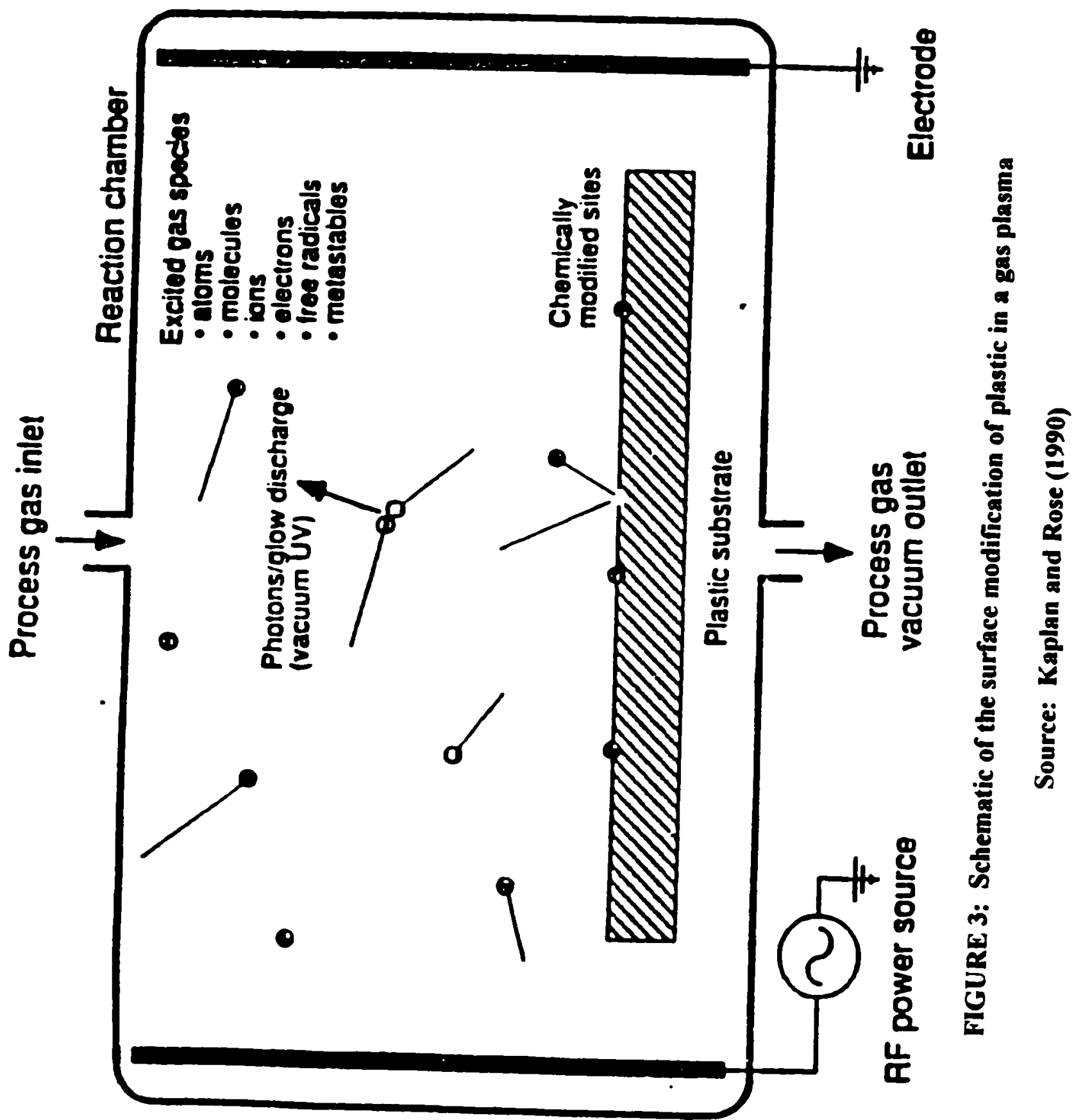


If oxygen is the plasma gas and a large sized polymer is the substrate, the dissociation process produces the free radical; atomic oxygen in this case. The atomic oxygen may break the carbon to carbon bond to produce a smaller chain and volatile low molecular weight chemicals, such as methane. On the other hand if hydrogen is created after the rupture of carbon-hydrogen bonds in the polymer, it may combine with the oxygen radical to form water and the modified polymer would probably undergo several additional reactions such as cross-linking or incorporating oxygen into the polymer surface thereby creating an oxygenated surface. Free radicals can also create an active site on the polymer surface. This active site can act as a receptive to other functional groups and change the surface properties of the polymer. Using argon as the plasma gas, on the other hand, physically breaks weak organic bonds. Plasma conditions generate argon to a higher energy level and create both a sputtering process and free radical process that interacts with the polymer surface.

In case of oxygen plasma different species such as $\mathrm{O}^{+}, \mathrm{O}^{-}, \mathrm{O}_{2}^{-}, \mathrm{O}, \mathrm{O}_{3}$, ionized ozone, metastable exited $\mathrm{O}_{2}$, and free electrons are formed. As these species recombine, they release energy and photons along with UV radiation. The released photons in the UV region have enough energy to break the carbon-carbon and carbon-hydrogen bonds. The reaction mechanism is as follows (Kaplan and Rose, 1990): 
$\mathrm{CH}+\mathrm{O}^{\bullet} \rightarrow \mathrm{C}^{\bullet}+\mathrm{OH}^{\circ}$

$\mathrm{CH}+2 \mathrm{O}^{\bullet} \rightarrow \mathrm{C}^{*}+\mathrm{H}^{*}+\mathrm{O}_{2}$

$\mathrm{CH} \quad \rightarrow \mathrm{C}^{\bullet}+\mathrm{H}^{*}$

The surface modification by reacting active species is called chemical (lateral) etching and the surface modification by bombardment of photons, ions, and neutral species on the substrate is called ion bombardment (vertical) etching.

In case of inert gases like helium, the surface reactions that have been observed by Clark and Dilks (1977) and Schonhorn and Hansen (1967) start with ablation. Ablation is an evaporation reaction in which the energy from the plasma breaks the surface bonds that hold the volatile components in place. The reactions that follow could be those in which molecules can react with an adjoining radical of the same chain forming a double or triple bond, and/or crosslinking in which molecules can form a bond with a nearby free radical on a different chain. Schonhorn and Hansen (1967) studied possible surface reactions that occurred on the plastic substrate when bombarded with helium.

The proposed reactions are as follows:

$$
\begin{aligned}
& \mathrm{C}_{1} \mathrm{H}+\mathrm{He}^{*} \rightarrow \mathrm{C}_{1} \mathrm{H}^{*}+\mathrm{He} \\
& \mathrm{C}_{1} \mathrm{H}^{*}+\mathrm{C}_{2} \mathrm{H}^{*} \rightarrow \mathrm{C}_{1} \mathrm{C}_{2}+\mathrm{H}_{2} \\
& \mathrm{He}^{*}+\mathrm{CH} \rightarrow \mathrm{C}^{*}+\mathrm{H}^{*}+\mathrm{He} \\
& \mathrm{He}^{*}+\mathrm{C}_{1} \mathrm{C}_{2} \rightarrow \mathrm{C}_{1}^{*}+\mathrm{C}_{2}^{*}+\mathrm{He} \\
& \mathrm{H}^{*}+\mathrm{CH} \rightarrow \mathrm{H}_{2}+\mathrm{C}^{*}
\end{aligned}
$$




$$
\begin{array}{ll}
\mathrm{C}^{\bullet}+\mathrm{C}_{1} & \rightarrow \mathrm{CC}_{1} \\
\mathrm{C}^{\bullet}+\mathrm{C}_{2} & \rightarrow \mathrm{CC}_{2} \\
\mathrm{C}^{\bullet}+\mathrm{C}^{\bullet} & \rightarrow \mathrm{CC}
\end{array}
$$

The above surface reactions may occur in conjuncture with ion bombardment.

For an inert gas, at low chamber pressures ( 2 to 75 mtorr), ion dosage and ion current densities that cause ion bombardment, play an important role in the cross-linking phenomena. At high chamber pressure, the above phenomena is less dominant since there is a decrease in gas atoms as the pressure is raised. Lateral etching is minimal with inert gases. For an active gas, like oxygen, chemical etching is prominent at low flow rates. At low flow rates, residence time of the chemically active species on the substrate increases to induce chemical etching. At higher flows residence time of the chemically active species on the substrate is reduced and ion bombardment is prominent. 


\subsection{LITERATURE REVIEW}

Literature review shows that there are many parameters that affect bond formation between the plastic and metal surfaces. Some of the parameters are: Surface conditions, mechanical or chemical bond formation, lateral or vertical etching conditions, plasma flow rate, etch time, type of gas, type of surface, chamber pressure, and radio frequency (RF) power. Papers reviewed below show the dependence of adhesion strength on the parameters listed above.

\subsection{THEORY OF MECHANICAL OR CHEMICAL BOND FORMATION}

Extensive research has been done on the mechanism of bond formation between the metal and plastic substrate. Some studies propose that mechanical interlocking is the main mechanism behind bonding of substrate to metal and others propose that chemical bond formation is behind the bonding mechanism.

Villamizar et. al. (1981) investigated the differences in adhesion of copper to ABS surfaces etched by two methods. The two methods were: 1) Chemical system constituting chromic acid solutions and 2) Plasma system formed by an oxygen gas stream that passes through a RF coil. The etched ABS specimens were then acid copper plated. Peel strength and cyclic thermal tests were performed to determine adhesion properties of metal to plastic substrate. Scanning electron microscopy (SEM) was used to study the surface characteristics of the 
plastic specimens after etching. Peel test analysis revealed copper in the pores, proving that mechanical interlocking was the predominant controlling factor in metal-to-plastic adhesion of the samples treated with chemical etchant. The study also showed that the peel strength depended on the surface porosity developed by the chemical etchant and revealed that there existed a critical pore radius, around $0.4 \mu \mathrm{m}$, at which an optimum peel strength was observed. In plasma etching one of the important factors controlling the adhesion of copper to ABS was found to be the strength of the surface layer produced by cross-linking or by the elimination of weak boundary layers. Surface wetability developed by an increase in the number of polar groups on the plastic surface was found to be the second factor controlling the adhesion strength. Viliamizar et al. (1981) concluded that the number and the size of the pores on the surface of ABS increased with etching time for both chromic acid etched and plasma etched samples.

Elmore and Davis (1968) investigated the mechanism of bonding electroless copper to organic substrates. The organic substrates were ABS, polysulfone, and epoxy. SEM was used to view the interfacial surfaces of the substrate subsequent to chemical processing and electroless and electrolytic plating. The results revealed that interlocking surfaces were present which permitted mechanical interaction at the copper-organic interface. They also studied the effect of aging on the bond strength. The results of aging revealed that there is a gradual increase of cohesive strength of the surface layer of ABS. They concluded by saying that a major factor contributing to good bonding between organic substrate and electroless 
copper is mechanical interlock of bonding surfaces. When these surfaces were replicated on epoxy, bonding between epoxy and electroless copper was obtained.

\subsection{EFFECT OF DIFFERENT PARAMETERS ON ADHESION}

Parameters such as lateral and vertical etching, surface porosity, etching time, and power, that affect the adhesion strength are discussed in the literature review below:

Bachman and Vasile (1989) characterized ion-bombardment surfaces of polyimide films with $\mathrm{x}$-ray photoelectron spectroscopy (XPS) as a function of ion dosage. Results indicated that at low ion dosage the surface of the polyimide did not change chemically, although the adsorbed species were eliminated. At higher ion dosage the chemical composition of polyimide surface altered drastically. They explained the phenomena of enhanced adhesion by stating that there is a crosslink or graphitic layer formation at the surface which increases mechanical strength of the bond and enhances adhesion. They believe that ion bombardment of polyimide causes abstraction of hydrogen at the surface creating radical sites that interact and form crosslinks. The study concluded that it is surface roughening that increases the interfacial contact area and / or graphitic structure formation that increase the mechanical strength of the surface.

Kato (1968) used replicating and thin sectioning techniques in conjunction with transmission electron microscopy to show the nature, extent, and depth of 
interfacial mechanical interlocking that occurs in ABS injection-moldings. The injection molding of thermoplastics usually produces moldings which are more or less anisotropic owing to orientation of the polymer molecules. The degree of anisotropy depends on the chemical and the physical properties of polymer involved, molding conditions, geometry of the mold used, etc. This type of anisotropy could be called molecular anisotropy. ABS polymers are heterogeneous in nature, being composed of a finely dispersed rubber phase and a continuous resin phase. As a result of this, injection molding can produce another type of anisotropy, caused by the orientation of the particulate phase along the flow lines. This phenomenon is called phase anisotropy. He concluded the study to say that the phase anisotropy rather than the molecular anisotropy is often of practical importance for delamination in polymer system like ABS. He found that the delamination occurred at some depth below the molded surface. This is due to a layered structure in which the rubber particles are segregated according to size, and grouped along the flow lines in rows. According to the results from the study, the above structure is formed during the molding process when a "certain shear rate" is exceeded. The paper did not provide a value of the "certain shear rate". The study also showed how porosity of the surface varies with the conditioning time.

Hartney et. al. (1988) studied oxygen plasma etching to find that the properties that make plasma efficient are: (1) the dissociation of oxygen into more reactive species and (2) the acceleration of ions by electromagnetic field. The 
reactive species chemically reacts with the surface while the ions cause bombardment of the surface being etched. The above phenomena is important since oxygen atoms initiate etching by extracting the hydrogen atoms from the polymer surface leaving behind free radical species. These radicals can react with oxygen molecules from the plasma to form carbonyl and alcohol groups, which are precursors to volatile species, that after desorption, are pumped away. In order for the volatiles to be liberated sufficient energy for desorption is necessary. The above energy is provided by ion bombardment. So, the degree of ionization and the production of neutral species are some of the aspects that influence etching. A faster etch rate occurs when there is a synergistic effect between neutral species and ion bombardment. The study also showed that the supply of the active species was the rate limiting step for lateral etching.

Lindsay and LaSala (1985) studied the vacuum preplate process for plating nickel and copper on ABS. They used the chemical bond formation approach to describe the adhesion mechanism. This theory suggests that a number of active species are created during the etching process at the surface that bond to the subsequently deposited metal film. They discussed the results of adhesion and durability with regard to DC and RF plasma operation. The study showed that increase in the plasma voltage increased the peel strength but after a certain optimum voltage of around $1200 \mathrm{~V}$ the peel strength reached it's maximum and then started falling. Similar results were also observed when the RF plasma time was increased. An optimum processing time of 7-10 minutes was indicated. 
Krulik's (1978) paper on electroless plating of plastics described the operations involved in plating of plastics. The paper examined the importance of each step namely 1) Etching 2) Neutralization, 3) Catalysis 4) Acceleration 5) Electroless plating. He explained the adhesion mechanism by two theories: 1) Chemical bond formation, and 2) Lock and Key mechanism. Some of the compounds formed by partial oxidation during etching are alcohol, carboxylic acids and probably sulfonated compounds. The presence of these compounds support chemical bond theory of adhesion since they provide a mechanism for ionic exchange effects.

Pao et. al. (1977) studied the etching effect on the metal-to-ABS surface adhesion in electroless plating by using SEM. They obtained a more qualitative picture of the relation between surface porosity and adhesion and determined an optimal composition of etching solution for ABS plastics. The study showed that the microporous openings on ABS plastic surfaces, namely the number of cavities per unit surface and the uniformity of the cavity size distribution were some of the most important factors that controlled metal-to-plastic surface adhesion. The optimal cavity size was found to be in the range of 0.03 to $0.2 \mu \mathrm{m}$. Chromicsulfuric acid mixture having a $\mathrm{CrO}_{3} / \mathrm{H}_{2} \mathrm{SO}_{4}$ weight ratio of about $0.4: 1$ to $0.6: 1$ was found to be the most suitable etching solution for ABS.

Wedel (1971) used SEM to study the effect of surface porosity on ability of ABS moldings to pass thermal cycle test. The study showed that thermal failure of plated ABS appeared to begin in small areas that had inadequate surface 
porosity. After the failure was initiated, it spread to regions of adequate porosity by lateral crack propagation. The other object of his study was to explore the influence of surface porosity on plateability of etched polypropylene. He concluded that uniform surface porosity always plate adequately and have good adhesion. The above conclusion can be extended for etched ABS surfaces since both polypropylene and ABS surfaces are similar.

Ghorashi (1977) studied the effect of chromic acid etch on adhesion of chemically deposited copper to polypropylene. The study concluded that chromic acid etching of plastic surface is the most important step in plating of plastics. The etchant creates an extensive network of fine, shallow pits on the surface of the plastic. These pores act as interlocking sites for the autocatalytically deposited metal film. The size and frequency of these cavities influence the metal adhesion to the plastic substrate. The study postulated that the chemical bond formed between metal and plastic substrate constituted the adhesion mechanism. The study also showed that adhesion increased with etch time until an optimum surface topography was reached after which the adhesion declined.

Matsunga et. al. (1968) studied adhesion of copper to ABS by using Electron Microscopy to investigate the bond nature. They discovered that etching conditions were one of the most important factors that affected adhesion strength between plastic and electroless copper. They used Jacquet or "pull" test to determine the adhesion strength. The conclusions were that the break occurs along a weak boundary layer within the plastic and the mechanism of adhesion is 
chemical bond formation. They came to the above conclusion because the electronmicroscopy showed that interface adhesion between metal and plastic was stronger than the surface strength of the plastic.

\subsection{EFFECT OF DIFFERENT PLASMAS ON ADHESION}

It has been shown that the type of plasma gas used in the etching process plays an important role in characterizing the surface of the substrate. The surface modification and the type of reactive species used affect the adhesion strength as discussed in papers below:

Clark and Dilks (1977) studied the crosslinking of ethylene-tetrafluoroethylene copolymer by exposure to argon plasma. The study showed that surface modification process of the polymer using plasma can be selectively controlled so that the bulk properties were not affected. They believe that reaction at the surface of a sample is associated with either direct energy transfer from the species in the plasma or the ultraviolet component (i.e. radiation $<\sim 3800 \mathrm{~A}^{\circ}$ in wavelength and therefore encompasses the vacuum region) of the electromagnetic radiation emitted from the plasma, or both. The direct and radiative energy transfer models showed that the outermost monolayer crosslinks are dominated by direct energy transfer from argon ions and metastables in the plasma.

Hall et. al. (1972) studied the effect of gas plasma treatment time on adhesive bondability of polymers. They investigated bondability of a range of 
polymers as a function of length of exposure to excited helium or oxygen. The study showed that the bond strength increases rapidly initially and then remains constant, perhaps decreases in some cases at long exposure times. Mechanisms which improve the bondability was explained by two theories: 1) There is a formation of strong surface layer by crosslinking and the elimination of low molecular weight fractions, 2) The improvement of wetability of the surface by adding polar and unsaturated groups which derives from radicals and radical ions formed by the activated gas. The study concluded by saying that the behavior of polymers upon exposure to activated gas varies. In some cases the bond strength rises to several times that of the untreated polymer in seconds, while in other cases, bond strength rises slowly. In some cases oxygen treated surfaces showed a more rapid increase in bond strength than those etched with helium, but in others the phenomena was reversed. Ultimately bond strength was seen to level off and in some cases it actually decreased.

Schonhorn and Hansen (1967) reported that crosslinking by activated species of inert gas increased cohesive strength at the surface of the substrate and thereby increased adhesion bonding between metal and the substrate. They are of the view that mere presence of polar groups are not sufficient to provide good adhesion. In case of polyethylene, even after wetability criteria was fulfilled, the adhesion strength did not improve. This lead to the theory of a weak boundary layer formation at the surface. Eliminating the weak boundary layer by modifying the 
surface and also by bombardment of polymer with high energy electrons led to better adhesion strength in polyethylene substrate.

Lerner and Wydeven (1989) studied the effect of flow rate and reactor loading on etch rate of polymers using oxygen plasma. They concluded that in general increased flow rate and/or decreased reactor loading lead to increased etch rate. The explanation behind it is that the increased flow rate increases the supply of etchant to the sample while decreased loading reduces the total rate of consumption of the etchant at the sample. Both effects lead to an increased etchant concentration at the sample, thus lead to increased etch rate. However, if reaction of the plasma generated active species with the substrate produces a secondary species which is more active than the first, the phenomenon is reversed. Now a decrease in flow rate and/or increase in reactor loading increases the etch rate. This is because at low flow rate or a higher reactor load tend to increase the concentration of the secondary species at the substrate.

Joubert et. al. (1989) studied the etching of photoresist polymers in oxygen based plasmas. They found that ion bombardment current density, ion energy, and concentration of atoms were the three variables in the process of oxygen based plasma etching of polymers in low pressure discharges. They also observed that for low values of the above parameters there was a linear variation in the etch rate. The etch rate increased with the increase in each of the above parameters whereas for high values of the same parameters saturation occurred. They also concluded that the etch rates did not appear to depend upon the chemical nature 
of the ions thus stating that ion bombardment have mechanical effects rather than chemical effects in plasma etching.

Gurly and McNeil (1992) studied the effect of varying plasma etch conditions on the adhesion of copper to ABS. Oxygen gas was used for plasma etching experiments. The main objective of the study was to determine the effect of varied plasma etching parameters on the peel strength of copper plating. Four plasma etch parameters, oxygen flow rate, time, RF power, and chamber pressure were varied to determine each parameter's role in modification of the plastic surface. Taguchi statistical method was used to establish trends and to set etching conditions for better adhesion. Results showed that ultimate peel strength was effectively increased by reducing the flow rate from $100 \mathrm{ml} / \mathrm{min}$. to $20 \mathrm{ml} / \mathrm{min}$. Refer to Figure 4 for the trend. It was also determined that the reduction in the chamber pressure somewhat increased the peel strength. Refer to Figure 5 for comparison. The experiments also showed that plasma etched samples with topography outside the critical pore size regime gave better peel strength implying that mechanical interlocking in the critical pore size regime is not the only factor for high quality plating. SEM study showed that as oxygen flow rate was decreased the number of pores increased. However, this effect was not quantified.

Abuelazaim (1994) studied the effect of varying gas flow rate on surface porosity of ABS using both oxygen and helium as plasma gas. The objective of this study was to determine the effect of changing the type of gas and the flowrate on the number and size of pores formed on the plastic substrate. The gas 
flow rate was varied between $25 \mathrm{ml} / \mathrm{min}$. and $100 \mathrm{ml} / \mathrm{min}$., while all the other plasma conditions were maintained constant. The results showed that increase in the gas flow increased the number of pores formed but average diameter of the pores decreased. Oxygen produced fewer pores with wider diameter than helium.

\subsection{SUMMARY}

The literature review shows that good adhesion between metal and plastic is important in POP industries. Extensive research is done on the mechanism of bond formation between metal and plastic substrate but there is variation in how the researchers tackle the problem at hand.

It was found that the porosity of the surface is a result of combination of both lateral and vertical etching (Gurly and McNeil, 1992). Lateral and vertical etching are also referred to as pure chemical etching, and etch resulting from ion bombardment, respectively. Increasing the gas flow rate reduces chemical etching but increases etching due to ion bombardment. This is because higher gas flow rate decreases the residence time of gas resulting in quicker removal of volatile species and products which results in less reaction. Ion bombardment on the other hand creates more of a vertical etching effect, generating what is called "surface damage" porosity. 


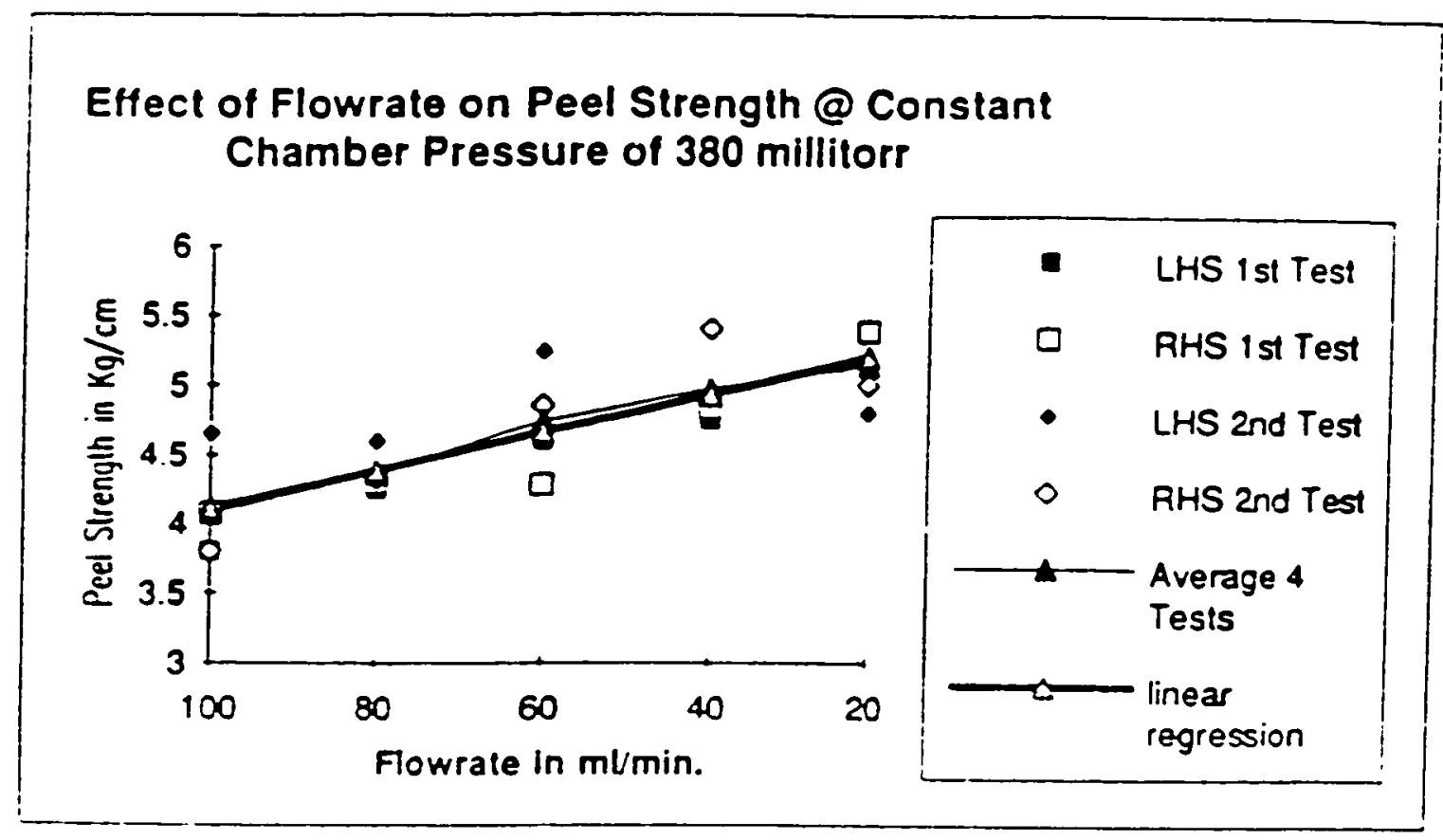

FIGLRE 4: One Variable Testing: Varied Flowrate

Source: Gurly and McNeil (1992) 


\section{Effect of Chamber Pressure on Peel Strength @ Constant Flowrate of $80 \mathrm{ml} / \mathrm{m} / \mathrm{n}$.}
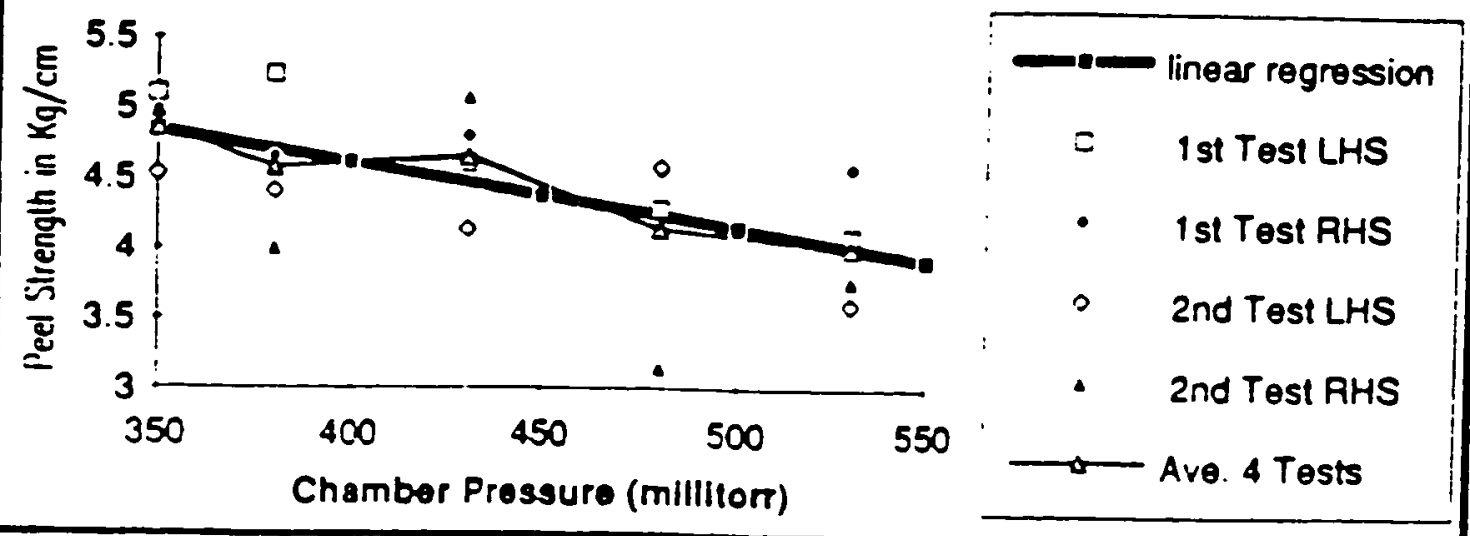

FIGLRE 5: One Variable Testing: Varied Chamber pressure, $80 \mathrm{ml} / \mathrm{min}$.

Source: Gurly and Mc.Veil (1992) 
The greatest etched surface area does not mean that good adhesion results between metal and plastic. The results obtained by Gurly and McNeil (1992), showed that peel strength decreased with increase in gas flow of oxygen, in the range of $20-100 \mathrm{ml} / \mathrm{min}$. This may be result of active species produced from chemical etching on the surface. In other words, in the absence of ion bombardment, the presence of active species result in stronger chemical bond between metal and plastic. Abuelazaim (1994) showed that for oxygen plasma, low gas flow produced lower number of pores with wide diameters. This criteria is typical of chemical etching. At higher gas flow greater number of pores with smaller diameters and greater depth was seen. This is typical of ion bombardment. In the case of helium as plasma gas, it was observed that ion bombardment had a significant contribution at all flow rates. Greater number of pores with small average diameter, typical of ion bombardment etching, was observed. Adhesion strength for helium gas plasma has not been determined. The above discussion also reflects the results of Lerner and Wydeven (1989).

Adhesion was found to be affected by both the type of gas used and the type of substrate etched. It was found that gas flow rate affected the adhesion strength and also the porosity of the surface etched (Gurly and McNeil, 1992, Abuelazaim, 1994). Oxygen gas flow rate was found to affect adhesion of copper to ABS drastically (Gurly and McNeil, 1992). It was also found that oxygen and helium flow variation affected the porosity of the substrate (Abuelazaim, 1994). However the above findings have not been verified and also the affect of helium 
gas flow rate on adhesion strength between copper and plastic has not been studied. There is also a need to verify the effects of lateral and vertical etching since there is not that much work done in that area.

In this work effect of gas flow rate, for both oxygen and helium, on adhesion strength, number of pores, diameter of pores, average diameter distribution, and average etched area will be studied. The results will be analyzed to see if there exists a correlation between peel strength and the topographic data obtained. 


\subsection{RESEARCH HYPOTHESIS AND OBJECTIVE}

\subsection{HYPOTHESES}

The peel strength for helium etched ABS will be lower than the peel strength for oxygen, since oxygen is an active gas and helium is an inert gas. The number of pores for oxygen etched ABS will decrease with increase in gas flow rate, while for helium etched $A B S$, the number of pores will increase with increase in flow rate. The average pore diameter will increase as the flow rate is increased for oxygen etched ABS. The average pore diameter will decrease with increase in flow rate for helium etched ABS. 


\subsection{OBJECTIVE}

The objective of this study is to investigate the variation in adhesion strength obtained after electro - plating copper to ABS plastic substrate by varying the plasma gas and their flow rates during the surface modification step of the substrate. Peel strength analysis will be done to quantify the adhesion strength. Graphs of peel strength versus plasma gas flow rate will be developed. Some SEM will also be done to verify the surface topography obtained in previous studies done by Gurly and McNeil (1992) and Abuelazaim (1994). Graphs of flow rate versus average diameter of pores, flow rate versus number of pores, flow rate versus fractional average etched area of pores, and average pore diameter distribution will be developed for oxygen and helium plasma etched surfaces to see if correlation exists between them. Lateral and vertical etching phenomena of the plasma along with bonding mechanism of copper to the plastic substrate will also be discussed. 


\subsection{EXPERIMENTAL PROCEDURE AND APPARATUS}

\subsection{PLASMA ETCHING}

Plasma etching was performed on standard ASTM certified ABS plastic coupons obtained from GE plastics. The coupon dimensions are $76.5 \mathrm{~mm} \times 89.5$ $\mathrm{mm} \times 3.1 \mathrm{~mm}$. Before etching, the coupons were cleaned using high phosphate soap (Alconex) containing no animal fat. The surface of the coupon should not be touched with bare hands. Gloves were used to handle the coupon to minimize particulate and oil contamination. The coupons were washed thoroughly in a solution of Alconex soap and DI water. The surface scrubbed with kim-wipes soaked in soap solution and then rinsed completely with DI water to remove all soap from the surface. Drying was accomplished in an stream of clean dry air available in the lab. Oxygen and helium plasma gases were used to etch the coupons using a March CS-1701 plasma etcher. Appendix A describes the equipment. High purity gases $(99.99 \%)$ were obtained from Prax-Air.

A total of twenty four coupons were etched. Table 2 shows the experimental procedure for plasma etching. Sixteen coupons were etched at a constant chamber pressure(P) of 380 millitorr, constant RF power(E) of 50 watts and constant etching period(te) of 10 minutes. The gas flow rate(F) was varied over the range of $25-100 \mathrm{ml} / \mathrm{min}$. with an increment of $25 \mathrm{ml} / \mathrm{min}$. To account for reproducibility two coupons were etched at $25 \mathrm{ml} / \mathrm{min}$. and $100 \mathrm{ml} / \mathrm{min}$. plasma 
gas flow rates respectively. One coupon from experiment numbers $9,10,11$ and 12 were used for SEM analysis and the second coupon from the same experiment was plated along with the other sixteen etched coupons in a manner shown in Table 3. The same coupons cannot be used for SEM as well as peel test due the difference in their test preparation procedure as stated below.

\subsection{COPPER PLATING}

Twenty coupons along with four blanks were copper plated within 48 hours after they were etched. The plating line used was laboratory scale baths but otherwise typical to plating lines used in the industry. The baths were characterized according to standard operating procedure available in the lab. Refer to Appendix B. Experimental procedure for plating is shown in Table 3. The coupons were plated in batches of four, this was done to eliminate surface area effects. The coupons were plated in a manner shown in Table 3 to study repeatability and reproducibility of the copper baths. 
ETCHING: EXPERIMENTAL PROCEDURE

\begin{tabular}{|c|c|c|c|c|c|c|}
\hline \multirow[t]{2}{*}{ Type of Gas } & \multirow[t]{2}{*}{ Experiment \# } & \multirow[t]{2}{*}{ No. of Coupons } & \multicolumn{4}{|c|}{ Etching Parameters } \\
\hline & & & Variable & & Constant & \\
\hline & & & $\mathrm{F}(\mathrm{ml} / \mathrm{min})$ & te(min) & $E$ (watts) & $\overline{P(m T)}$ \\
\hline \multirow[t]{4}{*}{ Oxygen } & 1 & 2 & 100 & 10 & 50 & 380 \\
\hline & 2 & 2 & 75 & 10 & 50 & 380 \\
\hline & 3 & 2 & $\overline{50}$ & 10 & 50 & 380 \\
\hline & 4 & 2 & 25 & 10 & 50 & 380 \\
\hline \multirow[t]{4}{*}{ Helium } & 5 & 2 & 100 & 10 & 50 & 380 \\
\hline & 6 & 2 & 75 & 10 & 50 & 380 \\
\hline & 7 & 2 & 50 & 10 & 50 & 380 \\
\hline & 8 & 2 & 25 & 10 & 50 & 380 \\
\hline \multicolumn{7}{|c|}{ Repeatability \& Reproducibility Experiments } \\
\hline \multirow[t]{2}{*}{ Oxygen } & 9 & 2 & 25 & 10 & 50 & 380 \\
\hline & 10 & 2 & 100 & 10 & 50 & 380 \\
\hline \multirow[t]{2}{*}{ Helium } & 11 & 2 & 25 & 10 & 50 & 380 \\
\hline & 12 & 2 & 100 & 10 & 50 & 380 \\
\hline
\end{tabular}

TABLE 2: Plasma etching experimental procedure 
PLATING: EXPERIMENTAL PROCEDL:RE

\begin{tabular}{|c|c|c|c|c|c|}
\hline Type of Gas & Batch $\#$ & \multicolumn{4}{|c|}{ Coupons used (Four per batch) } \\
\hline Oxygen & 1 & $1-1$ & $1-2$ & $2-1$ & $9-1$ \\
\hline & 2 & $2-2$ & $3-1$ & B & $10-1$ \\
\hline & 3 & $3-2$ & $4-1$ & $4-2$ & B \\
\hline Helium & 4 & $5-1$ & $5-2$ & $6-1$ & $11-1$ \\
\hline & 5 & $6-2$ & $7-1$ & B & $12-1$ \\
\hline & 6 & $7-2$ & $8-1$ & $8-2$ & B \\
\hline
\end{tabular}

NOTE:

"5-1" stands for "Coupon \#1 from experiment number 5 from Table = ?

$\because 5-2 "$ stands for "Coupon \#2 from experiment number 5 from Table = 2

"B" stands for "Blank coupon": This coupon is not etched 


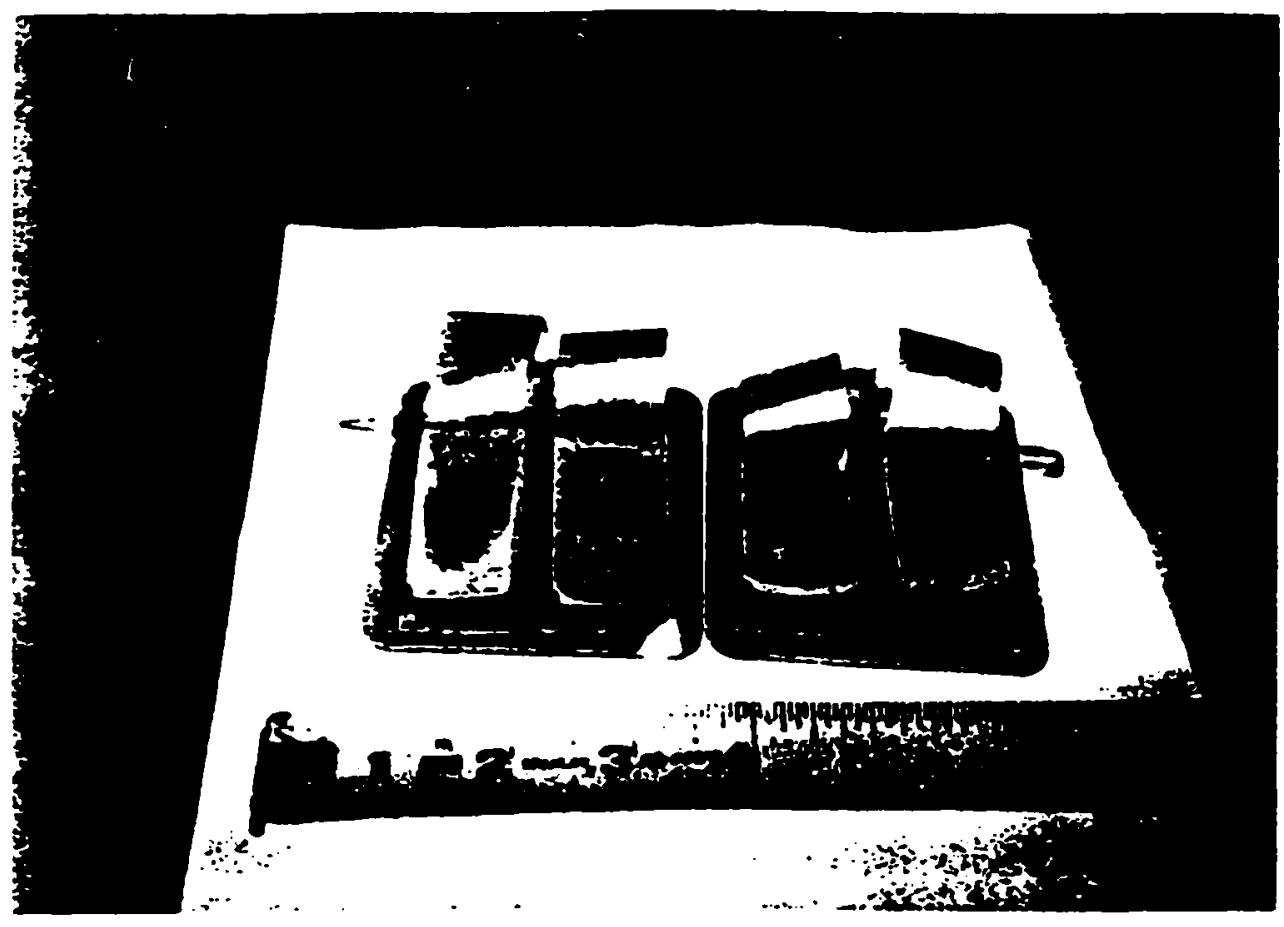

FIGLRE 6: Cohesive Failures

Source: $\quad$ Gurly and Mc.Yeil (1992) 


\subsection{PEEL TEST ANALYSIS}

$90^{\circ}$ peel tests were performed on the plated substrates using Sebastian 5 multipurpose tester per ASTM B 533-85. Appendix A describes the instrument and the ASTM procedure. All coupons were allowed to age at ambient conditions for a minimum of 48 hours prior to peel testing. Figure 6 shows that each coupon will have two peel tests. These coupons are standard peel test coupons used in the plating industry for research and are manufactured such that each coupon has a left hand side and right hand side peel strength for comparison purposes. The run is acceptable if the difference between the left hand side (LHS) and right hand side (RHS) is within ten percent.

\subsection{SCANNING ELECTRON MICROSCOPE (SEM) ANALYSIS}

The plasma etched samples for SEM analysis from experiments 9, 10,11 and 12 are cut into sizes of $12.3 \mathrm{~mm} \times 3.17 \mathrm{~mm}$ and covered with a layer of about $125 \mathrm{~A}^{\circ}$ of gold to provide surface conductivity. The actual thickness could not be measured due to instrumentation constraint. The gold covered samples were photographed using a Hitachi S-520 Scanning Electron Microscope. Due to the nature of surface magnification of 15,000 was used for all SEM analysis. These samples are used to verify the topography obtained by Abuelazaim (1994). The 
verification is being done so that the data from Abuelazaim (1994) can be used in this study. The variation between the two experiments have to be within ten percent for the data to be acceptable and used in this study.

\subsection{COPPER THICKNESS MEASUREMENT AND ANALYSIS}

Peel strength depends upon strength and thickness of the metal film, the rate and angle at which the metal is peeled off, the Young's modulus, the tensile strength of the failing plastic film and finally on the topography of the surface of the substrate prior to plating (Ghorashi, 1977). For the coupons used in this study everything will remain constant except topography of the surface and thickness of the metal film. In this experiment the effect of topography on adhesion is being studied and thus the metal film thickness must be similar for each sample so that it will have minimal effect on variation of peel strength.

Copper film thickness was done using a microscope and four point probe. These measurements were made on four randomly picked copper plated coupons to determine the plating thickness variation. These measurements were necessary since the thickness influences the peel strength as reported by Heymann et. al. (1970). This was done to show that copper film thickness was not a cause of variation in the peel strength measurement.

Two different methods were used for copper film thickness measurements. One of the method was microscope measurement and the other was four-point 
probe method. The procedure for both the methods is provided in Appendix B. Four samples were randomly chosen for the analysis. Refer to Table 14 in Appendix B for results. The microscope results showed that average copper film thickness was $50 \mu \mathrm{m}$ and the four-point probe method revealed average thickness to be $46 \mu \mathrm{m}$. The percent variation between the two methods was $8.7 \%$. This indicates that the role of varying copper film thickness was negligible on peel strength obtained for substrates etched with oxygen and helium.

\subsection{DATA ANALYSIS}

To understand the topography of the etched surface of the coupon, pores from the SEM micrograph were glass traced using tracing paper. One micrograph at $25 \mathrm{ml} / \mathrm{min}$. and $92 \mathrm{ml} / \mathrm{min}$. for oxygen and one at $25 \mathrm{ml} / \mathrm{min}$. and $100 \mathrm{ml} / \mathrm{min}$. for helium were traced respectively. In all, four traces were prepared. Refer to Appendix $\mathrm{C}$ for the traces.

These traces were used to report total number of pores, minimum and maximum pore diameter, average pore diameter, average area of pores, total etched area, total surface area, and fractional average etched area. Refer to Appendix $D$ for the data.

The total surface area for oxygen etched coupons was taken to be the whole micrograph. The size of the micrograph measured was $10.4 \times 9 \mathrm{~cm}$. The 
total surface area for helium on the other hand was taken to be $2.6 \times 9 \mathrm{~cm}$. This was done since the helium micrograph had a lot more pores and the pore distribution was more uniform than that for oxygen. The above measurements were converted to $\mu \mathrm{m}$ and divided by the magnification $(15,000)$ to calculate average pore area. Refer to Appendix D.

All pores were measured for two diameters. These were marked as the minimum and the maximum diameter, $D_{\min }$ and $D_{\max }$ respectively. These were measured using a scale in millimeters. These measurements were converted to $\mu \mathrm{m}$ and divided by the magnification to report the actual diameter of the pores. Average of these two measured quantity was reported as average diameter for that

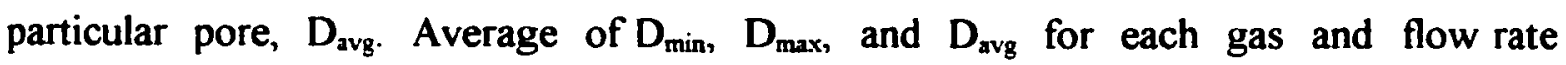
was also reported. Average area, $A_{\text {avg }}$ for each pore was calculated and summed to give the average total etched area. The average total etched area was divided by the total surface area to give average fractional etched area. The total number of pores obtained for each gas and flow rate was divided by the micrograph area to give pore density. This was done to normalize the data for comparison purposes. 


\subsection{GRAPHICAL ANALYSIS}

Graphs of peel strengths versus plasma gas flow rate, gas flow rate versus average diameter of pores, gas flow rate versus number of pores, gas flow rate versus average fractional etched pore area, and average pore diameter distribution were developed for oxygen and helium plasma etched surfaces. These graphs were compared to see their effect on adhesion for oxygen and helium plasma etched surfaces. 


\subsection{RESULTS}

\subsection{INTRODUCTION}

The following section will present results of the experiment outlined in section 4.0. This section is divided into two sub-groups for easy reading. The first sub-group contains peel test results for both oxygen and helium plasma etched substrates. The second sub-group contains results obtained from SEM analysis. The micrographs presented show topography of oxygen and helium etched surfaces at $25 \mathrm{ml} / \mathrm{min}$. and $92\left(\mathrm{O}_{2}\right)$ or $100(\mathrm{He}) \mathrm{ml} / \mathrm{min}$., respectively.

\subsection{PEEL STRENGTH RESULTS}

This section provides the results of plasma gas flow rate on peel strength for both oxygen and helium. Table 4 contains results for coupons etched with oxygen at $25 \mathrm{ml} / \mathrm{min}$., $50 \mathrm{ml} / \mathrm{min}$., $75 \mathrm{ml} / \mathrm{min}$, and $92 \mathrm{ml} / \mathrm{min}$. The etch time(te), RF Power(E), and Chamber Pressure(P) were maintained at $10 \mathrm{~min}$., 50 Watts, and 380 mtorr respectively. Thermodynamic restraint for oxygen at 380 mtorr chamber pressure only allowed for a maximum flow of $92 \mathrm{ml} / \mathrm{min}$. The flow was verified using a bubble flow meter and a calibrated mass flow controller (MFC). The actual flows are listed in Table 4. Coupons were labeled 01 through O30. Results 

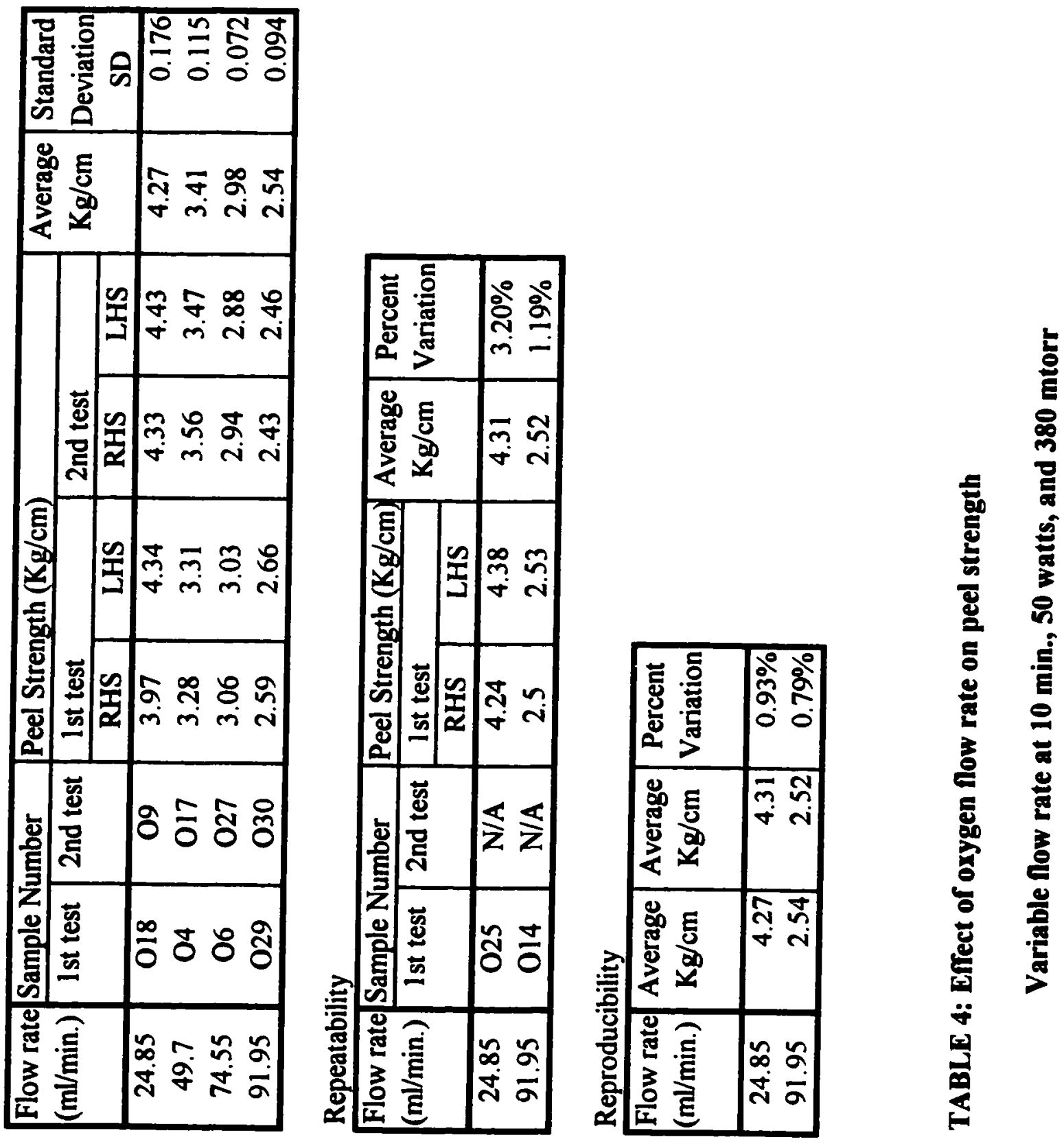


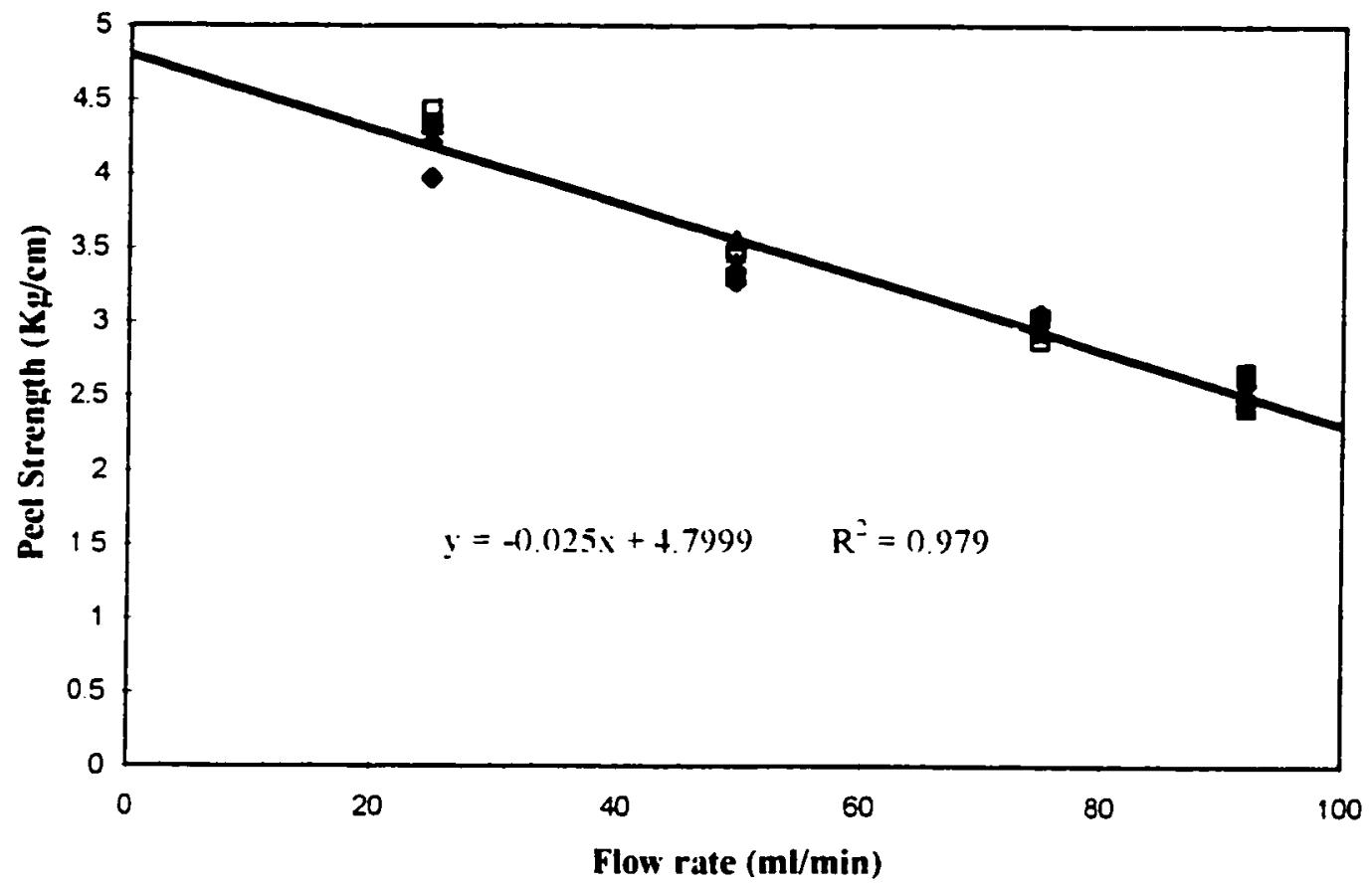

- Peel Strength $(\mathrm{Kg} / \mathrm{cm})$ Ist test RHS Peel Strength $(\mathrm{Kg} / \mathrm{cm})$ Ist test LHS

$\Delta$ Pcel Strength $(\mathrm{Kg} / \mathrm{cm})$ 2nd test RHS $\square$ Peel Strength $(\mathrm{Kg} / \mathrm{cm})$ 2nd test LHS

$x$ Average $\mathrm{Kg} / \mathrm{cm}$ Linear (Average $\mathrm{Kg} / \mathrm{cm}$ )

FIGURE 7: Effect of oxygen flow rate on peel strength Variable flow rate at $10 \mathrm{~min} ., 50$ watts, and $380 \mathrm{mtorr}$ 
for coupons that were successfully plated and peeled as per ASTM B 533-85 are listed in Table 4. RHS, LHS, average peel strength and standard deviation data at each flow rate are listed. The average peel strength for oxygen etched coupons at $25 \mathrm{ml} / \mathrm{min}$., $50 \mathrm{ml} / \mathrm{min}$., $75 \mathrm{ml} / \mathrm{min}$., and $92 \mathrm{ml} / \mathrm{min}$. are $4.27 \mathrm{~kg} / \mathrm{cm}, 3.41 \mathrm{~kg} / \mathrm{cm}$, $2.98 \mathrm{~kg} / \mathrm{cm}$, and $2.54 \mathrm{~kg} / \mathrm{cm}$ respectively. The maximum standard deviation was 0.176. Figure 7 graphically represents the peel strength, average peel strength and the trendline (linear regression) associated with varying oxygen flow rate. The equation of the trendline with correlation coefficient is also listed on the graph.

Table 5 contains results for helium etched coupons at $25 \mathrm{ml} / \mathrm{min}$., 50 $\mathrm{ml} / \mathrm{min}$., $75 \mathrm{ml} / \mathrm{min}$., and $100 \mathrm{ml} / \mathrm{min}$. There was no problem in maintaining the chamber pressure at $380 \mathrm{mtorr}$ for helium at $100 \mathrm{ml} / \mathrm{min}$. flow. The actual flows are listed in the table along with coupon number, LHS, RHS, and average peel strength data. Etch time(te), RF Power(E), and Chamber Pressure(P) for this experiment were also maintained at $10 \mathrm{~min}$., $50 \mathrm{Watts}$, and $380 \mathrm{mtorr}$ respectively. Coupons were labeled $\mathrm{Hl}$ through H18. Again, coupons that were successfully plated and peeled as per ASTM B 533-85 are listed in Table 5. The average peel strength for helium etched coupons at $25 \mathrm{ml} / \mathrm{min}$., $50 \mathrm{ml} / \mathrm{min}$., $75 \mathrm{ml} / \mathrm{min}$., and $100 \mathrm{ml} / \mathrm{min}$. are $2.42 \mathrm{~kg} / \mathrm{cm}, 2.00 \mathrm{~kg} / \mathrm{cm}, 1.35 \mathrm{~kg} / \mathrm{cm}$, and $1.13 \mathrm{~kg} / \mathrm{cm}$ respectively. The maximum standard deviation was 0.081 . Figure 8 is a graphical presentation of peel strength $(\mathrm{kg} / \mathrm{cm})$ with varying helium flow $(\mathrm{ml} / \mathrm{min}$.). Peel strength, average 

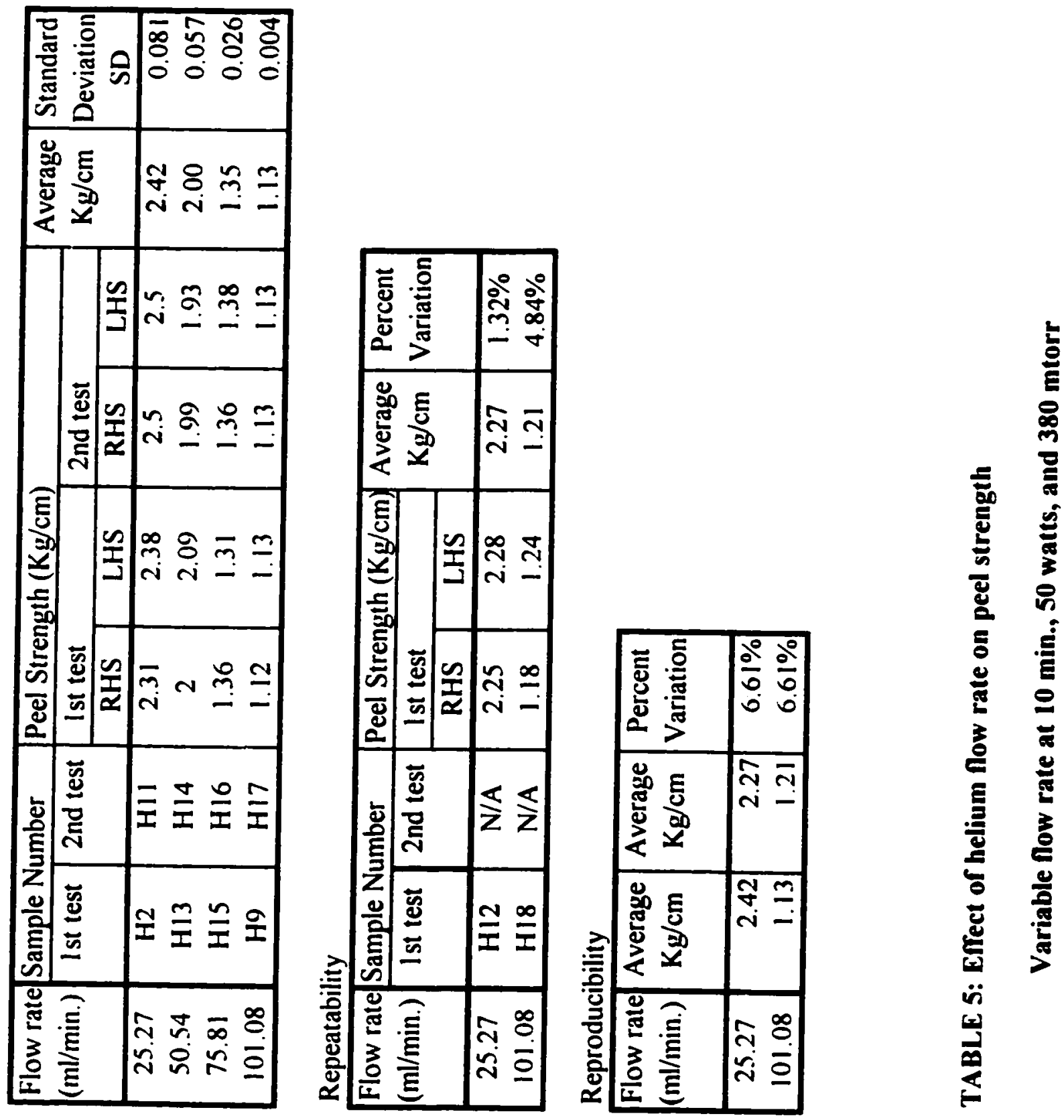


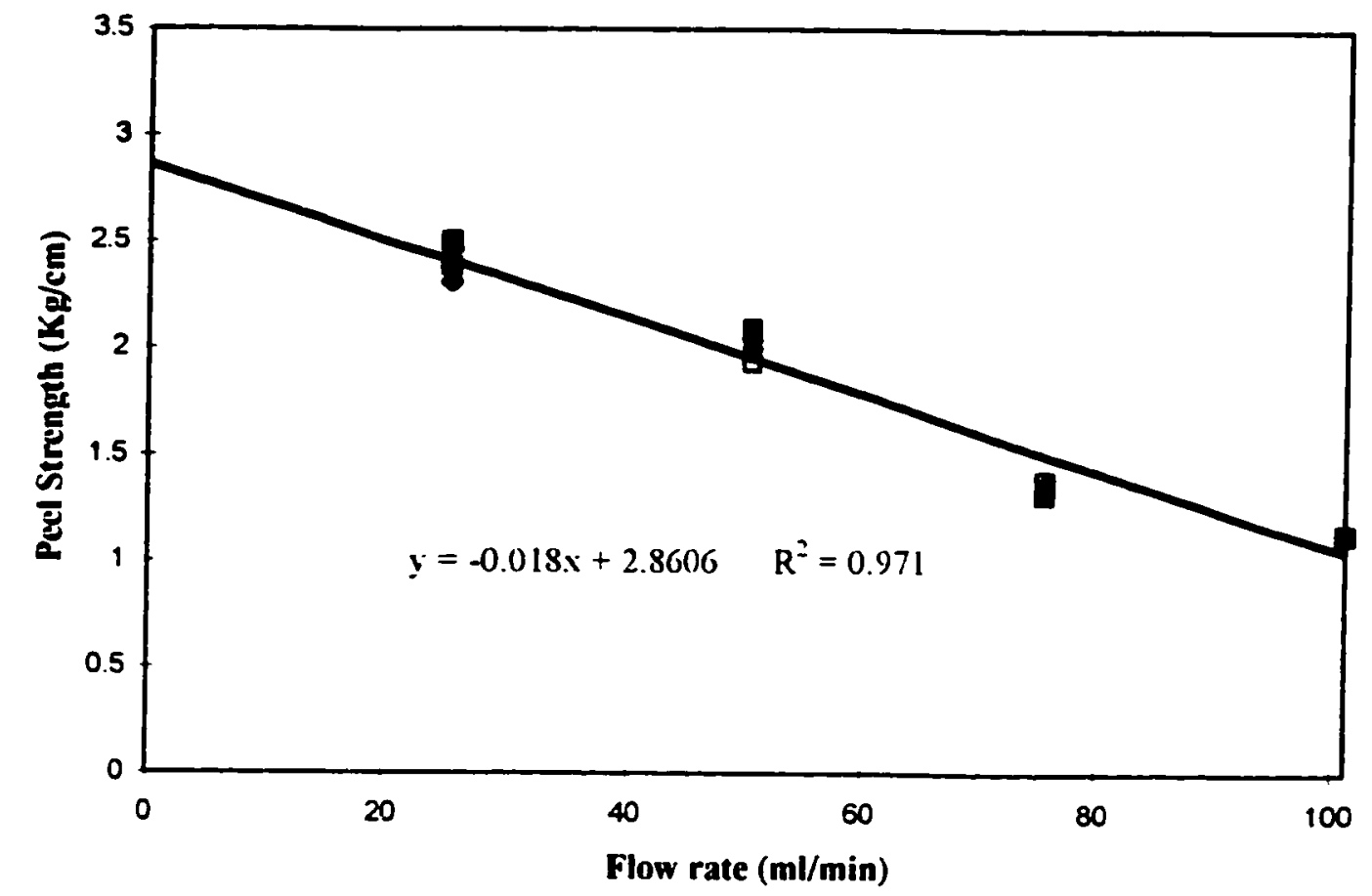

- Peel Strength $(\mathrm{Kg} / \mathrm{cm})$ Ist test RHS

- Pecl Strength $(\mathrm{Kg} / \mathrm{cm})$ 2nd test RHS

x Average $\mathrm{Kg} / \mathrm{cm}$

- Peel Strength $(\mathrm{Kg} / \mathrm{cm})$ lst test LHS

- Pecl Strength $(\mathrm{Kg} / \mathrm{cm})$ 2nd test LHS Linear (Average $\mathrm{Kg} / \mathrm{cm}$ )

FIGURE 8: Effect of helium flow rate on peel strength Variable flow rate at $10 \mathrm{~min}$., 50 watts, and $380 \mathrm{mtorr}$ 
peel strength, and linear regression (trendline) along with correlation coefficient is presented.

\subsection{REPEATABILITY AND REPRODUCIBILITY}

The degree of uncertainty of the experiment was quantified by performing repeatability and reproducibility analysis. Standard deviation and percentage variation were calculated and reported. Refer to Table 4 and Table 5 for oxygen and helium repeatability and reproducibility data. Repeatability is the random variation during a test when all process parameters are maintained constant. Reproducibility on the other hand shows the variation caused in the process conditions - plasma etching, plating, and peel test. Refer to Table 2 and Table 3 for the experimental setup for this study.

One coupon for both $25 \mathrm{ml} / \mathrm{min}$. and $92 \mathrm{ml} / \mathrm{min}$. oxygen flows was tested for repeatability and reproducibility. The average peel strength obtained was 4.31 $\mathrm{kg} / \mathrm{cm}$ and $2.52 \mathrm{~kg} / \mathrm{cm}$ respectively. Repeatability data show a percent variation of $3.20 \%$ and $1.19 \%$ at $25 \mathrm{ml} / \mathrm{rin}$. and $92 \mathrm{ml} / \mathrm{min}$., respectively. Reproducibility data show percent variation of $0.93 \%$ and $0.79 \%$ at $25 \mathrm{ml} / \mathrm{min}$. and $92 \mathrm{ml} / \mathrm{min}$., respectively.

One coupon for both $25 \mathrm{ml} / \mathrm{min}$. and $100 \mathrm{ml} / \mathrm{min}$. helium flows was tested for repeatability and reproducibility. The average peel strength obtained was 2.27 $\mathrm{kg} / \mathrm{cm}$ and $1.21 \mathrm{~kg} / \mathrm{cm}$ respectively. Repeatability data show a percent variation of 
$1.32 \%$ and $4.84 \%$ at $25 \mathrm{ml} / \mathrm{min}$. and $100 \mathrm{ml} / \mathrm{min}$. respectively. Reproducibility data shows percent variation of $6.61 \%$ for both $25 \mathrm{ml} / \mathrm{min}$. and $100 \mathrm{ml} / \mathrm{min}$.

From the above study, the percentage variation for the experiment was below $7 \%$. The largest percent variation was for helium at $6.61 \%$.

\subsection{SEM RESULTS}

This section contains results obtained by SEM for coupons etched with oxygen and helium at $25 \mathrm{ml} / \mathrm{min}$. and $92\left(\mathrm{O}_{2}\right)$ or $100(\mathrm{He}) \mathrm{ml} / \mathrm{min}$. Glass tracing on the micrographs were performed to have a better understanding of the pore size distribution and the count. These traces are shown in Appendix C. The total number of pores, minimum, maximum and average pore diameter, total surface area etched, total surface area, fractional etched area, and error associated with counting are listed in Appendix D. The pores were counted twice and the difference between counts was listed as error. Note that a certain amount of interpretation was necessary in order to decide what constituted a pore. However, the trend in the number of pores versus flow rate will not be effected.

Two SEM micrographs of etched coupons were taken for oxygen and helium flow rates. But, only one of the micrograph was glass traced for pore size distribution and reporting, since the process is very tedious. It was noted that the second micrograph had similar topography when compared to the micrograph traced. 
Figure 9 shows the micrograph of an unetched surface. This figure is used to show the difference between an etched and an unetched surface. It can be seen that there are some non-uniformity on this surface but is manufacture specific.

Figure 10 and Figure 11 represent micrographs of oxygen etched surface at $25 \mathrm{ml} / \mathrm{min}$. and $92 \mathrm{ml} / \mathrm{min}$, respectively. These figures show that there is a decrease in total number of pores as flow rate is increased. The size of these pores, on the other hand, increased as the flow rate was increased.

Figure 12 and 13 show micrographs of helium etched surface at $25 \mathrm{ml} / \mathrm{min}$. and $100 \mathrm{ml} / \mathrm{min}$., respectively. These figures show that helium has an opposite effect when compared to oxygen conditioned surfaces at the same plasma etching conditions. In use of helium, the number of pores increase as the flow rate is increased and the average pore diameter decreases as the flow rate is increased. It should be noted after close examination of the micrographs that the surface seems to be over etched. Certain areas show black stain like characteristics which may possibly be the exposed second ABS layer after complete ablation of the first layer. It should be noted that the surface analyzed for helium was $1 / 4^{\text {th }}$ of that analyzed for oxygen. In this experiment we are interested in trends and not actual numbers.

The change in average pore diameter for the two gases is not significant at the flows considered, but the shift in distribution is significant. Figure 14 shows that at $25 \mathrm{ml} / \mathrm{min}$. oxygen flow, the number of pores in the range of 0.1-0.4 $\mu \mathrm{m}$ are greater than at $92 \mathrm{ml} / \mathrm{min}$. For helium, the distribution is reversed. Figure 15 


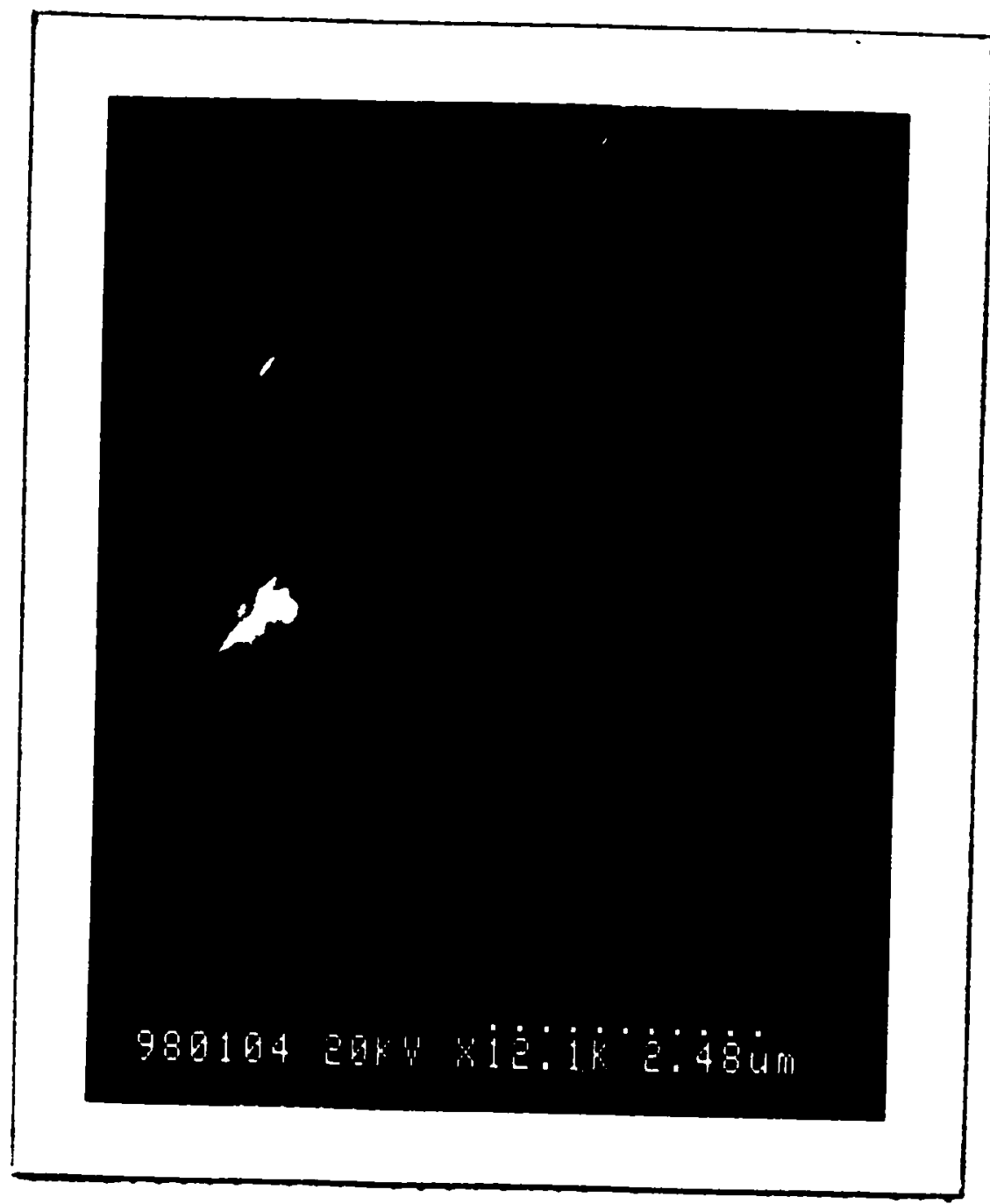

FIGLRE 9: SEM micrograph of an unetched ABS substrate 


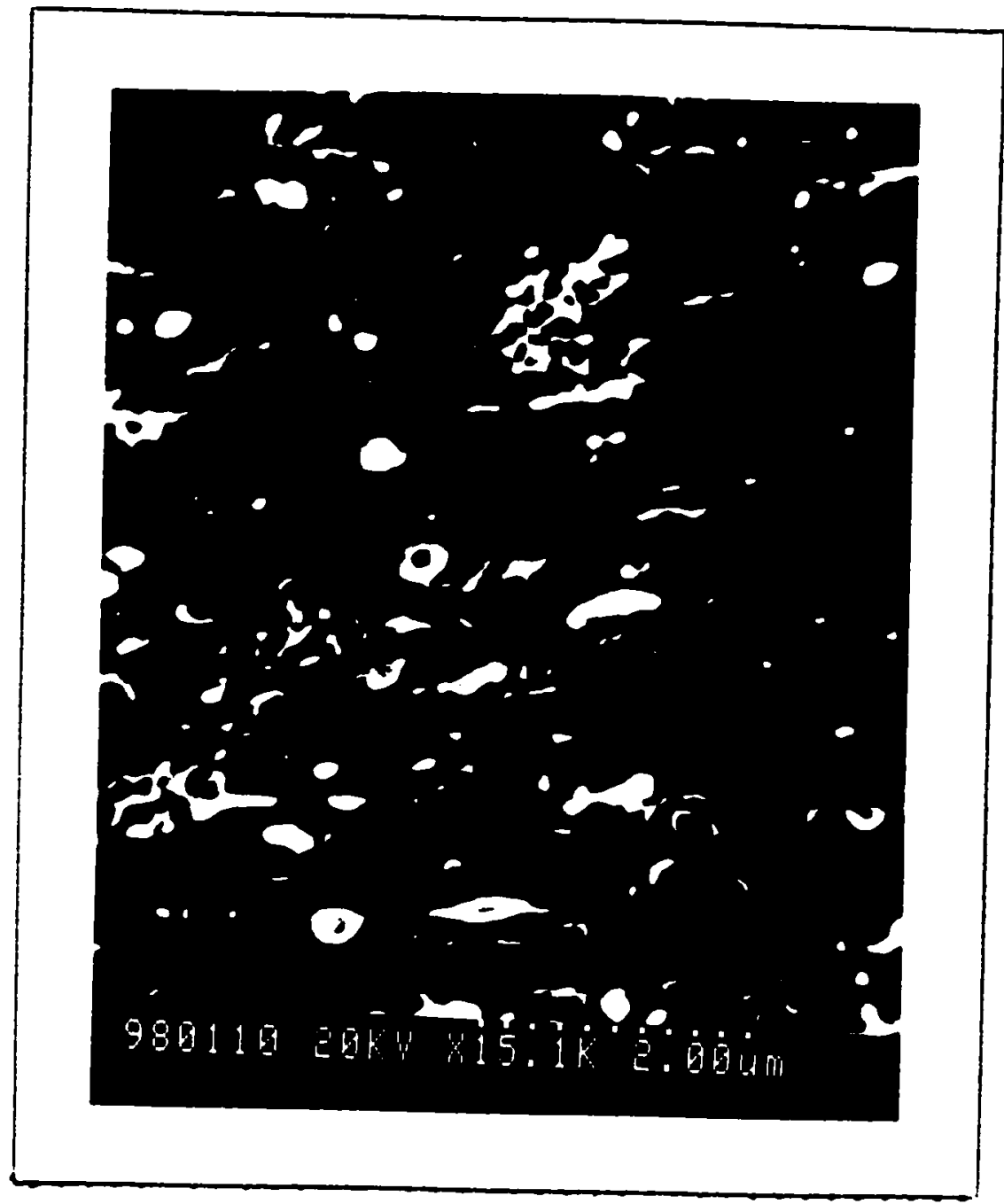

FIGIRE 10: SEM micrograph of an oxygen etched ABS substrate at $25 \mathrm{~mL} / \mathrm{min}$. 


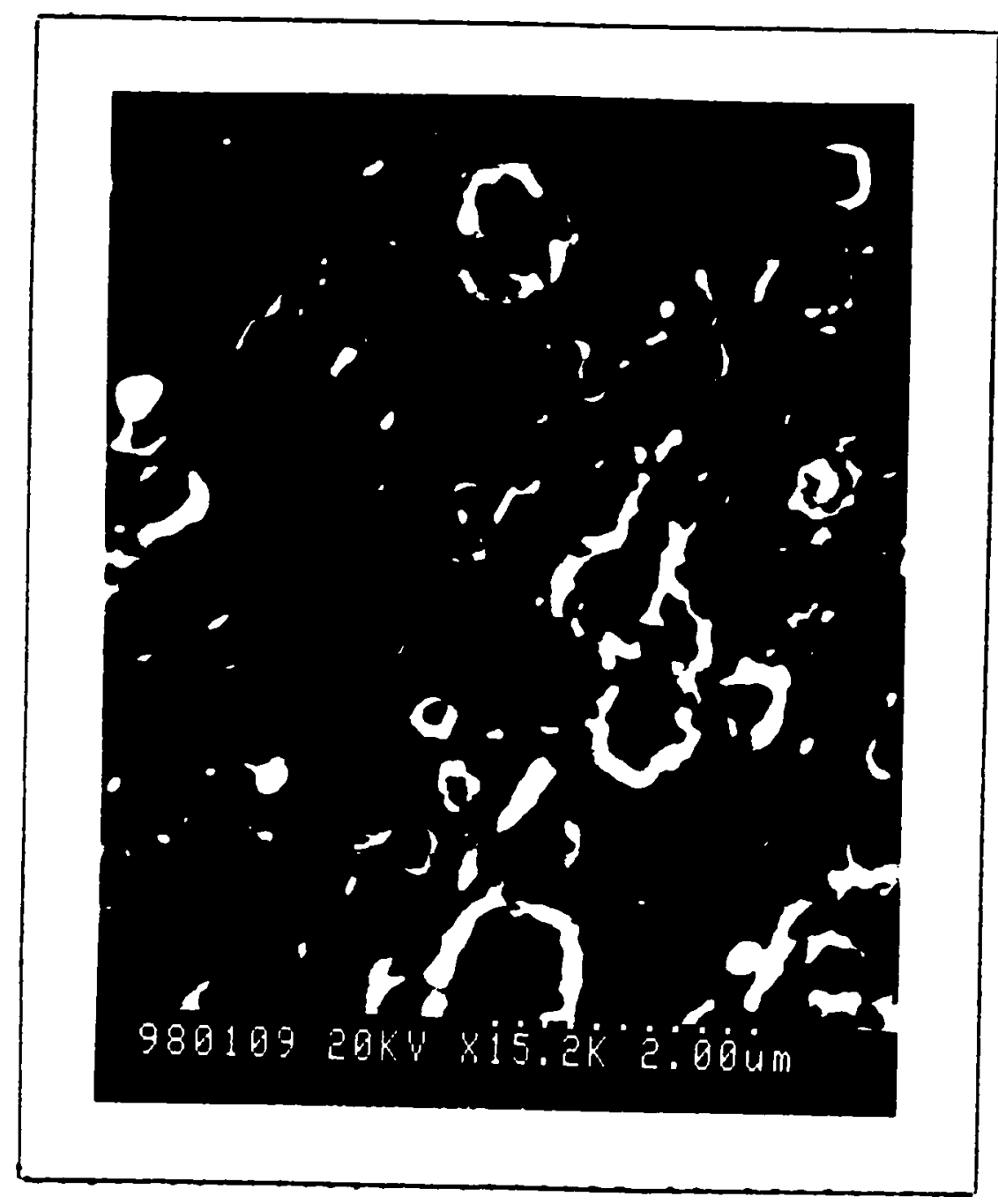

FIGLRE 11: SE.MI micrograph of an oxygen etched ABS substrate at $92 \mathrm{ml} / \mathrm{min}$. 


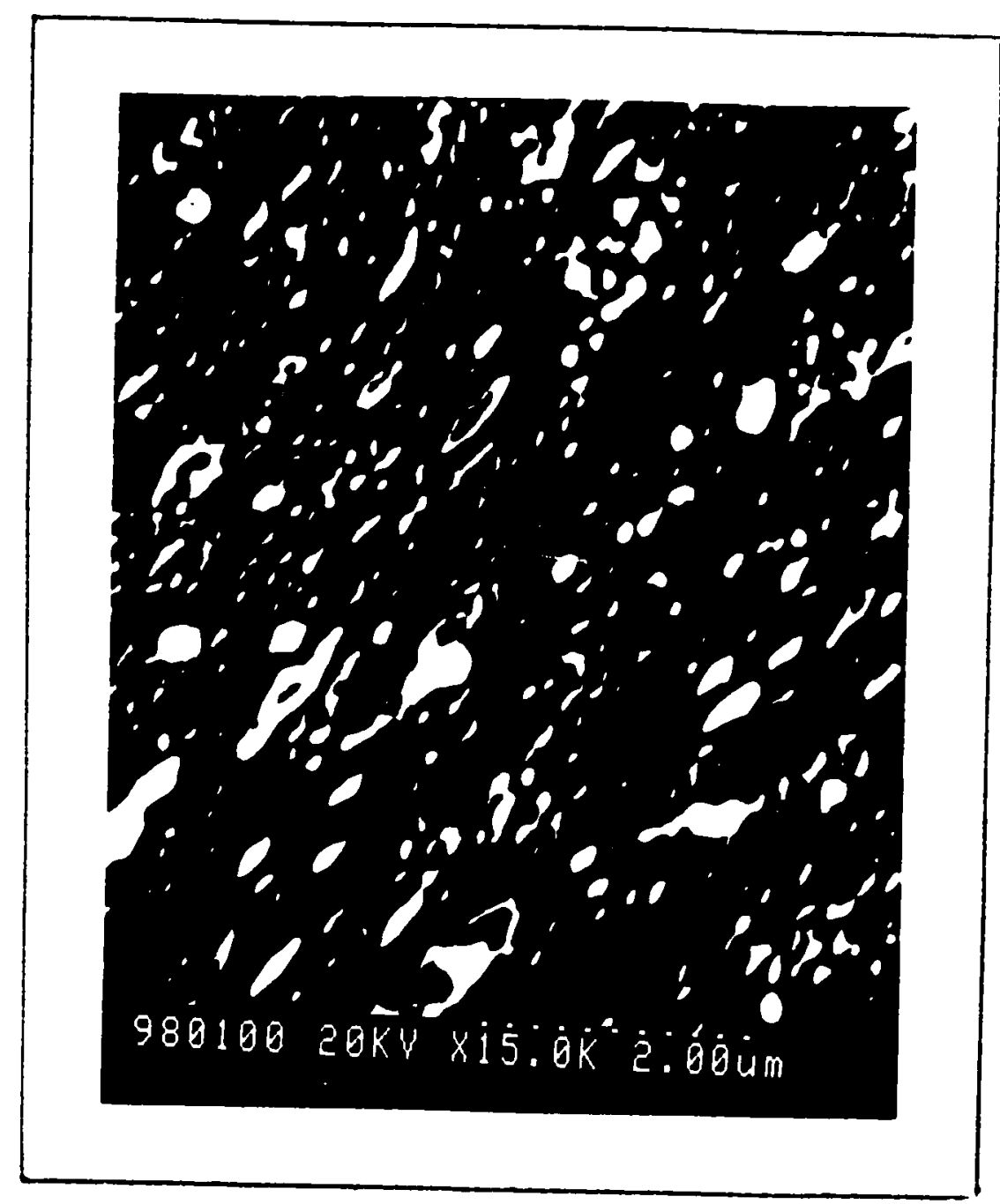

FIGLRE 12: SE.I micrograph of an helium etched ABS substrate at $25 \mathrm{ml} / \mathrm{min}$. 


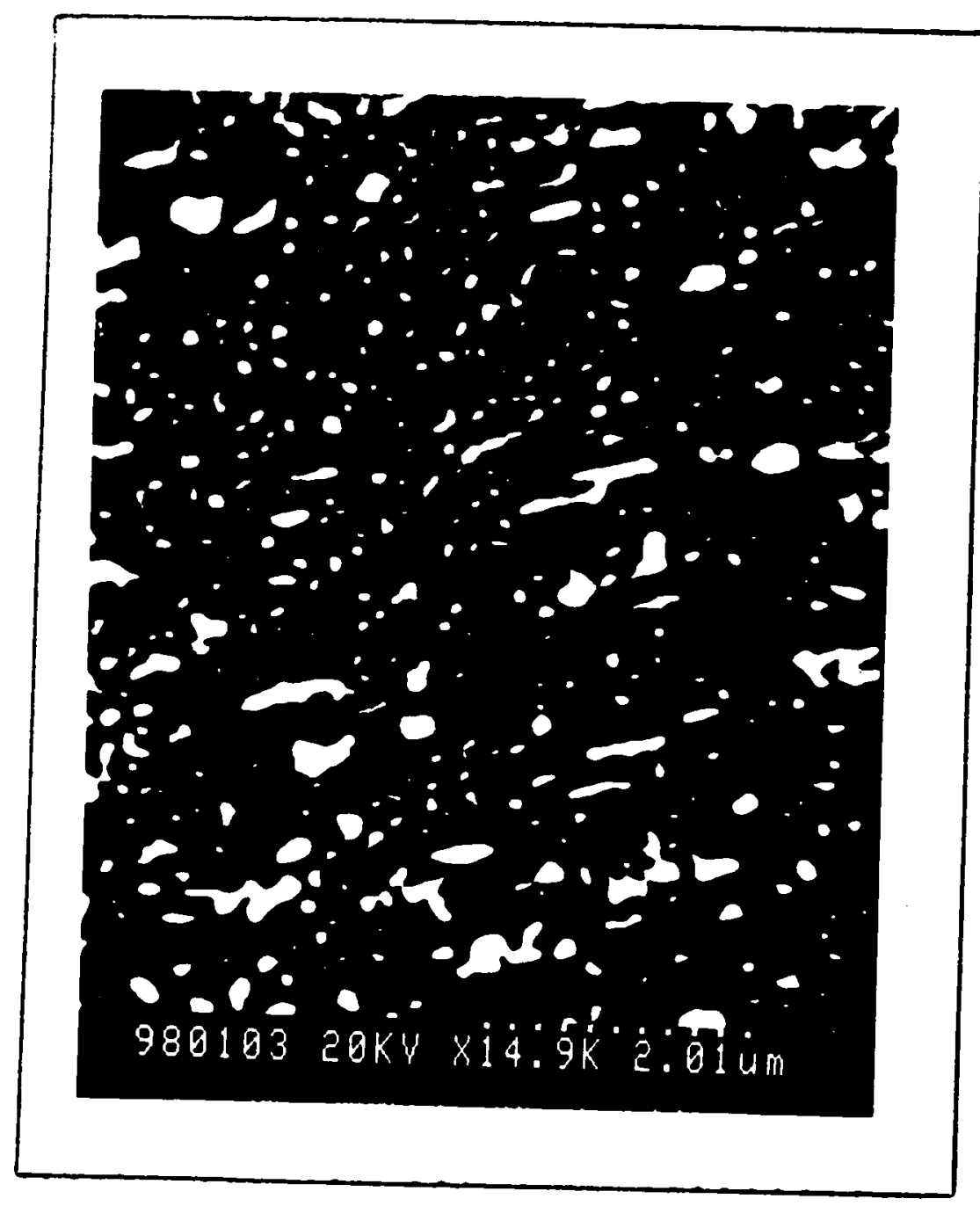

FIGLRE 13: SE.I micrograph of an helium etched ABS substrate at $100 \mathrm{ml} / \mathrm{min}$. 


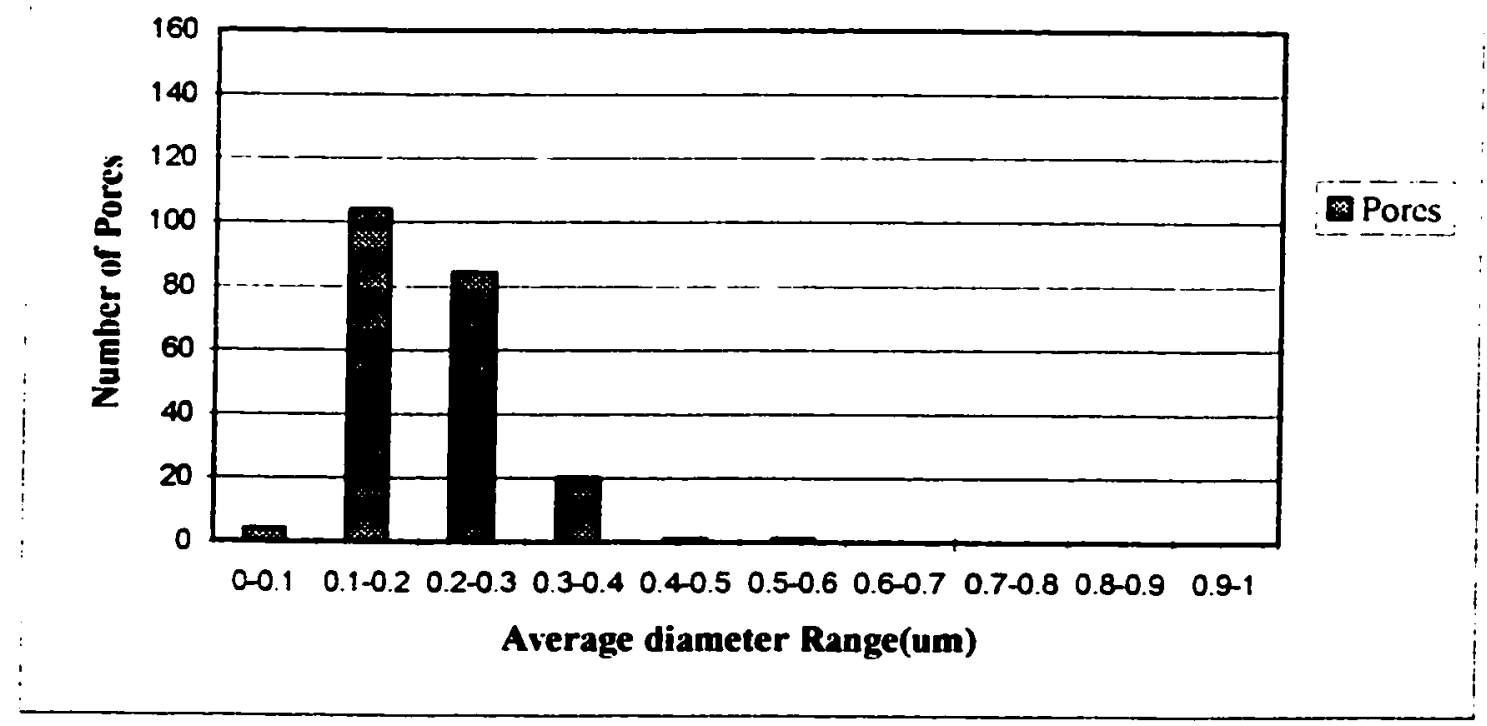

a)

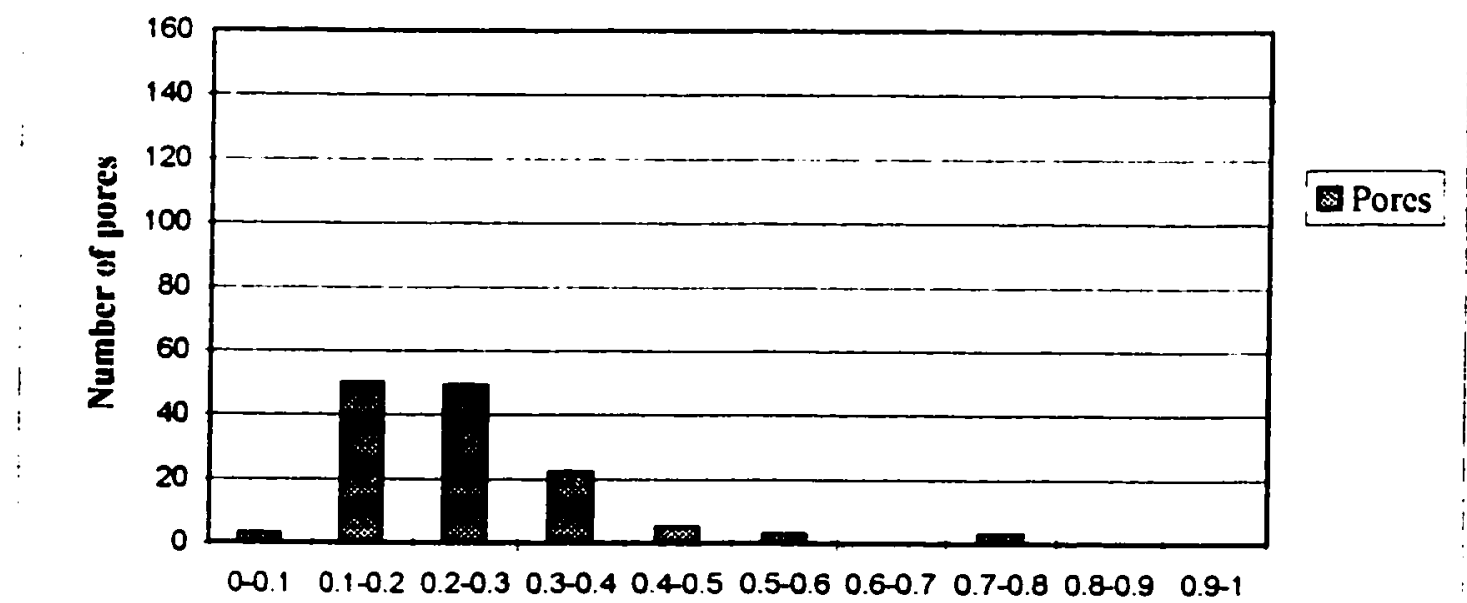

Average diameter range (um)

b)

FIGURE 14: Average pore diameter distribution for coupons etched with oxygen at

a) $25 \mathrm{mV} / \mathrm{min}$ and b) $92 \mathrm{mV} / \mathrm{min}$ 


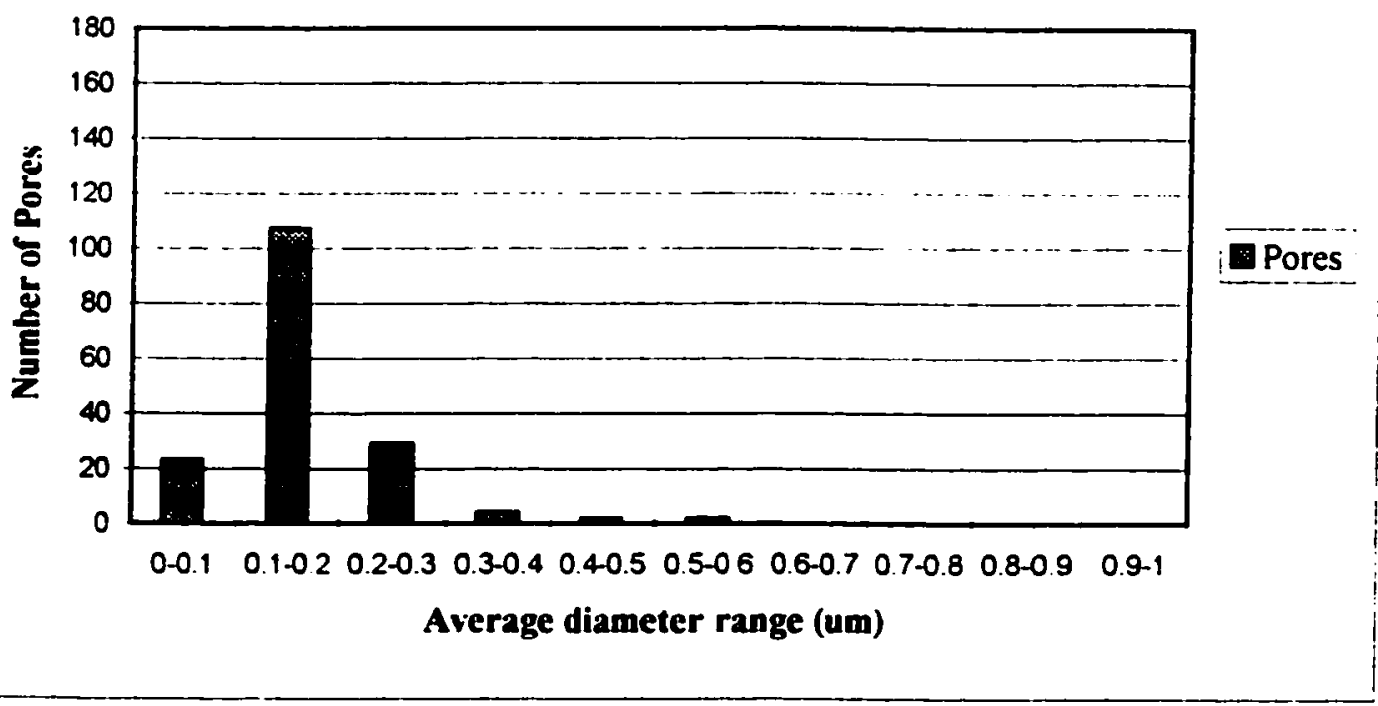

a)

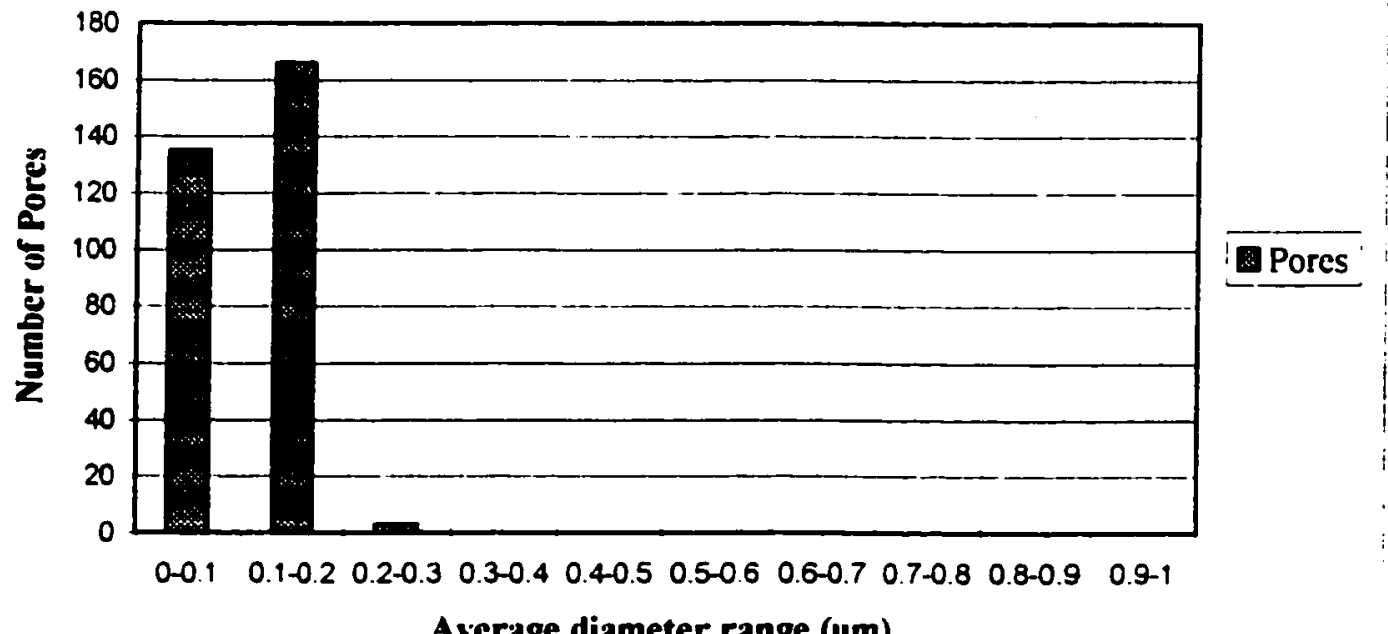

b)

FIGURE 15: Average pore diameter distribution for coupons etched with helium at

a) $25 \mathrm{mV} / \mathrm{min}$ and b) $100 \mathrm{mV} / \mathrm{min}$ 
shows that at $100 \mathrm{ml} / \mathrm{min}$., the distribution is skewed towards the lower range, 0 $0.2 \mu \mathrm{m}$, while at $25 \mathrm{ml} / \mathrm{min}$. the skew is not prominent.

In this particular experiment only two flows were considered, therefore the bar graph shows comparison between $25 \mathrm{ml} / \mathrm{min}$. and $92\left(\mathrm{O}_{2}\right)$ or $100(\mathrm{He}) \mathrm{ml} / \mathrm{min}$. for oxygen and helium, respectively. It should be noted that there is a possibility to have a maximum or minimum somewhere in between $25 \mathrm{ml} / \mathrm{min}$. and $92\left(\mathrm{O}_{2}\right)$ or $100(\mathrm{He}) \mathrm{ml} / \mathrm{min}$. Figure 16 represents a graphical presentation of the total number of pores versus gas flow rate for both oxygen and helium. The figure shows that for oxygen, as the flow rate is increased the number of pores decreases, while for helium an increase in the flow rate increases the number of pores. Figure 17 shows variation of average pore diameter with flow rate for both oxygen and helium. We see an opposite effect for both gases. An increase in flow for oxygen increases the average pore diameter while an increase in flow for helium decreases the average pore diameter. Figure 18 shows the effect of variation in flow rate on average fractional etch area of the pores. The trend for both gases is the same, the average fractional etch area decreases with increase in flow rate for both oxygen and helium. 


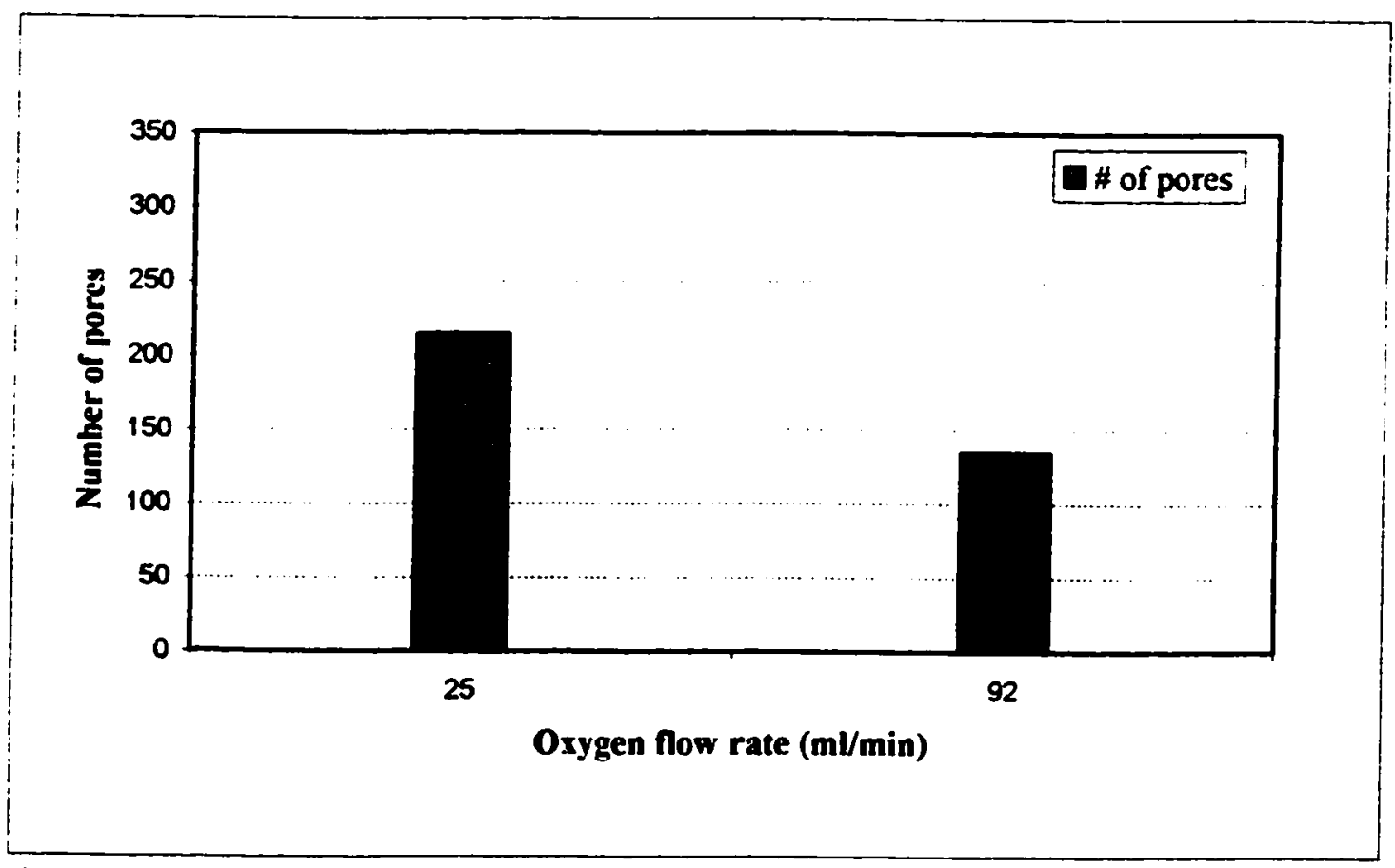

a) Oxygen

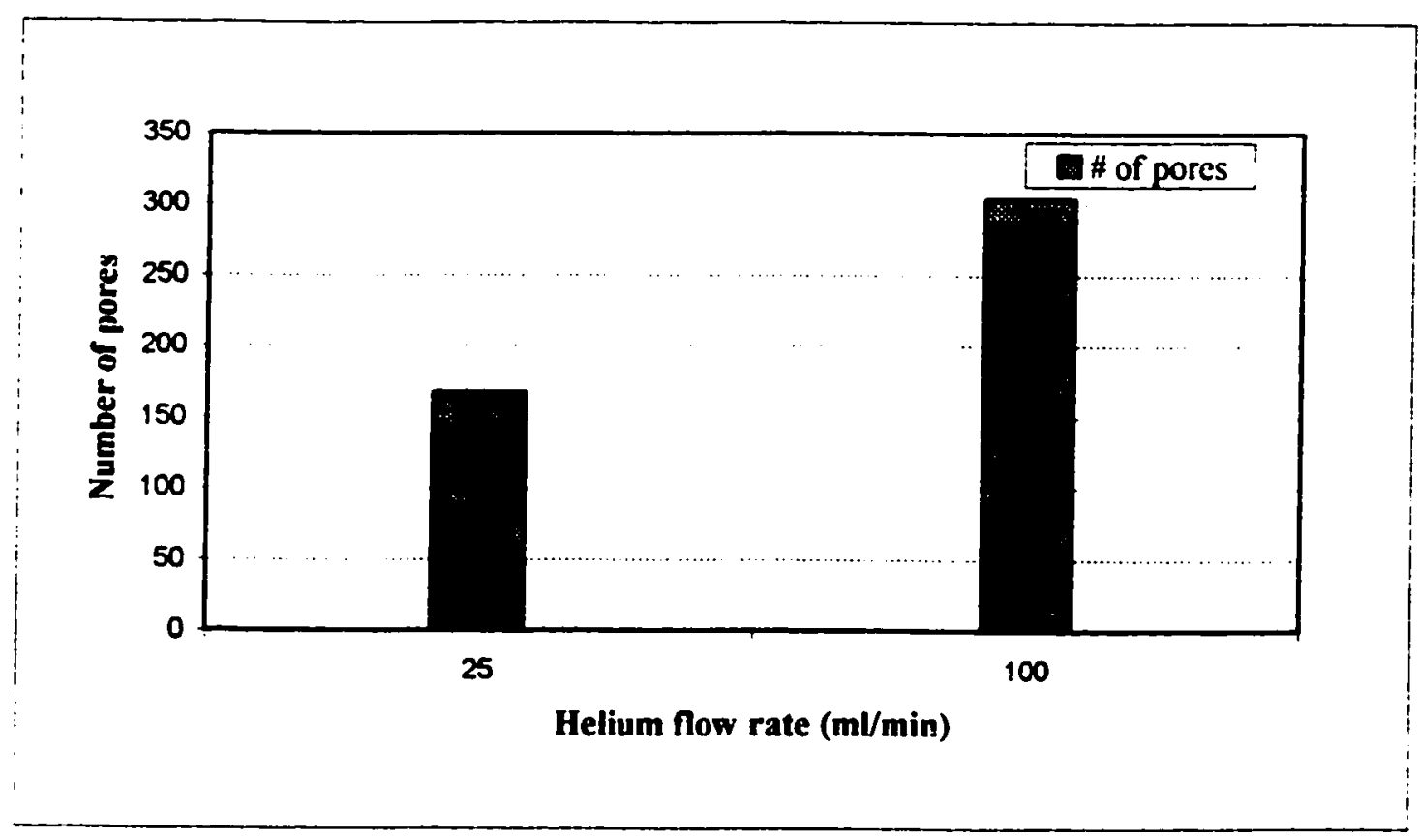

b) Helium

FIGURE 16: Number of pores versus gas flow rate for a) oxygen and b) helium 


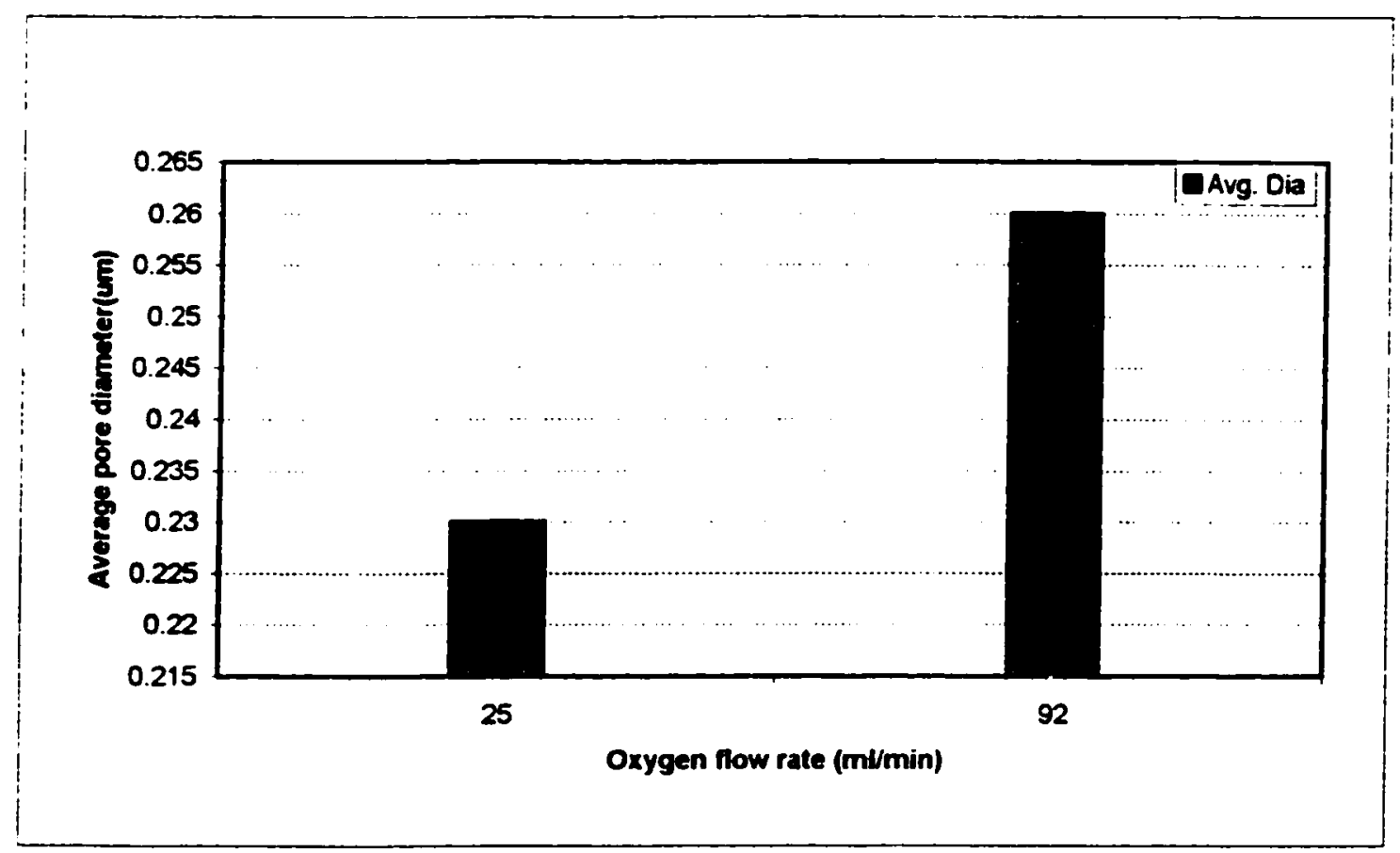

a) Oxygen

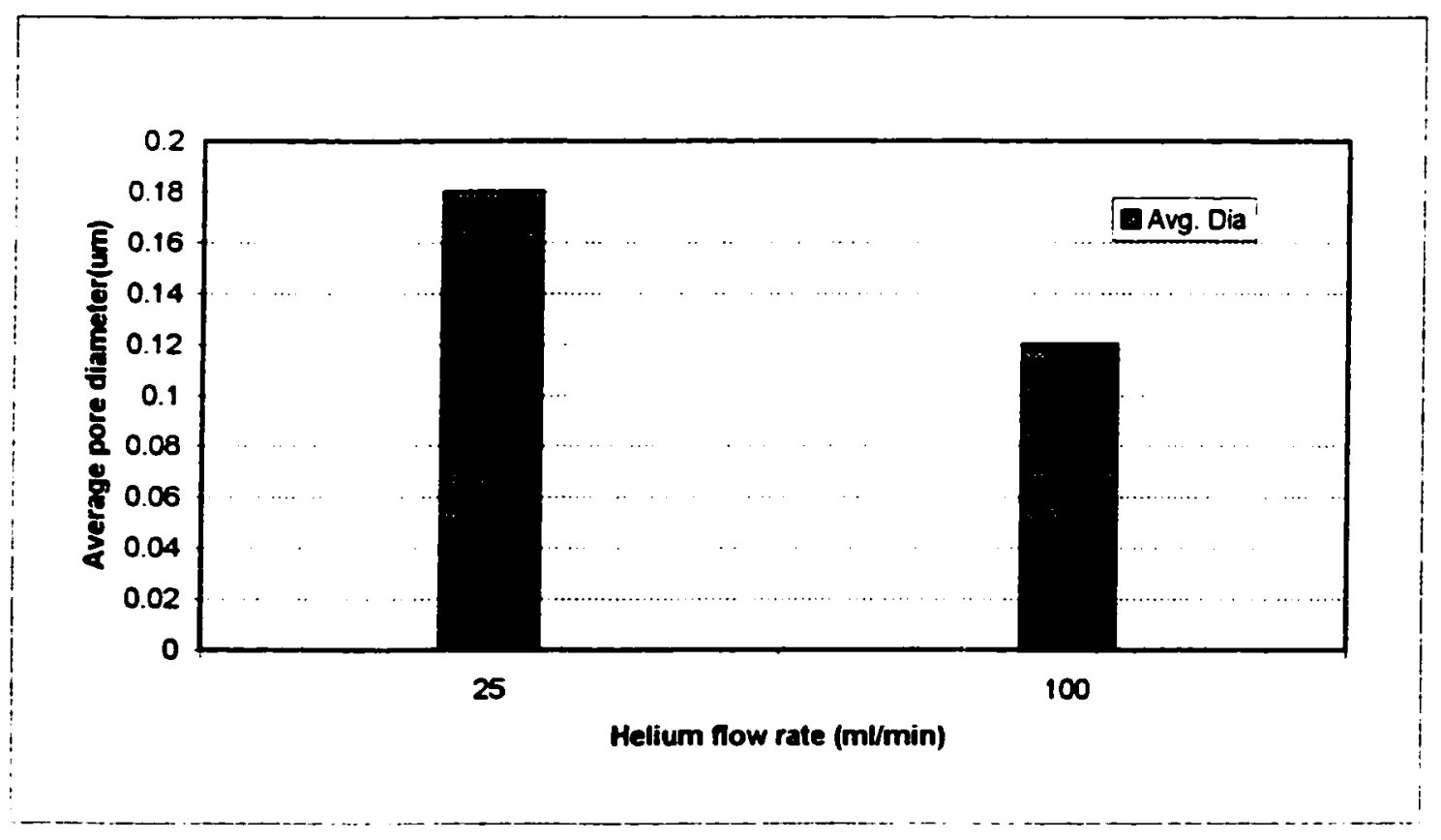

b) Helium

FIGURE 17: Average pore diameter versus gas flow rate for

a) oxygen and b) helium 


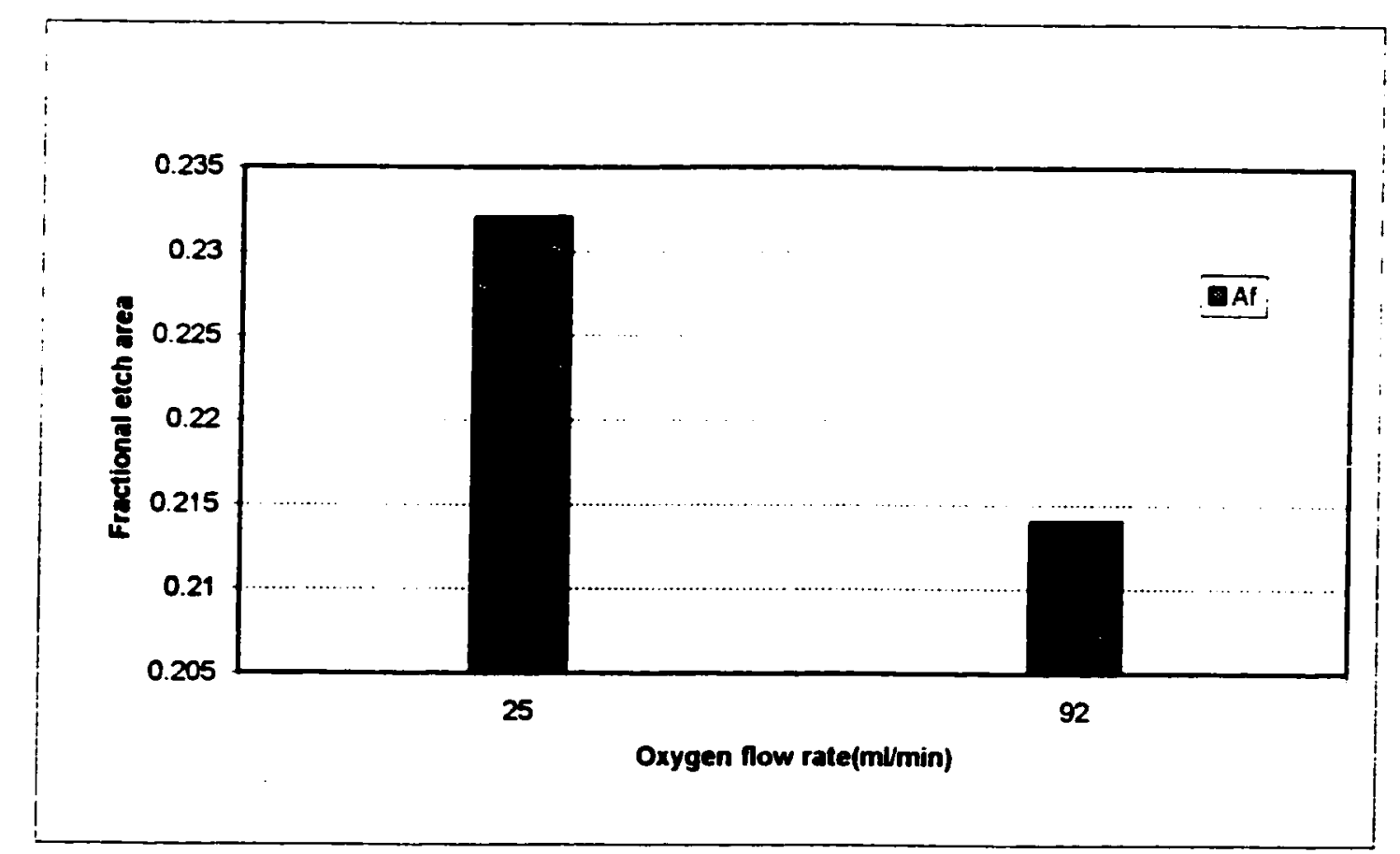

a) Oxygen

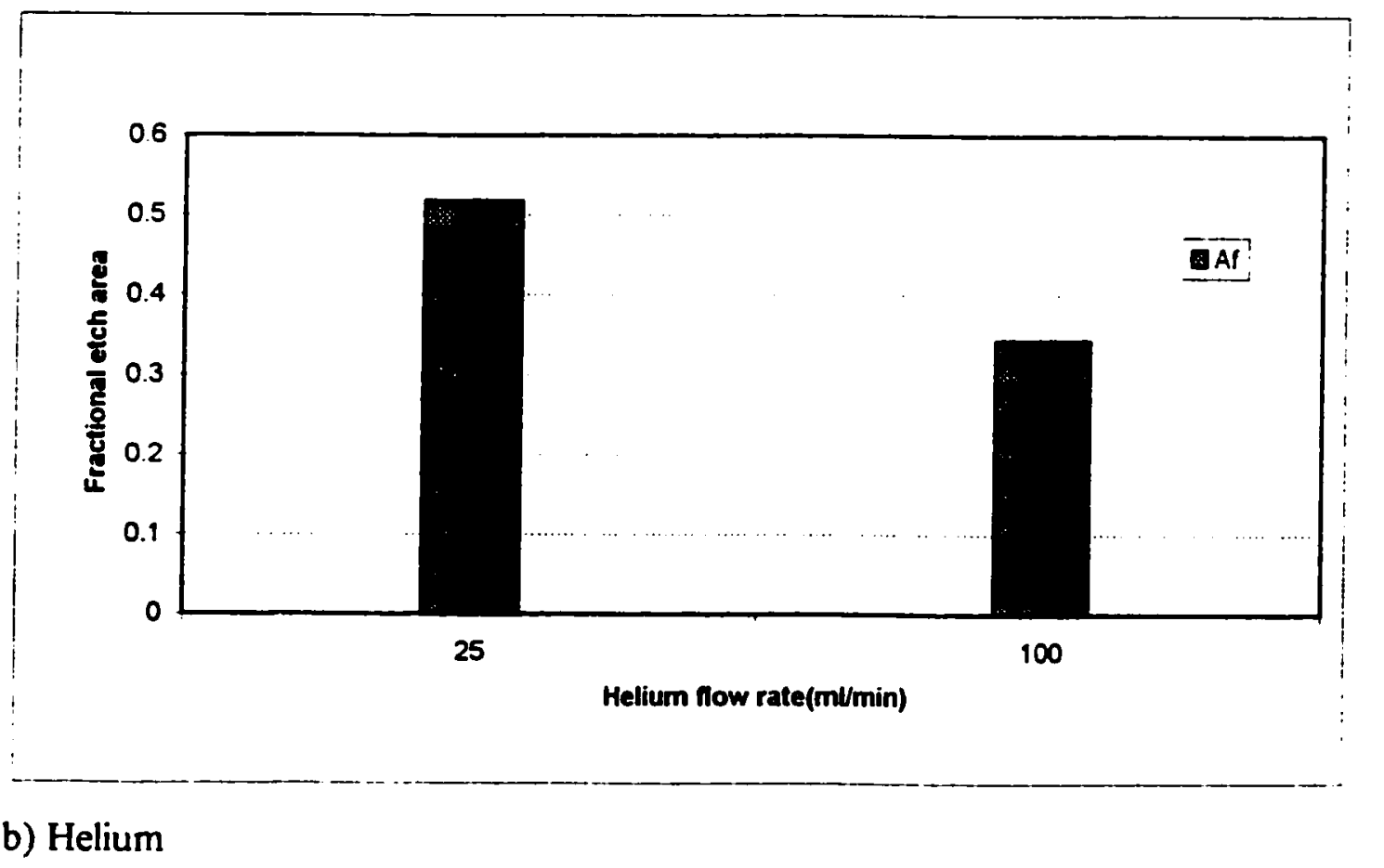

FIGURE 18: Average fractional etch area of pores versus gas now rate for a) oxygen and b) helium 


\subsection{DISCUSSION}

\subsection{EFFECT OF FLOW RATE ON PEEL STRENGTH}

Table 4 and Table 5 presented in the results section show the effect of varying plasma gas flow rate on the peel strength of the coupons. Etch time, RF power and the chamber pressure for all runs were maintained constant at $10 \mathrm{~min}$, 50 watts, and 380 millitorr respectively.

The results for oxygen show that peel strength decreases with increasing flow rate. It reduces from an average of $4.27 \mathrm{~kg} / \mathrm{cm}$ at $24.85 \mathrm{ml} / \mathrm{min}$. to 2.54 $\mathrm{kg} / \mathrm{cm}$ at $91.95 \mathrm{ml} / \mathrm{min}$. This is about $48 \%$ reduction in peel strength. This effect is similar to exposing the substrate to a longer etching period, where at a relatively long etching period no improvement or even deterioration in the peel strength value is observed. This is because over-etch of the substrate increases the size of the pores beyond an optimum value that may cause a decrease in bonding of metal to plastic (Villamizar et. al., 1981). This may be true, since we do see an increase in the pore size as we go from $24.85 \mathrm{ml} / \mathrm{min}$. to $91.95 \mathrm{ml} / \mathrm{min}$., but the results do not agree with the theory that critical pore size produces better bonding. The difference in average diameter of pores at $24.85 \mathrm{ml} / \mathrm{min}$ and 91.95 $\mathrm{ml} / \mathrm{min}$ as reported in Appendix $\mathrm{D}$ is negligible, about $0.03 \mu \mathrm{m}$. But, we do see a $48 \%$ decrease in peel strength. In other words, critical pore size of $0.4 \mu \mathrm{m}$ as stated by Villamizar, et. al. (1981) does not hold true for this experiment. Note 
that these results agree with Gurly and McNeil (1992). The average pore size as observed via SEM was found to be $0.23 \mu \mathrm{m}$ and $0.26 \mu \mathrm{m}$ respectively for the two flows under consideration. This is close to $0.2 \mu \mathrm{m}$ optimal cavity size obtained by Pao et. al. (1977). It has been stated that at optimum pore size there exists a better mechanical bond between the substrate and the plastic. This experiment agrees with the part that there is mechanical bonding but it's not the critical pore size that dominates the peel strength value. Researchers have never looked at depth of the pores as a factor contributing to better mechanical bonding. It is a possibility that the pore depth might significantly effect adhesion. However, helium with deeper pores had lower peel strength.

The results suggest that apart from mechanical bonding there is another factor, like unsaturated oxygen linkages causing chemical bonding between the substrate and copper that is enhancing the adhesion strength. It has been shown by Matsunaga et. al. (1968) that the interface adhesion between the metal and plastic is stronger than the surface strength of the plastic, proving that chemical bonding should be considered. Also, it has been suggested that the conditioning of the substrate results in the loss of butadiene from the acrylonitrile-butadiene-styrene matrix and the dipole interactions between the metal and polar groups produced by oxidation in the butadiene space produce a strong chemical bond (Matsunaga et. al., 1968). This experiment could not prove which phenomena might be occurring. To do so future work will be required. The SEM micrograph for 24.85 $\mathrm{ml} / \mathrm{min}$. shows more but shallower pores when compared to the SEM micrograph 
at $91.95 \mathrm{ml} / \mathrm{min}$. for oxygen. More pores at the lower flow rate i.e. increased porosity increases bonding characteristics of the substrate to copper by providing a better interlocking mechanism between metal and plastic. This is in agreement with the paper published by Elmore and Davis (1968). The above statement does not explain why the peel strength for helium is lower when the number of pores is much higher than that of oxygen. It has also been noted that exposure to activated oxygen can ultimately lead to deterioration and erosion of the polymer surface (Hall et. al., 1972). This may possibly be the case for oxygen at 91.95 $\mathrm{ml} / \mathrm{min}$. since the SEM in some areas visually show deeper and wider pores. This may be the second polymer layer. Atomic force microscopy (AFM) or the like will have to be performed to prove the above statement.

The type of failure seen in the case of oxygen was cohesive, since plastic attached to the peeled copper film was visually observed. The trend for adhesion strength values and type of failure are the same as observed by Gurly and McNeil (1992). In the study done by Abuelazaim (1994), results showed that the number of pores increased as flow rate increased, but in this experiment, under the specified flow rate regime, over etching might have occurred and the results obtained are opposite of that obtained by Abuelazaim 1994.

The results for helium show the same trend observed for oxygen. The peel strength values decrease with increase in flow rate. It reduces from an average $2.42 \mathrm{~kg} / \mathrm{cm}$ at $25.27 \mathrm{ml} / \mathrm{min}$. to $1.13 \mathrm{~kg} / \mathrm{cm}$ at $101.08 \mathrm{ml} / \mathrm{min}$. This is about a $53 \%$ reduction in peel strength. It has been noted that polymers like ABS are 
readily made bondable with oxygen but not helium (under similar operating conditions) because chain scission dominates over crosslinking in the latter case (Hall et. al., 1972). The results of this experiment support the beneficial nature of oxygen over helium as mentioned by Hall et. al. (1972). Fall-off in bond strength may also occur when destruction or ablation of the surface occur. The SEM micrographs for helium at $25.27 \mathrm{ml} / \mathrm{min}$. and $101.08 \mathrm{ml} / \mathrm{min}$. reveal visually, that the surface has been over-etched. The number of pores are more than compared to oxygen, but there are regions where streaks of black spots are seen which may possibly be the second polymer layer of the substrate. It has been noted that an inert gas at lower chamber pressure, lower flows, and shorter etch time produces cross-linking of the polymer substrate to produce comparable adhesion results to that of oxygen.

The number of pores for helium etched ABS is about four times greater than that of oxygen etched ABS. If mechanical interlocking was a dominant phenomena, helium etched substrates should have a better bondability to copper, but this is not the case. The type of failure seen in the case of helium was cohesive, since plastic attached to the peeled copper film was visually observed.

Oxygen etched surfaces have better bonding characteristics than surfaces etched with helium. This is because oxygen produces active species at the polymer surface that chemically alter the substrate for better bondability with copper. Helium on the other hand, being an inert gas, etches the surface by ion bombardment. This nature of etching mechanism is shown by SEM taken for 
oxygen and helium at $25 \mathrm{ml} / \mathrm{min}$. and $92\left(\mathrm{O}_{2}\right)$ or $100(\mathrm{He}) \mathrm{ml} / \mathrm{min}$. Visual observation shows that the pores for oxygen are shallower and wider while those for helium are deeper and smaller. Shallow and wide pores are characteristic of lateral etching while deep and small pores are characteristic of vertical etching. Future work is advised for helium at lower pressure and flow to study the crosslinking phenomena of the plasma that was not verified in this experiment.

\subsection{EFFECT OF FLOW RATE ON ETCHING}

The SEM micrographs shown in Figure 9 through 13 represent unetched surface, oxygen etched surface at $24.85 \mathrm{ml} / \mathrm{min}$. and $91.95 \mathrm{ml} / \mathrm{min}$, and helium etched surface at $25.27 \mathrm{ml} / \mathrm{min}$. and $101.08 \mathrm{ml} / \mathrm{min}$. In general, increased flow rate led to increased etch rate. This is because an increase in flow rate increases the supply of the etchant to the sample. This leads to increased etchant concentration at the surface and thus increased etch rate. However, if reaction of the plasma generated active species with the material to be etched produces a secondary species, which is more active than the former, the result will be an increase in etch rate as the flow rate is decreased. This is because, lower flow rate tends to increase the concentration of the secondary species at the sample. It has been noted by Lerner and Wydeven (1989), that when a polymer similar to ABS was etched in oxygen, etch rate decreased with increase in the flow rate. This was explained on the basis that these polymers were not being etched directly by $O\left({ }^{3} P\right)$ 
but by a secondary species produced by the interaction of $\mathrm{O}\left({ }^{3} \mathrm{P}\right)$ with the polymer. The secondary species might be $\mathrm{OH}$. The emission spectrum of $\mathrm{OH}$ has been observed during plasma etching. $\mathrm{OH}$ is formed by the reaction of $\mathrm{O}\left({ }^{3} \mathrm{P}\right)$ with hydrocarbons. Studies have shown that both $\mathrm{O}\left({ }^{3} \mathrm{P}\right)$ and $\mathrm{OH}$ undergo similar reaction with hydrocarbons, but the rate of reaction of $\mathrm{OH}$ is 2-100 times greater than that of $O\left({ }^{3} \mathrm{P}\right)$, a similar effect is also seen in the study done by Mance et. al. (1989) and Hartney et. al. (1988).

SEM micrographs for oxygen etched substrate show that an increase in gas flow rate decreases the etch rate. This is consistent with the explanation stated above. It can be inferred that the properties that make plasma efficient are the dissociation of oxygen into more reactive species and the acceleration of ions. The reactive species chemically react with the surface while the ions cause bombardment of the surface being etched. The above phenomena is important since oxygen atoms initiate etching by extracting the hydrogen atoms from the polymer surface leaving free radical species. These radicals can react with oxygen molecules from the plasma to form carbonyl and alcohol groups, which are precursors to volatile species, that after desorption, are pumped away. In order for the volatiles to be liberated sufficient energy for desorption is necessary. The above energy is provided by ion bombardment. So, the degree of ionization and the production of neutral species are some of the aspects that influence etching. A faster etch may occur when neutral species and ion bombardment are present. In other words, at lower oxygen both lateral(chemical) and vertical(ion-bombardment) etching may be 
significant. The SEM photographs show shallow and more pores at $24.85 \mathrm{ml} / \mathrm{min}$. and fewer and deeper pores at $91.95 \mathrm{ml} / \mathrm{min}$. oxygen flow. It can be assumed that for oxygen etched surface, vertical etching is more prominent and lateral etching is less prominent at higher flow rate. This cannot be said with certainty since the depth of the pores were not quantified, the above assumption is being made just by looking at the topography observed from SEM micrographs. The average pore diameter increases with increase in the gas flow rate. Vertical etching generally causes deeper and smaller pores (Abuelazaim, 1994). The SEM micrograph at $91.95 \mathrm{ml} / \mathrm{min}$. does not clearly show this effect. This may be because exposure to activated oxygen can ultimately lead to deterioration and erosion of the polymer surface (Hall et. al., 1972). So, the surface we are looking at may be already eroded and the gas is working through the second polymer layer. The average fractional surface area etched decreased as the flow rate was increased. Figure 14 through Figure 18 graphically present the data obtained. It should be noted that there is a possibility of a maximum somewhere in-between $25 \mathrm{ml} / \mathrm{min}$. and $92\left(\mathrm{O}_{2}\right)$ or $100(\mathrm{He}) \mathrm{ml} / \mathrm{min}$. if other flows were considered. Figure 14 shows a graphical presentation of average pore diameter distribution for coupons etched with oxygen at $25 \mathrm{ml} / \mathrm{min}$. and $92 \mathrm{ml} / \mathrm{min}$. The maximum number of pores are between 0.1 $0.4 \mu \mathrm{m}$ for both flows. The results obtained were opposite of that found by Abuelazaim (1994), so the latter cannot be incorporated in this study. However, her top flow rate may have been at a rate which did not cause the surface to over etch. 
SEM micrographs for helium show that the substrate is over-etched. The number of pores increase with increase in flow rate. It should be noted that it was difficult to trace these micrographs. There is a possibility of operator induced errors. The pores look deeper and smaller than those obtained by oxygen plasma for $25 \mathrm{ml} / \mathrm{min}$. gas flow. This implies that vertical (ion-bombardment) etching is prominent in case of helium. But, again the depth of the pores was not quantified. At $100 \mathrm{ml} / \mathrm{min}$. helium gas flow, the nature of the surface is hard to decipher. The black spots are either deep pores or the exposed second layer of the polymer (for tracing purposes they were considered as pore). There is a possibility that the surface has been eroded. This cannot be said with certainty since the surfaces of the coupons were not characterized. Figure 15 through 18 graphically present the data obtained. Figure 15 shows a graphical presentation of average pore diameter distribution for coupons etched with helium at $25 \mathrm{ml} / \mathrm{min}$. and $100 \mathrm{ml} / \mathrm{min}$. The maximum number of pores for helium at $25 \mathrm{ml} / \mathrm{min}$. and $100 \mathrm{ml} / \mathrm{min}$. are between $0-0.3 \mu \mathrm{m}$ and $0-0.2 \mu \mathrm{m}$ respectively. The distribution is skewed towards the lower range and implies that vertical etching is dominant. It should be noted that surface analyzed for helium was $1 / 4^{\text {th }}$ of that analyzed for oxygen. In this experiment we are interested in trends and not actual numbers. The average fractional surface area etched decreased as the flow rate increased but is about $30 \%$ higher than that obtained from oxygen. The results follow the same trend as observed by Abuelazaim (1994).

Visual inspection of the SEM micrographs revel that the number of pores 
are lower, average diameter of the pores are larger, and the fractional etched area is smaller for oxygen when compared to helium. Oxygen in general, being an active gas, chemically reacts with the surface to produce shallower and larger pores. Helium, being an inert gas produces deeper and smaller pores. In other words, for oxygen, both lateral and vertical etching, may be significant, while for helium vertical etching is more prominent. Oxygen etched surfaces have better bondability to copper than helium etched surfaces. This is because chemical bond formed between the metal and plastic, in case of oxygen, is stronger than mechanical interlock between the pores and the metal, for helium. In plating of plastics (POP) industry, an active gas such as oxygen should be used in a flow rate range of 0.1 to $25 \mathrm{ml} / \mathrm{min}$. for etching ABS. This will condition the substrate to provide best bondabilty.

The literature review reveled that parameters such as surface porosity, etching time, type of gas, gas flow rate, RF power, chamber pressure, vertical or lateral etching, and chemical or mechanical bond formation affect the adhesion strength. In this experiment, etching time, chamber pressure, and RF power were maintained constant. Results showed that the type of gas and flow rate affected the surface porosity and the pore shape. These affected parameters provided variation in adhesion strength, as reflected in the results. Good adhesion was observed while using an active gas at low flow rate. 


\subsection{CONCLUSION}

The objective of this study was to investigate the variation in adhesion strength obtained after electro - plating copper to ABS plastic substrate by varying plasma gas and their flow rates during the surface modification step of the substrate. Coupons were etched at $25 \mathrm{ml} / \mathrm{min}$., $50 \mathrm{ml} / \mathrm{min} ., 75 \mathrm{ml} / \mathrm{min}$., and (92) $100 \mathrm{ml} / \mathrm{min}$. for both oxygen and helium. The etch time(te), RF Power(E), and Chamber Pressure(P) were maintained at $10 \mathrm{~min}$., 50 Watts, and $380 \mathrm{mtorr}$ respectively.

Peel strength analysis reveled that the average peel strength for oxygen etched coupons at $25 \mathrm{ml} / \mathrm{min}$., $50 \mathrm{ml} / \mathrm{min}$., $75 \mathrm{ml} / \mathrm{min}$, and $92 \mathrm{ml} / \mathrm{min}$. are 4.27 $\mathrm{kg} / \mathrm{cm}, 3.41 \mathrm{~kg} / \mathrm{cm}, 2.98 \mathrm{~kg} / \mathrm{cm}$, and $2.54 \mathrm{~kg} / \mathrm{cm}$ respectively. The average peel strength for helium etched coupons at $25 \mathrm{ml} / \mathrm{min}$., $50 \mathrm{ml} / \mathrm{min}$., $75 \mathrm{ml} / \mathrm{min}$., and $100 \mathrm{ml} / \mathrm{min}$. are $2.42 \mathrm{~kg} / \mathrm{cm}, 2.00 \mathrm{~kg} / \mathrm{cm}, 1.35 \mathrm{~kg} / \mathrm{cm}$, and $1.13 \mathrm{~kg} / \mathrm{cm}$ respectively. There is a linear decrease in peel strength as the flow rate is increased for both gases.

Variation of flow rate on topography of the etched surface reveal that an increase in flow rate reduces the number of pores, increases the average pore diameter and reduces the average fractional etch area for oxygen etched substrate. For helium etched substrate an increase in the flow rate increases the number of pores, reduces the average pore diameter and reduces the average fractional etch area. The average pore diameter distribution shows that in the case of oxygen 
etched substrate the maximum number of pores are between $0.1-0.4 \mu \mathrm{m}$ for 25 $\mathrm{ml} / \mathrm{min}$. and $92 \mathrm{ml} / \mathrm{min}$. The maximum number of pores for helium at $25 \mathrm{ml} / \mathrm{min}$. and $100 \mathrm{ml} / \mathrm{min}$. are between $0-0.3 \mu \mathrm{m}$ and $0-0.2 \mu \mathrm{m}$ respectively.

At lower oxygen flow both lateral (chemical) and vertical (ion-bombardment) etching may occur, but at higher flow lateral etching seems to be more dominant. For helium etched surfaces vertical (ion-bombardment) etching is more prominent over the entire range of flow rates. This experiment recommends use of oxygen as the etching gas to condition ABS in the POP industry. The flow rate range should be between 0.1 and $25 \mathrm{ml} / \mathrm{min}$. to achieve good adhesion.

Future work is recommended. The effect of helium plasma for conditioning the substrate was not well accomplished since it appears that the surface has undergone ablation. This study should be followed with helium at lower chamber pressure and lower flow rate. The literature review has suggested that at lower chamber pressure and gas flow, helium etched substrate produces adhesion strength comparable to that obtained by oxygen. It is not correct to assume that conditions ideal for oxygen should be ideal for helium. The depth of pores were not quantified and should also be studied to better understand the etching and the bond formation phenomena. This can be done by using an atomic force microscope (AFM). Pore depth plays an important role in mechanical interlocking and also provides insight to vertical etching phenomena. The effect of lowering oxygen gas flow below $25 \mathrm{ml} / \mathrm{min}$. will shed more light on the presence of secondary, more active species phenomena and should be studied. If the secondary, 
more active species is present, the adhesion strength might be higher than that obtained in this experiment. Copper deposition mechanism should be studied by decorating the pores using electroless copper plating. This will show if there is an existence of a preferential deposition phenomena. SEM for more oxygen flow rates should be studied and the number of pores determined. This will show if there is a maximum in-between the flow rate regime studied in this experiment. 


\section{REFERENCES}

Abuelazaim, M.M., "The effect of gas flow rate on plasma etched porosity of ABS plastic", A Thesis presented to the faculty of the department of Chemical Engineering, San Jose State University (1994)

Bachman, B.J.; Vasile, M.J.; "Ion bombardment of polyimide films", J. Vac. Sci.

Technology A, Vol.7, No.4, (1989) pp 2709-2716

Clark, D.T.; Dilks A., "ESCA Applied to Polymers. XV. RF Glow-Discharge Modification of Polymers, Studied by Means of ESCA in terms of a direct and Radiative Energy-Transfer Model", Journal of Polymer Science, Vol.15, (1977) pp 2321-2345

Coburn, J.; "Notes on plasma etching and RIE"; American Vacuum Society, (1989) pp 3-9

Elmore, G.V.; Davis, K.C., "Mechanism of Bonding Electroless Metal to Organic Substrates", Journal of Electrochemical Society: Electrochemical Technology, Vol.116, No. 10, (1968), pp 1455-1458

Ghorashi, H.M., "Chromium Affects Metal Polypropylene Adhesion-Radioactive Tracer Study", Plating and Surface Finish, (1977), pp 42-45

Gurly E.S.; McNeil, M.A, "The effect of plasma etching parameters on adhesion of copper plating to ABS plastic", Industrial Electrolysis and Electrochemical Division and Electrode position Division, Proceedings, Vol. 92, (1992) pp 207-219

Hall, R.J.; Westerdahl, C.A.L.; Bodnar, M.J.; Levi, D.W.; "Efiect of Activated Gas Plasma Treatment Time on Adhesive Bondability of Polymers", Journal of Applied Polymer Science, Vol. 16, (1972) pp 1465-1477

Hartney, M.A.; Green, W.M.; Soane, D.S.; Hess D.W., "Mechanistic studies of oxygen plasma etching", Journal of Vac. Sci. Technology, Vol. 6, No. 6, (1988), pp 18921895

Hepfer, I.C.; Hampel K.R.; Timmer R.J.; Boehm D.R., "The Use of Electroplated Plastics for Exterior Automotive Trim", Plating, (1968), pp 584-588

Herb, K.; "Notes on plasma etching for microelectronic fabrication", Materials Research Society, (1989) 
Heymann, K.; Reidel W.; and Woldt G.; "Electroplating of plastics in theory and practice, Angewandte Chmie, International Edition, Vol. 9, No. 6, (1970) pp 50965100

Jameson, M.N; "New and improved pre-plate chemicals and technology", A.S.E.P. Sixth Annual Conference of the American Society of Electroplated Plastics, (1973)

Joubert O.; Pelletier J.; Arnal Y., "The etching of polymers in oxygen-based plasmas: A parametric study", Journal of Applied Physics, Vol. 65, No. 12, (1989), pp 5096-5100

Kaplan, S.L.; Holland, R.; "Gas plasma technology and its applications", Plasma Science, Vol. 15, No. 2, (1987), pp 84-96

Kaplan, S.L; Rose, P.W.; "Plasma surface treatment of plastics to enhance adhesion: An Overview", Plasma Science Technical Notes, Vol. 18, No. 9, (1990), pp 211-215

Kato, $\mathbf{K}$., "Molding anisotropy in ABS polymers as revealed by electron microscopy", Polymer, Vol. 9, (1968), pp 225-232

Krulik, G.A; "Electroless plating of plastics", Journal of Chemical Education, Vol. 55, No.6, (1978) pp 361-365

Lerner, N.R.; Wydeven T., "Polymer Etching in the Oxygen Afterglow: Increased Etch Rate with Increased Reactor Loading", Journal of Electrochemical Society, Vol. 136, No. 5, (1989), pp 1426-1430

Lindsay, J.H.; LaSala, J.; "Vacuum preplate process for plating on ABS", Plating and Surface Finishing, Vol. 72, (1985) pp 54-59

Mance, A.M.; Waldo, R.A.; Dow, A.A., "Interactions of Electroless Catalysts with Plasma-Oxidized Surfaces of Polystyrene-Based Resins", ", Journal of Electrochemical Society, Vol. 136, No. 6, (1989), pp 1667-1671

Marsh Instruments, Inc.; “A guide to plasma treatment”, (1993)

Matsunga, M.; Hagiuda, Y.; Ito, K., "Adhesion of Electrodeposits to Plastics-An Electron Microscopy Investigation", Metal Finishing, (1968), pp 80-84

Peng W.; "The effect of gas flow rate on adhesion of copper plating to ABS plastics", MatE 281, (1994)

Poa, S.P.; Wan, C.C.; Wu, C.J., "A Study of the Etching Effect on the Metal-to-ABS Surface Adhesion in Electroless Plating", Metal Finishing, (1977), pp 13-16 
Ryntz, R. A; "Coating adhesion to low surface free energy substrates", Progress in Organic Coatings, Vol. 25, No.1, (1994) pp 73-83

Schonhorn, H.; Hansen R.H., "Surface Treatment of Polymers for Adhesive Bonding", Journal of Applied Polymer Science, Vol. 11, (1967) pp 1461-1474

Villamizar, C.A.; Rojas, J; Frais P.; "Chemical etching versus plasma etching in electroplating ABS resin surfaces", Metal Finishing, Vol.3, (1981) pp 27-33

Wedel, R.G.; "The Effects of Surface Porosity on the Plateability and Adhesion of Metal to Nonconductors", Plating, (1971), pp 225-229 


\section{APPENDICES}




\section{APPENDIX A}

\section{DESCRIPTION OF APPARATUS}

\section{PLASMA ETCHER}

The CS-1701 plasma system is a parallel plate, reactive ion etcher. It's designed to offer fast, uniform, selective, anisotropic etching. It consists of two modules: the main unit and the solid state RF generator. The chamber of the etcher has internal dimensions of $10^{\prime \prime} \mathrm{d} \times 1.5^{\prime \prime} \mathrm{h}$ and holds up to $150 \mathrm{~mm}$ diameter wafers. It is constructed of hard anodized aluminum and has a ceramic ring which concentrates plasma at the bottom electrode to maximize power utilization. This increases the anisotropy and etch rate. The electrodes are water cooled to maintain the substrate at low temperature during processing. The smaller bottom electrode produces a negative DC bias that increases ion bombardment and anisotropy. The CS-1701 is equipped with a Z80 based computer which controls all of the processing functions. The system has 8 analog channels which control the 6 gas channels, pressure and the RF power. These parameters are programmed by the front panel where up to 9 process recipes can be stored. Refer to Figure 19. The system controller also has a manual override which is interrupt driven and can be used to override the process end-point and program the process desired. The instrument is programmed with various safety features, which monitor the process 


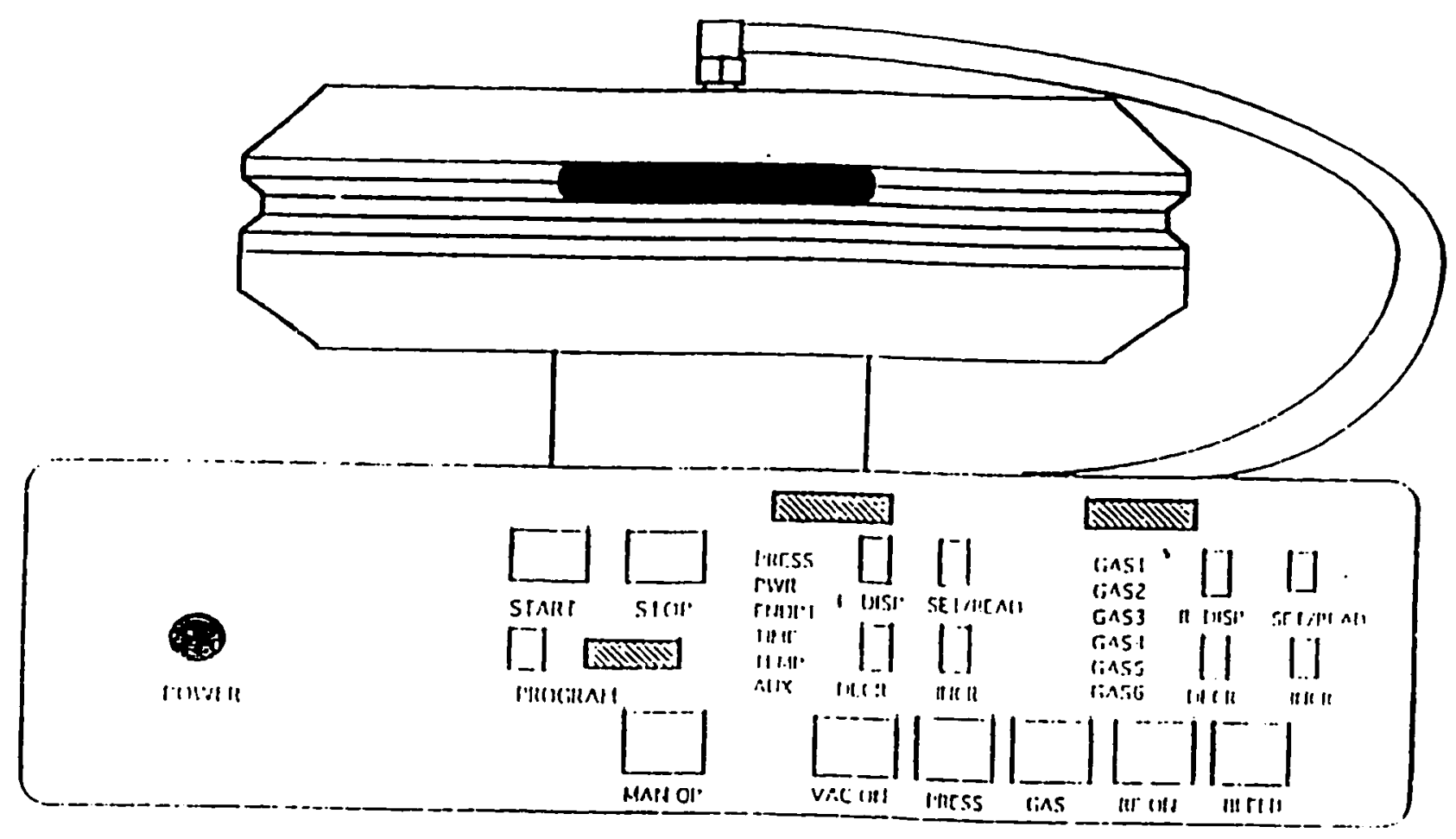

FIGLRE 19: March Plasma Etcher CS-1701 
and shuts the equipment in the event of a failure. The parameters monitored are: pressure, reflected power, gas flow and time. The stop button in the front panel interrupts the system, shuts down the process and resets the machine. The system specifications are:

Dimensions:

Weight:

RF Generator:

Process Controls:

Pump: $20^{\prime \prime} \times 18^{\prime \prime} \times 14^{\prime \prime}$

$50 \mathrm{lbs}$

600 watts max., 13.56 MHz, solid state digitally controlled forward and reflected power

Two mass flow controllers, Baratron pressure gauge, computer control with override, automatic pressure control

11 CFM, fluorinated synthetic oil with an optional recirculation system

\section{SEBASTIAN FIVE MULTIPURPOSE TESTER}

The Sebastian Five is a simple and precise system for measuring strength of materials. The basic load application system is contained entirely within an enclosure. It has number of interchangeable platens which are installed atop the pull stack of the instrument. Electrically the unit has been modified to contain a precise linear potentiometer and electronic circuitry which are capable of measuring the travel of the lower platen continuously. A DC output jack in the back of the unit can be used to monitor the output voltage. An output voltage of 0.10 Volt DC represents $250 \mathrm{Kg}(550 \mathrm{Lb})$. Plotting of the peel strength tests can be readily 
accomplished by connecting the two output jacks in the rear panel to a high impedance XY recorder. The unit available does not have a micro-range feature. In other words it means that the machine can record only the maximum attainable peel strength, this means that continuous peel values can be recorded until an ultimate value is reached after which no lesser values can be recorded. All peel tests will be performed using an attachment called "Gallows Structure", the top of this gallows is a take up wheel. The purpose of the wheel is to take-up the peel at a precisely measured rate, that is $1 \mathrm{inch} / \mathrm{min}$ in our case. The sample is mounted on a spring loaded slider. The spring loaded slider is installed into the gripper part of the tower. The tower contains the load cell which measures resistance of the film being pulled normal to the surface. The slider moves to keep the peeling edge of the film normal to the gallows structure.

\section{ASTM B 533-85}

\section{Standard Test Method for Peel Strength of Metal Electroplated Plastics}

Summary: A properly prepared standard test specimen called a coupon is metal plated. The plated coupon is either tested as is or at least 48 hours after plating. The coating is cut through the plastic substrate using a sharp chisel or a knife in a way that two strips of coating are formed. Refer to Figure 20. An approximate $15 \mathrm{~mm}$ tab is peeled back on the strips at the end adjacent to the mold tab. $3 \mathrm{M}$, 


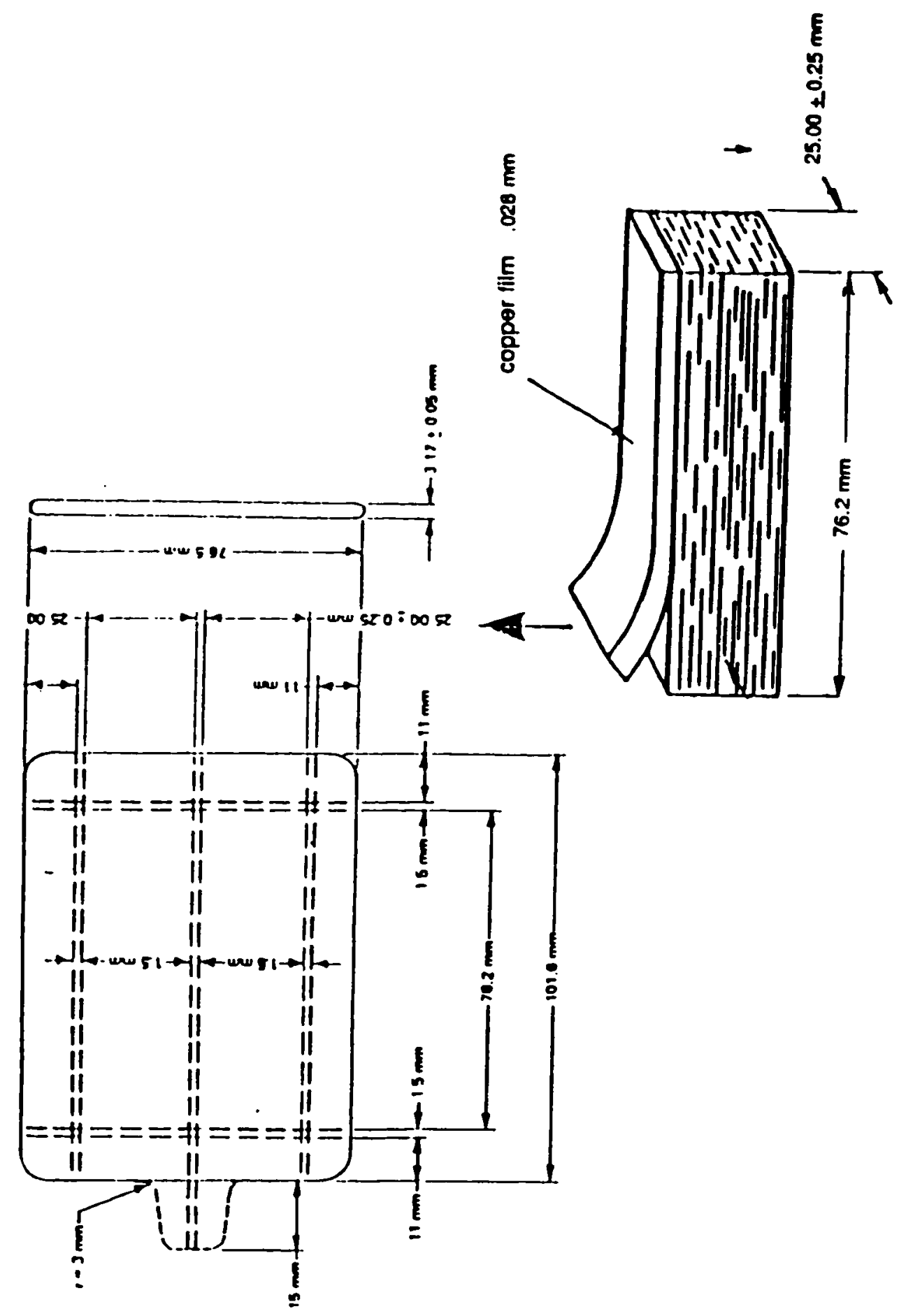

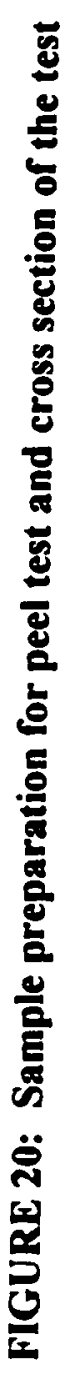


\#890T tape is applied to the tab. The free end of the tape also called as the tab extender is inserted into the angled slot on the take up wheel of the gallows. Each strip is peeled from the substrate at a right angle. The speed of separation of the crossarms of the machine will be adjusted to give a separation rate of $25 \pm$ $3 \mathrm{~mm} / \mathrm{min}$. The machine automatically records the load. The test should be repeatable. 70 percent of the length of the metal strip must be pulled without tearing the film for the test to be valid.

\section{SEM: HITACHI S 520}

The instrument used for SEM analysis was Hitachi S 520. Standard operating and sample preparation procedures were used. Listed below are the specifications:

Standard Specifications:

- Resolution

$60 \mathrm{~A}^{\circ}$ guaranteed

- Magnification Range

$20 \sim 200,000 X$

- Electron Optical System

Filament

Pre-centered hair pin type filament

Bias

Auto Bias System

Beam Current

$150 \mu \mathrm{A}$ maximum

Accelerating Voltage

$1 \sim 30 \mathrm{kV}(1 \mathrm{kV}$ step $)$ 
Lens System

Stigmator

Deflection Coil

Objective lens aperture

- Specimen Goniometer Stage

X Movement
Y Movement
Tilting Angle
Rotation Angle
Z Movement

Specimen Size

Specimen Exchange

- Display Unit

CRT openings)

3-stage reduction system

8-pole electromagnetic system (X, Y)

2-stage electromagnetic deflection system

Movable aperture $(0.1,0.2,0.3,0.4 \mathrm{~mm}$ diameter

$$
\begin{aligned}
& 0 \sim 40 \mathrm{~mm} \text { (continuous) } \\
& 0 \sim 40 \mathrm{~mm} \text { (continuous) } \\
& -20 \sim+90^{\circ} \text { (continuous) } \\
& 360^{\circ} \text { (continuous) } \\
& 5 \sim 35 \mathrm{~mm} \text { (semi-fixed).... Working Distance } \\
& (=\mathrm{WD})
\end{aligned}
$$

102 (4") $\mathrm{mm}$ dia. $\times 6 \mathrm{~mm} \mathrm{H}(\max )$

$15 \mathrm{~mm}$ dia. $\times 10 \mathrm{~mm} \mathrm{H}$ (max)

Draw-out system

Viewing CRT

(Afterglow type $150 \times 135 \mathrm{~mm}$ ) $\times 2$

Photographing CRT

(Non-afterglow type $120 \times 90 \mathrm{~mm}$ ) $\times 1$

For Viewing $0.04,0.5,1.5,10(8.5), 40(34)$

sec/frame $(60 \mathrm{~Hz})$

For Photographing 40(34). 80(100), 200(200), $400(400) \mathrm{sec} /$ frame $(60 \mathrm{~Hz})$ 
Electrical Image shift $\pm 20 \mu \mathrm{m}(\mathrm{X}, \mathrm{Y})$ at $30 \mathrm{kV}$ and $\mathrm{WD}=15 \mathrm{~mm}$

- Signal Detecting Mode

Secondary electron, backscattered electron (via post $\mathrm{HV}$ off), reflected electron (via Hi-pass detector)*, absorbed electron*, transmitted electron*, cathodluminescence*, X-rays*

(Note ${ }^{*}$ ) Indicates optional items

- Scanning Mode

Full frame rapid scan, reduced area rapid scan, slow scan, photoscan, position set, spot, line analysis, analysis area finder, dual magnification, split screen, dynamic focus, oblique

- Signal Processing Mode

Auto focus, auto brightness / contrast, gamma control, differential, polarity reverse / invert, dynamic stigmamonitor, auto data display

- Evacuating System

System

Vacuum Gauge

Ultimate Vacuum

Vacuum Pump

Evacuating Time

(for specimen change)
Fully automated, solenoid valve control system

Pirani gauge $\times 1$

$5 \times 10^{-6}$ Torr

DP $4001 / \sec \times 1, R P 1601 / \min \times 1$

About 3 minutes

- Safety Device

Safety devices for power interruption, water supply interruption, and vacuum deterioration are provided

- Power Supply

$100,115,200^{*}, 208^{*}, 220^{*}$, or $240^{*} \mathrm{~V} \mathrm{AC} \pm 10 \%, 50 / 60 \mathrm{~Hz}, 3.0 \mathrm{kVA}$

(Note ${ }^{*}$ ) For $200,208,220$, and $240 \mathrm{~V}$ area, an auto transformer is required 
- Water Facilities

Flow Rate

Pressure

Temperature

Supply Port

Drainage

- Ambient Conditions

Temperature

Humidity
$2 \sim 41 / \min (0.5 \sim 1 \mathrm{gpm})$

$0.5 \sim 2 \mathrm{~kg} / \mathrm{cm}^{2}(7 \sim 29 \mathrm{psi})$

$10 \sim 25^{\circ} \mathrm{C}\left(50 \sim 77^{\circ} \mathrm{F}\right)$

$\times 1$, outer dia. of faucet $12 \mathrm{~mm}$ dia (city water hose should be connectable) It is recommended to use a filter in case of water containing much deposit

Natural drainage

$15 \sim 30^{\circ} \mathrm{C}\left(59 \sim 86^{\circ} \mathrm{F}\right)$

less than $70 \%$

- Stray Magnetic Field

When the stray magnetic field measured at the installation site before installing the instrument complies with the requirements, no image trouble will occur. Check stray magnetic field before installing. If there is a chance of an abrupt change in the electric field in the vicinity of the instrument due to a large sized magnetic clutch, power cables for other equipment, etc., the requirement may not be satisfied. 


\section{APPENDIX B}

\section{DESCRIPTION OF PROCEDURE}

\section{PLASMA ETCHING (MARCH ETCHER)}

\section{System Preparation}

Figure 21 shows the back side of the etcher and shows the line connections which should be checked prior to operation. Figure 22 shows the front panel display of the etcher and is referred in the operating instructions by using the button numbers corresponding to the etcher. Figure 23 is the conversion factor chart for a series of different gases.

1) Turn the power on for the vacuum pump on the floor, the power unit and the etcher. Turn on the purge gas $\left(\mathrm{N}_{2}\right)$ and the gas being used for etching. In this experiment Gas 1 and Gas 2 were used for $\mathrm{O}_{2}$ and $\mathrm{He}$ respectively. The MFC size is 250 SSCM for both inlets. MFC \# 1 was calibrated by an outside vendor (SIMCO). MFC \# 2 calibration was verified by comparing the gas flow measured with MFC \#1 at the same settings.

2) Clean inside of the etcher with isopropyl alcohol. Apply vacuum grease on the 0 -ring. Remove any excess vacuum grease from the 0 -ring.

3) Close the etcher lid, press "MAN OP"(6), then "VAC ON"(7). Wait for several seconds and then press "PRESS"(8). Pressure should drop below 100 mtorr in less than 30 seconds. Note the base pressure, and let the system be at these settings for 20 minutes. This helps in evacuating all moisture from the 


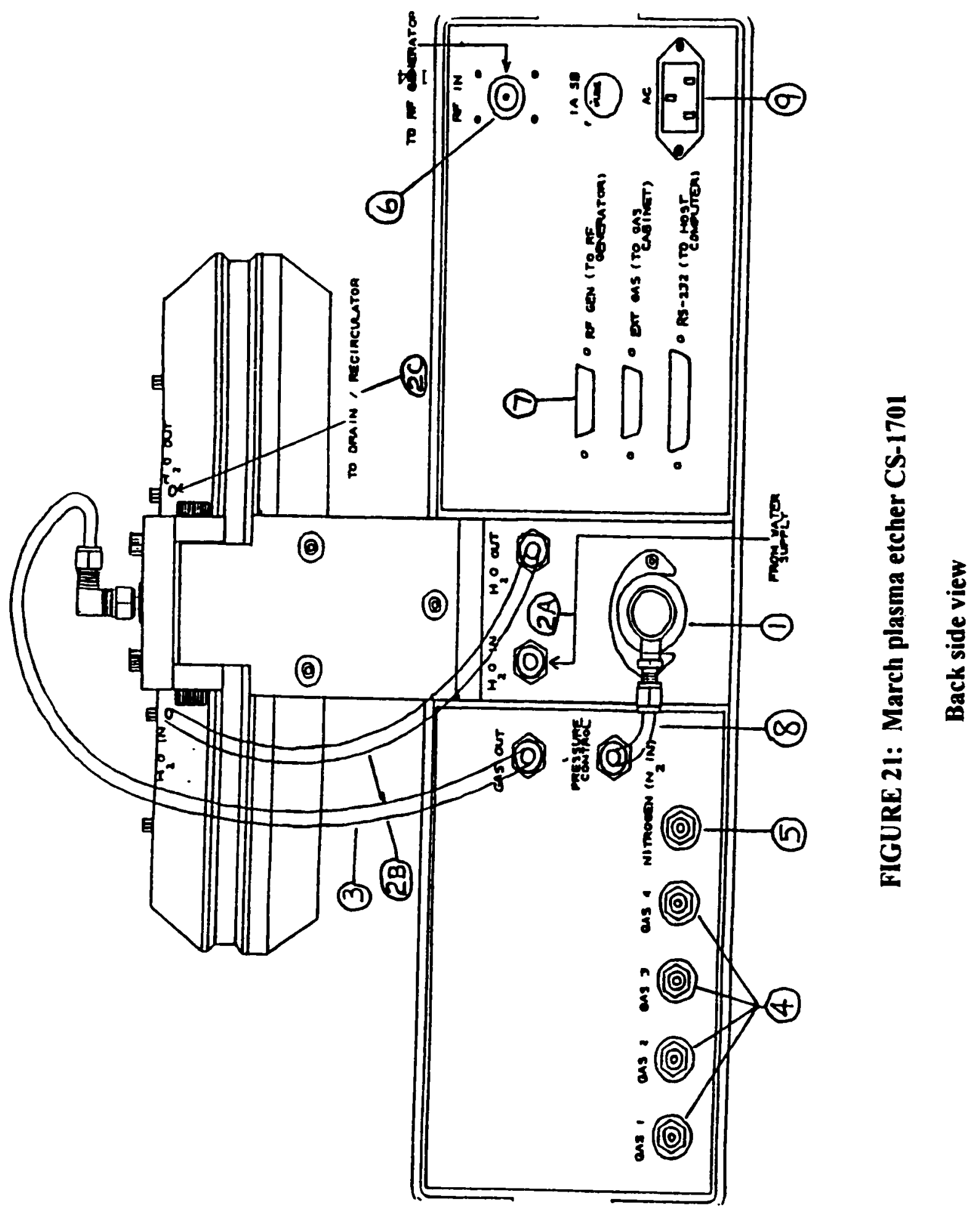




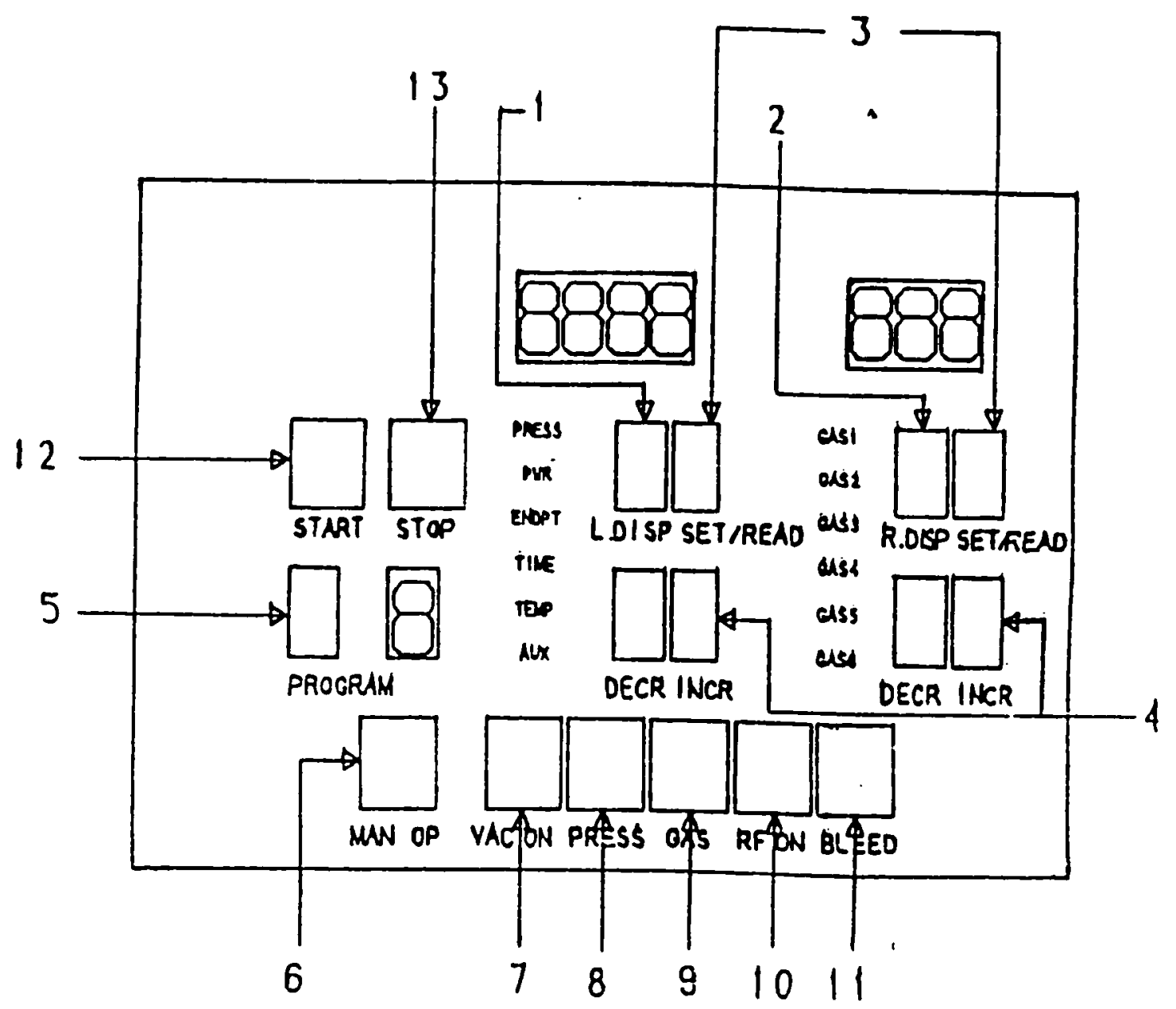

FIGL:RE 22: Front Panel Display of March Etcher CS-1701 


\begin{tabular}{|c|c|c|}
\hline Gas & Symbol & $\begin{array}{l}\text { Conversion } \\
\text { Factor }\end{array}$ \\
\hline Argon & $\mathrm{Ar}$ & 1.44 \\
\hline Carbon Telrachloride & $\mathrm{CCl}_{4}$ & 0.309 \\
\hline Freoll II & $\mathrm{CCl}_{3} \mathrm{~F}$ & 0.34 \\
\hline Freon 12 & $\mathrm{CCl}_{2} \mathrm{~F}_{2}$ & 0.34 \\
\hline Freon 13 & $\mathrm{CCIF}_{3}$ & 0.383 \\
\hline Freon 13 B I & $\mathrm{CBrF}_{3}$ & 0.36 \\
\hline Freon 14 & $\mathrm{CF}_{2}$ & 0.41 \\
\hline Freoll 21 & $\mathrm{CHCl}_{2} \mathrm{~F}$ & 0.42 \\
\hline Freoll 22 & $\mathrm{CHClF}_{2}$ & 0.438 \\
\hline Freon 23 & $\mathrm{CHF}_{3}$ & 0.50 \\
\hline Freon 113 & $\mathrm{CCl}_{2} \mathrm{FCClF}_{2}$ & 0.20 \\
\hline Freon 114 & $\mathrm{C}_{2} \mathrm{ClF}_{4}$ & 0.22 \\
\hline Freon 115 & $\mathrm{C}_{2} \mathrm{ClF}_{3}$ & 0.24 \\
\hline Freon 116 & $\mathrm{~F}_{3} \mathrm{CCF}_{3}$ & 0.24 \\
\hline Freon C 318 & $\mathrm{C}_{4} \mathrm{~F}_{8}$ & 0.17 \\
\hline Freon $1132 \mathrm{~A}$ & $\mathrm{C}_{2} \mathrm{H}_{2} \mathrm{~F}_{2} \cdot$ & 0.43 \\
\hline Helium & $\mathrm{He}$ & 1.444 \\
\hline Nitrogen & $\mathrm{N}_{2}$ & 1.000 \\
\hline Oxygen & $\mathrm{O}_{2}$ & 0.994 \\
\hline Sulfur Hexafluoride & $S F_{\mathfrak{i}}$ & 0.27 \\
\hline
\end{tabular}

FIGLRE 23: Conversion Factor Chart 
system.

4) After 20 minutes press "VAC ON" again. This switches off the vacuum valve. Here, we are checking for a system leak. The pressure will rise slowly. The operating manual suggests that the leak rate should be less than $50 \mathrm{mtorr} / \mathrm{min}$. If there is a leak check all the connections, O-ring, MFC clippard valve and the vacuum valve.

5) Press "VAC ON" again and then "PRESS". After the pressure drops below 100 mtorr and stabilizes, press "GAS"(9). After few seconds press "RF ON"(10). This should be done with the RF power set fairly high (600W) to clean the chamber. Run with the plasma on for 20 minutes before etching. The latter step is done just once after switching gases or initial startup.

6) Check the baratron calibration. This is done after switching on the vacuum pump for the first time for the day. Start the vacuum pump, "MAN OP", and "VAC ON". Wait for 5 minutes. Press "PRESS". The pressure should stabilize at 29 or 31 mtorr. Use the "Adjust Zero" on the baratron to set the baratron to read the above.

\section{Parameter Setting}

Set the desired parameters by going through the options. Refer to the operation manual. Be sure to distinguish between "SET" and "READ" modes(3). Use the "INCR" and "DCR" keys to set the parameters desired.

The parameters used in this experiment were set as follows: 
PRESS $=380$ mtorr

PWR $=50$ Watts

ENDPT $=100$

TIME $=600 \mathrm{sec}$

TEMP $=0$

AUX $=50$

The gas flow rates are set in the same manner. The display for the gas flow reads as percentage open of MFC's. Refer to Figure 23 for the conversion factors for different gases. Use the equation in the operation manual to calculate the percentage open for a desired flow and gas. Set all other MFC's to zero except the one in use.

\section{Etching}

Prepare the substrate and place it in the center of ceramic plate of the etcher. Make sure that the surface to be etched is facing upward. One can program the etcher to run automatically in "AUTO" mode by pressing the "START" key or run in "MAN" mode. Move from left to right on the front panel of the etcher and stop after "RF ON". In manual mode the clock starts at zero and has to be monitored till it reaches 600 seconds and the etching is stopped by using the "STOP" key. Press the "BLEED" key to bleed the system. This exhausts the system and brings it back to atmospheric condition. If the base pressure for the etching cycle was below 50 mtorr, the system starts pumping down and "PUMP" and "PRESS" panel lights goes on after pressing "BLEED". To avoid this problem press "MAN" button after "STOP". The display panel goes 
blank for a second. Within that second press "BLEED". The system will bleed without turning on the "VAC" and the "PRESS" indicators.

The system should be left under vacuum after use. For shut down move from right to left on the front panel. Blinking red lights on the panel indicate problems in the setup. Make sure that the independent pressure controller is hooked up to the machine. The independent pressure controller helps control the pressure inside the chamber to the desired set value. For this system we cannot set the chamber pressure lower than that obtained by a gas at a certain flow rate. For example, say for oxygen the chamber pressure at $100 \mathrm{ml} / \mathrm{min}$. is $410 \mathrm{mtorr}$. We cannot set the chamber pressure to $380 \mathrm{mtorr}$. On the other hand if the attainable pressure was 360 mtorr and we wanted to set the chamber pressure at 380 mtorr, there would be no problem. The independent pressure controller is connected to the vacuum line and helps control the chamber pressure by counter balance.

\section{ELECTROLESS COPPER PLATING PROCEDURE}

1) $\quad \mathrm{PD}$ (as is at room temperature): Substrate in bath for 5 mimutes(min.) or 24 hours(max.)

2) No rinse

3) Catalyst PD \& PTC(97\% PD and 3\% PTC by volume at room temperature): Substrate in bath for 5 mimutes

4) Double DI water rinse 
5) Activator (Accelerator) AA (7\% in DI water at room temperature):

Substrate in bath for 6-7 mimutes for $1 \mathrm{micron} / \mathrm{minute}$

6) Double DI water rinse

7) Electroless Copper Bath( MR-A $10 \%$ and MR-B $10 \%$ ir. DI water at $80-90^{\circ} \mathrm{F}$ ):

Substrate plated for 30 mimutes. Add $10 \mathrm{ml} / \mathrm{gl}$ of MR-D and mix followed by 10 $\mathrm{ml} / \mathrm{gl}$ of HDR after 5 minutes and mix. This should be done every morning

8) Drag out rinse in 3\% sulfuric acid to neutralize

9) Anti-Tarnish(2\% ATC in DI water):Substrate in bath for 2 mimutes

10) DI Water rinse and air blow dry

11) Electrolytic copper plating: Substrate in bath at $11.6 \mathrm{Amps}, 20 \mathrm{ASF}$, and 90 minutes

12) Oxyban 60: Substrate in bath for 2 mimutes

13) DI Water rinse and air blow dry

\section{PLATING BATH(S) AND MAINTENANCE}

The electroless copper line consists of the following baths:

1. PD Pre-catalyst Bath

2. PD \& PTC Catalyst Bath: Low acid Palladium-Tin Catalyst

3. Accelerator AA Bath

4. Electroless Copper Bath MR-A and MR-B

5. $3 \%$ Sulfuric Acid

6. AT-C Anti-Tarnish for Copper Bath 
Followed by the acid copper line which contains the following baths:

7. Electrolytic (Coppergleam PC acid copper)

8. Oxyban 60 antioxidant

All baths are kept at room temperature. The following table lists the amounts to be used in making new baths, as well as the frequency of analysis for each bath. Following are the procedures for analysis of each tank.

\begin{tabular}{|c|c|c|}
\hline Bath & Make-Up & Analysis Frequency \\
\hline PD-pre Catalyst & As is $100 \%$ & 1 time / month \\
\hline PD and PTC Catalyst & $\begin{array}{l}30.23 \text { liter of PD } \\
0.93 \text { liter of PTC } \\
\text { in } 8.2 \text { gallon of tank }\end{array}$ & $\begin{array}{l}1 \text { time / month } \\
1 \text { time / month }\end{array}$ \\
\hline Accelerator AA & $\begin{array}{l}2.18 \text { liter of } \mathrm{AA} \\
\text { fill to } 8.2 \text { gallon with DI } \mathrm{H} 2 \mathrm{O}\end{array}$ & l time / month \\
\hline Electroless Copper MR & $\begin{array}{l}3.12 \text { liter of MR-A } \\
3.12 \text { liter of MR-B } \\
\text { fill to } 8.2 \text { gallon with DI } \mathrm{H} 2 \mathrm{O}\end{array}$ & $\begin{array}{l}1 \text { time / day } \\
1 \text { time / day }\end{array}$ \\
\hline $3 \%$ Sulfuric Acid Solution & $\begin{array}{l}0.93 \text { liter of sulfuric acid } \\
\text { fill to } 8.2 \text { gallon with DI H2O }\end{array}$ & 1 time / month \\
\hline AT-C Anti-tarnish & $\begin{array}{l}0.62 \text { liter of AT-C } \\
\text { fill to } 8.2 \text { gallon of DI } \mathrm{H} 2 \mathrm{O}\end{array}$ & I time / month \\
\hline Electroless Copper & $\begin{array}{l}560 \mathrm{ml} \text { of coppergleam PC } \\
10.64 \text { liter of sulfuric acid } \\
21 \mathrm{lbs} \text { of } \mathrm{CuSO} 4.5 \mathrm{H} 2 \mathrm{O} \\
15 \mathrm{ml} \text { of } \mathrm{HCl}\end{array}$ & $\begin{array}{l}1 \text { time / day } \\
1 \text { time / month } \\
1 \text { time / month } \\
1 \text { time / month } \\
1 \text { time / month }\end{array}$ \\
\hline Oxyban 60 & $\begin{array}{l}290 \mathrm{ml} \text { of Oxyban } 60 \\
\text { fill to } 8.2 \text { gallon of DI } \mathrm{H} 2 \mathrm{O}\end{array}$ & Dump weekly \\
\hline
\end{tabular}

Table 6: Bath make up and analysis frequency of for electroless and electrolytic copper baths

Analysis procedures for electroless and acid copper lines are as follows: 
(1) PD- Pre Catalyst

Operating Parameters

Temperature $\quad 60-90^{\circ} \mathrm{F}\left(16-32^{\circ} \mathrm{C}\right)$

Immersion Time $\quad 30$ seconds minimum

$\mathrm{pH} \quad 0.5$ or lower ( maintain with hydrochloric acid in small portions )

\begin{tabular}{|l|l|l|l|l|}
\hline Test & Chemicals Needed & Procedure & Additions \\
\hline Specific & N/A & SG/Be & Concentration & M\&T PDR Replenishment \\
Gravity & & $1.142 / 18^{\circ}$ & $100 \%$ & \\
& & $1.132 / 16.9^{\circ}$ & $90 \%$ & $27.5 \mathrm{~g} /(3.7 \mathrm{oz} / \mathrm{gal})$ \\
& & $1.116 / 15.1^{\circ}$ & $80 \%$ & $55 \mathrm{~g} / 1(7.4 \mathrm{oz} / \mathrm{gal})$ \\
& & $1.104 / 14.1^{\circ}$ & $70 \%$ & $82.5 \mathrm{~g} /(11.1 \mathrm{oz} / \mathrm{gal})$ \\
\hline
\end{tabular}

Table 7: Analysis tests for PD-Pre Catalyst bath

Discard the Pre-Catalyst when:

- The concentration falls below $70 \%$

- The copper concentration of the bath exceeds $1 \mathrm{~g} / 1$

(2) PD \& PTC Catalyst

Operating Parameters

Temperature

$16^{\circ}-40^{\circ} \mathrm{C}\left(60-105^{\circ} \mathrm{F}\right)$

Agitation

Mechanical ( Do not use air )

Immersion Time

3-6 minutes

Solution Strength

$70-110 \%$

Pd Concentration

$0.1-0.16 \mathrm{~g} / 1$

pH

Less than 0.5

Acid Normality

0.4 to 0.6 


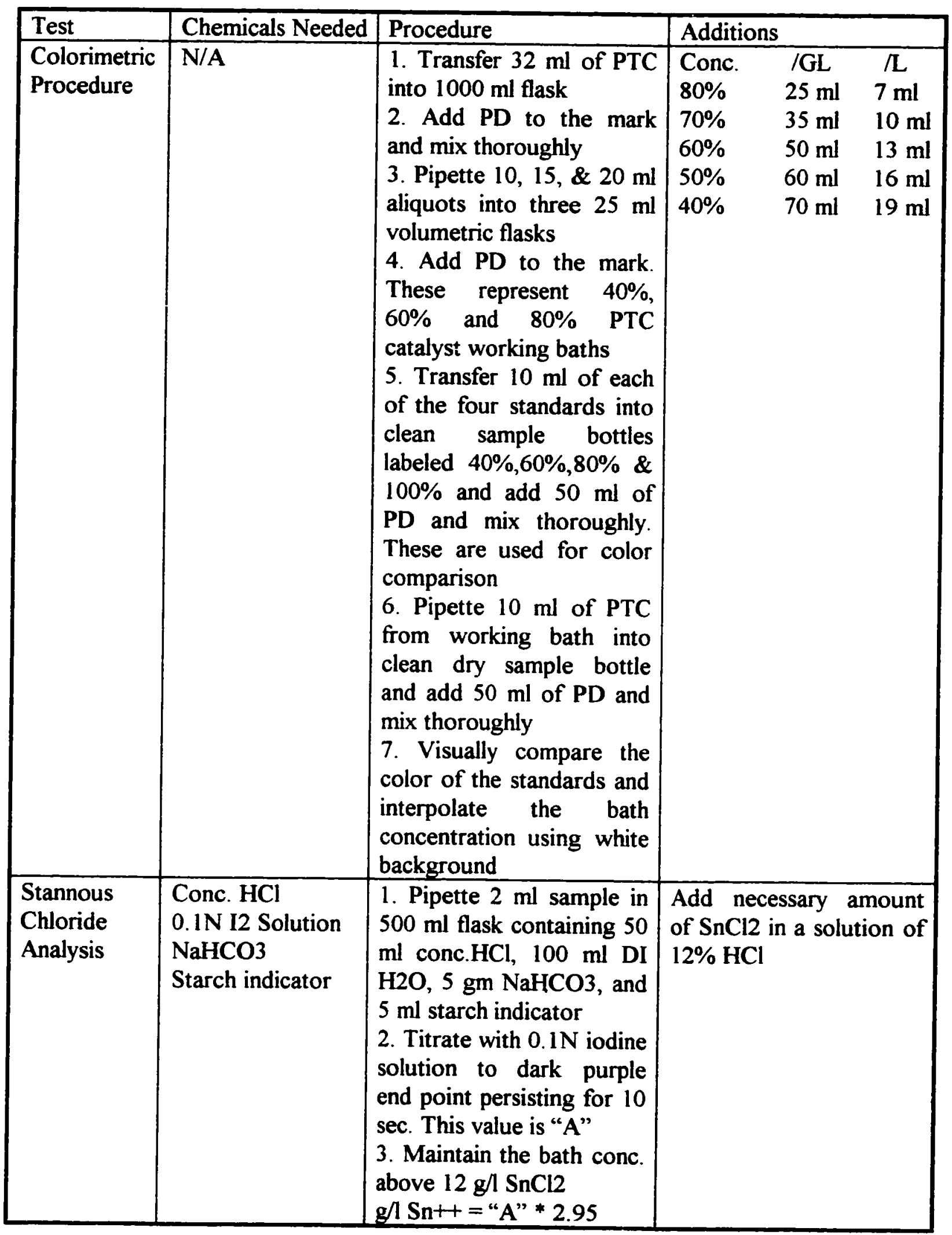




\begin{tabular}{|c|c|c|c|}
\hline & & $\mathrm{g} / \mathrm{SnCl} 2=" \mathrm{~A}$ " * 4.75 & \\
\hline $\begin{array}{l}\mathrm{pH} \text { analysis } \\
\text { Normality }\end{array}$ & $\begin{array}{l}\mathrm{HCl} \\
\mathrm{H} 2 \mathrm{O} 2 \\
\mathrm{DI} \mathrm{H} 2 \mathrm{O} \\
0.1 \mathrm{~N} \mathrm{NaOH} \\
\text { Phenolphthalein } \\
\text { Con. } \mathrm{HCl}\end{array}$ & $\begin{array}{l}\text { 1. Check the pH } \\
\text { 2. Pipette } 5 \mathrm{ml} \text { into } 250 \mathrm{ml} \\
\text { flask } \\
\text { 3. Add } 20 \text { drops }(1 \mathrm{ml}) \text { of } \\
\mathrm{H} 2 \mathrm{O} 2 \\
\text { 3. Solution should be } \\
\text { amber, if not add some } \\
\text { more } \mathrm{H} 2 \mathrm{O} 2 \\
4 \text {. Add } 50 \mathrm{ml} \text { of DI } \mathrm{H} 2 \mathrm{O} \\
5 \text { Add } 10 \text { drops of } \\
\text { phenolphthalein } \\
6 \text { Titrate with } 0.1 \mathrm{~N} \\
\mathrm{NaOH} \text { to faint pink } \\
\text { endpoint. This value is "B" } \\
\mathrm{N}=\text { "B" * } 0.1 \mathrm{~N} / 5 \mathrm{ml}\end{array}$ & $\begin{array}{l}\text { Add } \mathrm{HCl} \text { to adjust the } \\
\mathrm{pH} \text { below } 0.5 \\
\text { Normality should be } \\
\text { maintained between } 0.4- \\
0.6 \mathrm{~N} \text { with addition of } \\
\mathrm{HCl} \\
\text { Addition of } 8.5 \mathrm{ml} / \mathrm{h} \text { of } \\
\text { conc. } \mathrm{HCl} \text { will raise the } \\
\text { Normality by } 0.2 \\
\text { Normality should be } \\
\text { checked once a week }\end{array}$ \\
\hline
\end{tabular}

Table 8: Analysis tests for PD \& PTC Catalyst bath

\section{(3) AA Accelerator}

\section{Operating Parameters}

Temperature $\quad 18^{\circ}-32^{\circ} \mathrm{C}\left(65^{\circ}-90^{\circ} \mathrm{F}\right)$

Time 2-10 minutes

Agitation Mechanical, to remove air bubbles in the holes

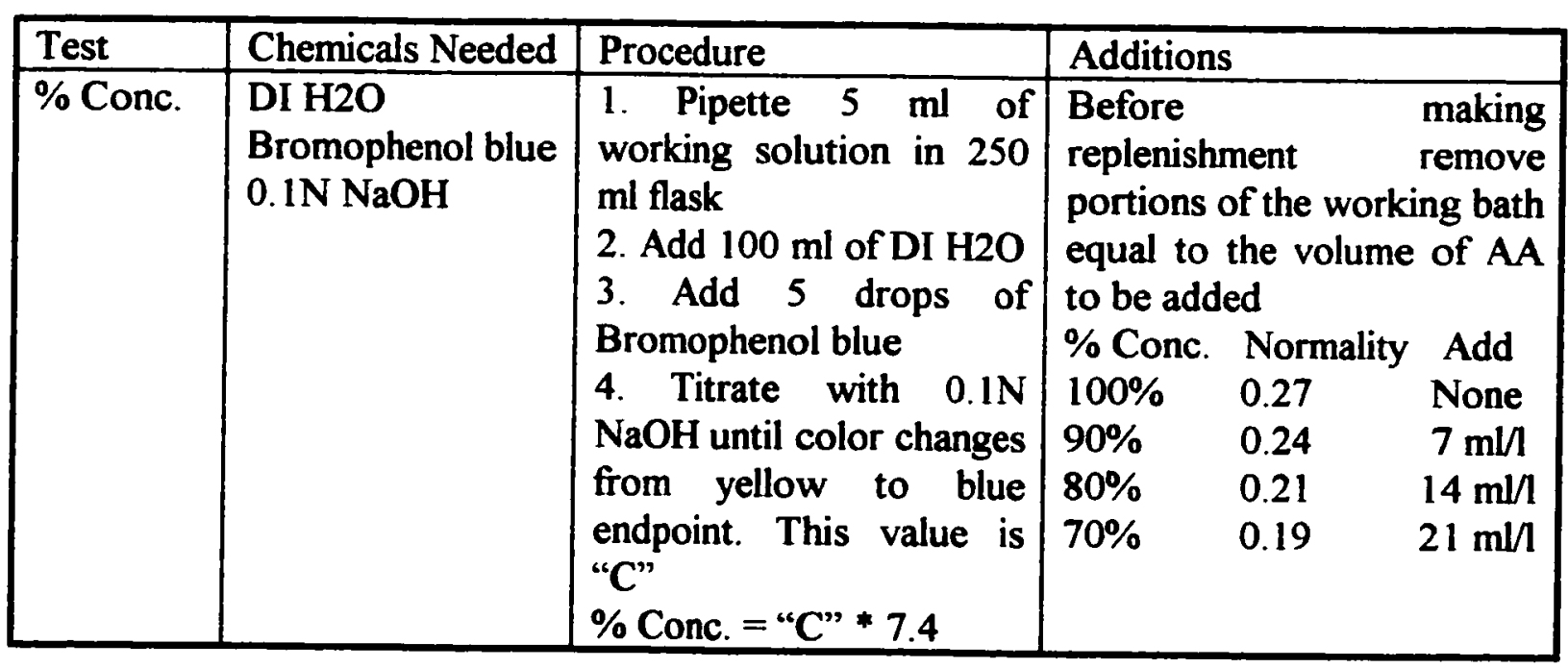




\begin{tabular}{|c|c|c|c|}
\hline $\begin{array}{l}\mathrm{Cu} \\
\text { Analysis }\end{array}$ & $\begin{array}{l}\text { DI H2O } \\
\text { Ammonia Buffer } \\
\text { PAN Indicator } \\
\text { 0.05M EDTA }\end{array}$ & $\begin{array}{l}\text { 1. Pipette } 20 \mathrm{ml} \text { of } \mathrm{AA} \\
\text { into } 250 \mathrm{ml} \text { flask and } \\
\text { dilute to } 50 \mathrm{ml} \text { with DI } \\
\mathrm{H} 2 \mathrm{O} \\
2 \text {. Add } 25 \mathrm{ml} \text { of } \\
\text { Ammonia Buffer }(\mathrm{pH}=10) \\
\text { 3. Add } 10 \text { drops of PAN } \\
\text { indicator solution }(0.1 \%) \\
\text { 4. Titrate against } 0.05 \mathrm{M} \\
\text { EDTA until pink color } \\
\text { fades to yellow green. } \\
\text { This value is "D" } \\
\mathrm{g} / \text { of } \mathrm{Cu}=\text { "D" } 0.16\end{array}$ & $\begin{array}{l}\text { Discard bath when copper } \\
\text { content exceeds } 0.7 \mathrm{~g} / \mathrm{l}\end{array}$ \\
\hline $\begin{array}{l}\text { Ammonia } \\
\text { Buffer }\end{array}$ & & $\begin{array}{l}70 \text { gms of } \mathrm{NH} 4 \mathrm{Cl} \text { in } 900 \\
\mathrm{ml} \text { of } \mathrm{DI} \mathrm{H} 2 \mathrm{O} \text { add } \\
\mathrm{NH} 4 \mathrm{OH} \text { to } \mathrm{pH} 10 \text { and } \\
\text { dilute to } 1000 \mathrm{ml} \text { with } \mathrm{DI} \\
\mathrm{H} 2 \mathrm{O}\end{array}$ & \\
\hline $\begin{array}{l}\text { PAN } \\
\text { Indicator }\end{array}$ & & $\begin{array}{l}\text { Dissolve } 0.1 \mathrm{gm} \text { of } 4-(2 \\
\text { pyridylazo)-resorcinol in } \\
\text { water and dilute to } 100 \\
\mathrm{ml}\end{array}$ & \\
\hline $\begin{array}{l}0.05 M \\
\text { EDTA }\end{array}$ & & $\begin{array}{l}\text { Dissolve } 18.619 \text { gms of } \\
\text { EDTA disodium salt in } \\
\text { water and dilute to } 1 \text { liter }\end{array}$ & \\
\hline
\end{tabular}

Table 9: Analysis tests for AA Accelerator bath

(4) MR-A \& MR-B Electroless Copper Bath

\section{Operating Parameters}

Copper: (MR-A)

Formaldehyde: (HD-R)

Sodium Hydroxide: (MR-B)

Temperature:
Range

$3.0-4.5 \mathrm{~g} / 1$

$6.0-8.0 \mathrm{~g} / 1$

$6.0-10.0 \mathrm{~g} / \mathrm{l}$

$15.5-40^{\circ} \mathrm{C}$
Optimum

$3.8 \mathrm{~g} / \mathrm{l}$

$7.0 \mathrm{~g} / 1$

$8.0 \mathrm{~g} / 1$

$25^{\circ} \mathrm{C}$

Agitation: The bath should be continuously agitated to provide for uniform distribution of solution in holes. This can be accomplished by mechanically moving the workload or mild air agitation. Mild air agitation with an aquarium pump type aerator is necessary to maintain stability during overnight or weekend shutdowns. 


\begin{tabular}{|c|c|c|c|}
\hline Test & $\begin{array}{l}\text { Chemicals } \\
\text { Needed }\end{array}$ & Procedure & Additions \\
\hline \begin{tabular}{|l}
$\mathrm{Cu}$ \\
Analysis
\end{tabular} & $\begin{array}{l}0.1 \mathrm{M} \text { EDTA } \\
\text { DI H2O } \\
\text { PAN Indicator } \\
\text { Ammonia Buffer }\end{array}$ & $\begin{array}{l}\text { 1. Pipette } 20 \mathrm{ml} \text { of bath in } \\
\text { 250 ml flask } \\
\text { 2. Add } 75 \mathrm{ml} \text { of DI H2O } \\
\text { 3. Add } 25 \mathrm{ml} \text { of Ammonia } \\
\text { Buffer } \\
\text { 4. Add } 6-10 \text { drops of PAN } \\
\text { indicator } \\
5 \text {. Titrate with } 0.1 \mathrm{M} \text { EDTA } \\
\text { to get green end point. This } \\
\text { value is "E" } \\
\mathrm{g} / \mathrm{l} \text { of } \mathrm{Cu}=\text { "E" } * 0.32 \\
\end{array}$ & $\begin{array}{llr}\mathrm{g} / \mathrm{Cu} & \text { MR-A } & \text { MR-B } \\
3.8 & \text { None } & \text { None } \\
3.4 & 311 \mathrm{ml} & 311 \mathrm{ml} \\
3.0 & 621 \mathrm{ml} & 611 \mathrm{ml} \\
2.7 & 932 \mathrm{ml} & 932 \mathrm{ml} \\
2.3 & 1242 \mathrm{ml} & 1242 \mathrm{ml} \\
1.9 & 1552 \mathrm{ml} & 1552 \mathrm{ml} \\
\text { The additions of MR-A and } \\
\text { MR-B are based on } 8.2 \\
\text { gallon tank }\end{array}$ \\
\hline $\begin{array}{l}\mathrm{NaOH} \mathrm{\&} \\
\mathrm{HCHO} \\
\text { Analysis }\end{array}$ & \begin{tabular}{|l|}
$0.1 \mathrm{~N} \mathrm{HCl}$ \\
DI H2O \\
Sodium Sulfite
\end{tabular} & $\begin{array}{l}\text { 1. Pipette } 5 \mathrm{ml} \text { of bath into } \\
100 \text { ml of DI } \mathrm{H} 2 \mathrm{O} \\
\text { 2. Titrate with } 0.1 \mathrm{~N} \mathrm{HCl} \text { to } \\
\mathrm{pH} 10.2 \text {. This value is "F" } \\
\text { 3. Add approx. } 3 \text { gms of } \\
\text { sodium sulfite powder to } \\
\text { the Titrate and mix for } 5 \\
\text { min. } \\
\text { 4. Titrate wit } 0.1 \mathrm{~N} \mathrm{HCl} \text { to } \\
\mathrm{pH} 10 \text {. This value is "G" } \\
\mathrm{g} / \text { of } \mathrm{NaOH}=\text { "F" }{ }^{*} 0.8 \\
\mathrm{~g} / \text { of } \mathrm{HCHO}=" \mathrm{G} " * 0.6\end{array}$ & $\begin{array}{l}\text { Add } 7 \mathrm{~m} / / 1 \text { of MR-A to } \\
\text { increase } \mathrm{NaOH} \text { by } 1 \mathrm{~g} / 1 \\
\text { Or } \\
\text { Add } 10 \mathrm{~m} / 1 \text { of MR-D to } \\
\text { increase } \mathrm{NaOH} \text { by } 1 \mathrm{~g} / 1 \\
\text { Add } 2.6 \mathrm{ml} / 1 \text { of } \mathrm{MR}-\mathrm{A} \text { to } \\
\text { increase } \mathrm{HCHO} \text { by } 1 \mathrm{~g} / 1 \\
\text { Or } \\
\text { Add } 10 \mathrm{~m} / / \text { of } \mathrm{HD}-\mathrm{R} \text { to } \\
\text { increase } \mathrm{HCHO} \text { by } 1 \mathrm{~g} / 1\end{array}$ \\
\hline $\begin{array}{l}\text { By } \\
\text { workload }\end{array}$ & & & \begin{tabular}{|lcc} 
Plating time & MR-A & MR-B \\
Min. & $/ \mathrm{ft2}$ & $/ \mathrm{ft2}$ \\
10 & 9.5 & 9.5 \\
20 & 18.9 & 18.9 \\
30 & 28.4 & 28.4 \\
40 & 37.9 & 37.9 \\
50 & 56.8 & 56.8 \\
\end{tabular} \\
\hline
\end{tabular}

Table 10: Analysis tests for MR-A \& MR-B electroless copper bath 


\section{Operating Parameters}

$\begin{array}{lll} & \text { Range } & \text { Optimum } \\ \text { Bath Concentration: } & 0.25-2.0 \% \text { bv } & 0.5 \% \text { bv } \\ \text { Temperature: } & 27-66^{\circ} \mathrm{C} & 60^{\circ} \mathrm{C} \\ \text { Time: } & 10-60 \text { seconds } & 30 \text { seconds } \\ \text { pH } & 8.0-9.0 & \\ & \text { Adjust with Ammonia or Acetic acid }\end{array}$

\begin{tabular}{|c|c|c|c|}
\hline Test & Chemicals Needed & Procedure & Additions \\
\hline Conc. & $\begin{array}{l}1.5 \mathrm{M} \mathrm{NH} 4 \mathrm{OH} \\
(100 \mathrm{ml} \text { of } 28 \% \\
\mathrm{NH} 4 \mathrm{OH} \text { in } 1 \text { liter of } \\
\text { DI } \mathrm{H} 2 \mathrm{O}) \\
0.1 \mathrm{~N} \mathrm{AgNO}(17 \mathrm{~g} / \mathrm{l}) \\
\text { DI } \mathrm{H} 2 \mathrm{O}\end{array}$ & $\begin{array}{l}\text { 1. Measure } 25 \mathrm{ml} \text { of DI } \\
\mathrm{H} 2 \mathrm{O} 50 \mathrm{ml} \text { test tube } \\
\text { 2. Pipette } 0.5 \mathrm{ml} \text { of } 1.5 \mathrm{M} \\
\mathrm{NH} 4 \mathrm{OH} \\
\text { 3. Pipette } 1 \mathrm{ml} \text { of AT-C } \\
\text { from bath } \\
4 \text {. Add } 0.5 \mathrm{ml} \text { of } 0.1 \mathrm{~N} \\
\text { AgNO3 and swirl gently } \\
\text { and compare with } \\
\text { standards }\end{array}$ & \\
\hline Standards & & $\begin{array}{l}\text { 1. Prepare } 100 \mathrm{ml} \text { of } \\
\text { stock solution of exactly } \\
0.5 \% \text { bv of AT-C by } \\
\text { diluting } 0.5 \mathrm{ml} \text { of AT-C } \\
\text { in } 100 \mathrm{ml} \text { of DI } \mathrm{H} 2 \mathrm{O} \\
2 . \text { Prepare four } 25 \mathrm{ml} \text { test } \\
\text { tubes as described in } 1 . \\
\& 2 \text {. above } \\
\text { 3. In step3. of above, add } \\
0.25,0.5,0.75, \& 1 \mathrm{ml} \text { of } \\
\text { stock solution into each } \\
\text { of the test tubes } \\
\text { 4. Add AgNO3 into each } \\
\text { tube }\end{array}$ & $\begin{array}{l}\text { Estimate: Compare the } \\
\text { sample with the nearest } \\
\text { standard. If the turbidity } \\
\text { is between } 0.25 \& 0.5 \\
\text { standards, the bath } \\
\text { strength is about } 0.4 \% \\
\text { bv. Add } 0.1 \% \text { AT-C } \\
\text { conc. to maintain } 0.5 \% \\
\text { bv }\end{array}$ \\
\hline
\end{tabular}

Table 11: Analysis tests for AT-C Anti-Tarnish Bath 
(6) Electrolytic acid copper plating bath

\begin{tabular}{|c|c|c|c|c|}
\hline Test & $\begin{array}{l}\text { Chemicals } \\
\text { Needed }\end{array}$ & Procedure & Additions & \\
\hline CuSO4 & $\begin{array}{l}\mathrm{NaOH} \text { (Conc.) } \\
\text { DI H2O } \\
\text { PAN Indicator } \\
\text { 0.1M EDTA }\end{array}$ & $\begin{array}{l}\text { 1. Pipette } 1 \mathrm{ml} \text { of acid } \mathrm{Cu} \\
\text { bath to } 250 \mathrm{ml} \text { flask } \\
\text { 2. Add conc. NaOH until } \\
\text { solution turns blue } \\
\text { 3. Add } 100 \mathrm{ml} \text { of DI } \mathrm{H} 2 \mathrm{O} \& \\
5 \text { drops of PAN indicator } \\
\text { 4. Titrate with } 0.1 \mathrm{M} \text { EDTA } \\
\text { to clear green endpoint. This } \\
\text { value is " } \mathrm{H} \text { " } \\
\text { oz/gal } \mathrm{CuSO4}=\text { " } \mathrm{H"}{ }^{*} 0.83 \\
\end{array}$ & \begin{tabular}{|l} 
CuSO4 \\
(oz/gal) \\
12 \\
11 \\
10 \\
9.5 \\
9 \\
8.5 \\
8
\end{tabular} & $\begin{array}{l}\text { Addition } \\
\text { (CuSO4) } \\
\text { None } \\
\text { None } \\
\text { None } \\
2.45 \text { liter } \\
4.9 \text { liter } \\
7.35 \text { liter } \\
12.25 \text { liter }\end{array}$ \\
\hline $\begin{array}{l}\text { \% } \\
\mathrm{H} 2 \mathrm{SO} 4\end{array}$ & $\begin{array}{l}1.0 \mathrm{~N} \mathrm{NaOH} \\
\text { DI } \mathrm{H} 2 \mathrm{O} \\
\text { Methyl Orange } \\
\text { Indicator }\end{array}$ & $\begin{array}{l}\text { 1. Pipette } 2 \text { ml of acid } \\
\text { copper bath in a flask } \\
\text { 2. Add } 100 \mathrm{ml} \text { of } \mathrm{DI} \mathrm{H} 2 \mathrm{O} \\
\text { and } 4 \text { drops of methyl } \\
\text { orange indicator } \\
\text { 3. Titrate with } 1.0 \mathrm{~N} \mathrm{NaOH} \\
\text { to yellow end point. This } \\
\text { value is "I" } \\
\% \mathrm{H} 2 \mathrm{SO} 4=\text { "l" * } 1.3\end{array}$ & \begin{tabular}{|l|}
$\% \mathrm{H} 2 \mathrm{SO} 4$ \\
12 \\
11 \\
10 \\
9.5 \\
9 \\
8.5 \\
8 \\
\end{tabular} & $\begin{array}{l}\text { Addition } \\
\text { (H2SO4) } \\
\text { None } \\
\text { None } \\
\text { None } \\
550 \mathrm{ml} \\
1100 \mathrm{ml} \\
1650 \mathrm{ml} \\
2200 \mathrm{ml} \\
\end{array}$ \\
\hline $\begin{array}{l}\text { Chloride } \\
\text { PPM }\end{array}$ & $\begin{array}{l}\text { 1:1 HNO3 } \\
\text { DI Water } \\
0.1 \mathrm{~N} \mathrm{AgNO3} \\
0.01 \mathrm{~N} \mathrm{HgNO3}\end{array}$ & $\begin{array}{l}\text { 1. Pipette } 50 \mathrm{ml} \text { of acid } \\
\text { copper bath in a flask } \\
\text { 2. Add } 30 \mathrm{ml} \text { of DI } \mathrm{H} 2 \mathrm{O} \text { and } \\
20 \mathrm{ml} \text { of } 1: 1 \mathrm{HNO} \\
\text { 3. Add } 2 \text { drops of } 0.1 \mathrm{~N} \\
\text { AgNO3 ( enough to produce } \\
\text { turbidity) } \\
4 \text { Titrate with } 0.01 \mathrm{~N} \\
\text { HgNO3 until turbidity } \\
\text { disappears. This value is " } \mathrm{J} " \\
\text { ppm Cl }=\mathrm{J} * 7.1\end{array}$ & \begin{tabular}{|l}
$\mathrm{ppm} \mathrm{Cl}$ \\
$\mathrm{HCl})$ \\
70 \\
65 \\
60 \\
55 \\
50 \\
45 \\
40 \\
35 \\
30 \\
\end{tabular} & 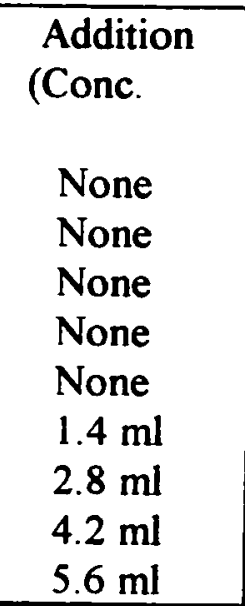 \\
\hline
\end{tabular}

Table 12: Analysis tests for Electrolytic copper plating bath 


\begin{tabular}{|l|l|l|l|l|l|l|l|}
\hline BATH & PD & PD \& PTC & AA & MR & H2SO4 & Electrolytic & Oxyban \\
\cline { 2 - 7 } TLME & $5 \mathrm{~min}$ & $5 \mathrm{~min}$ & $7 \mathrm{~min}$ & $30 \mathrm{~min}$ & $2 \mathrm{~min}$ & $* 90 \mathrm{~min}$ & $2 \mathrm{~min}$ \\
\hline
\end{tabular}

\section{Table 13: Electroless and Acid Copper Plating Time Schedule}

* Note: The acid copper bath is to be run as follows:

1. Four plates must be plated together because of surface area consideration

2. The plates are placed in the bath at equal spacing, using the black holding clamps, so as to not be closer to one electrode or the other, and not to interfere with other plates

3. When the plates are placed in the bath, the first 30 seconds is to be run at a current of 0.5 Amp. Then the next 30 seconds run at $1.0 \mathrm{Amp}$. The remaining minutes are to be at 11.6 Amps.

Calculations:

$1 \mathrm{ml}=0.001 "=0.0025 \mathrm{~cm}=25 \mu \mathrm{m}$

Coupon size $=7.7 \mathrm{~cm} \times 8.95 \mathrm{~cm} \times 0.3 \mathrm{~cm}$

Area of 1 side $=0.0725 \mathrm{ft}^{2}$

Area of 2 sides $=0.145 \mathrm{ft}^{2}$

Area of 4 coupons $=0.58 \mathrm{ft}^{2}$

Thickness $=45$ microns of $\mathrm{Cu}$ at $20 \mathrm{ASF}$, Area $=0.58 \mathrm{ft}^{2}$

I (Current in Amps) $=$ ASF $\times$ Area

$\mathrm{V}\left(\right.$ Volume of $\mathrm{Cu}$ needed in $\left.\mathrm{cm}^{3}\right)=$ Area $\times$ Thickness

$\mathrm{W}$ (Weight of $\mathrm{Cu}$ needed in $\mathrm{gms})=\mathrm{V} \times \operatorname{density}\left(8.92 \mathrm{~g} / \mathrm{cm}^{3}\right)$

$W=\frac{I t}{96500} \times \frac{A}{z}$

$\mathrm{z}=2$ for $\mathrm{Cu}$

Calculate time $(t)$ in minutes from the above formula

After the plates are run through the plating lines, they need to be cut using the template that divides each plate into two strips. Cut the bottom $1 / 4$ " in a " $U$ " shape. Run the peel test on these panels at a later time. 


\section{FOUR POINT PROBE FOR THICKNESS MEASUREMENT}

This apparatus is generally used to measure the resistance of a semiconductor wafer without any metal contacts on the surface of the wafer. In this experiment it is being used to measure the thickness of copper layer on the substrate. The pointed probes are placed directly on the surface of a plated coupon. Since the current is injected into the top surface of the substrate, greater amount of current will tend to flow along the top, dividing in some geometrical fashion throughout the substrate thickness. Therefore the measured resistance is dependent on thickness $t$ of the substrate and probe spacing.

The current is supplied through the outer two contacts to the substrate, but the voltage is measured between the inner two contacts. The current flow establishes a voltage drop along the substrate. The difference in potential between the inner two contacts is dependent on the substrate's resistance. For effectiveness of this technique there should be negligible current flow to high impedance of the voltmeter, so that the contact resistance does not effect the measured voltage. The size of the substrate can also play a role in the measurement. If the diameter of the substrate is not significantly larger than the probe spacing, i.e. $D<50$ s, the correction factor is necessary. In this case the diameter of the substrate is greater than 50 s.

The formula used for measuring thickness: 


$$
\begin{aligned}
& \rho=\frac{1}{\sigma}=\frac{\Pi \mathrm{t} \mathrm{V}}{\ln 2 \mathrm{I}} \\
& \therefore \mathrm{t}=\frac{\ln 2 \mathrm{I} . \rho}{\Pi \mathrm{V}} \\
& \rho=1724 \mu \Omega \mathrm{cm} \text { for annealed copper at } 20^{\circ} \mathrm{C} \\
& \mathrm{V}=\text { Voltage(measured) in } \mathrm{mV} \\
& \mathrm{I}=\text { Current(measured) in Amps }
\end{aligned}
$$

\section{OLYMPUS MICROSCOPE FOR THICKNESS MEASUREMENT}

Turn on the light switch power supply. This is a separate power supply. Start at low intensity and then increase to the desired level. Do not force the high light intensity past the stop. This feature is to save light bulbs from burning out. There are four objectives: $5,10,15$, and 20 . The magnification power is 50, $100,200,400 \mathrm{X}$. Always start with the lowest power objective, this is the shortest one. Always finish with the lowest power objective. This ensures safe removal of the substrate without scratching the objective. The focus knob is located at the lower back side of the equipment (both sides). The big back knob is for coarse focus. The front small knob is for fine focus. Focus on the substrate at low power using the big coarse focus knob. If it's difficult to focus, turn the knob all the way up, then slowly watch as you turn it back down. If it's still out of focus, check the objective position, feel the click. If still there is a problem focusing, check the "Pull BF" lever. This is the Bright Field / Dark Field lever and 
should be all the way out. This should do the trick but if the above does not work, ask the lab instructor to check the light bulb adjustment. The lab instructor will remove the eye piece to find the bulb filament and will adjust the collimator stop for about $2 / 3$ field illumination. After good focus at low power, switch to the next power. From now on use only fine focus. Continue increasing the power to the desired setting. At the final power slightly adjust collimator knob on the light path.

For this particular experiment, 200X was used. The scale was calibrated/ set to read 5 microns per division.

\begin{tabular}{|c|c|c|c|c|}
\hline $\begin{array}{c}\text { Flow Rate } \\
\mathrm{ml} / \mathrm{min} .\end{array}$ & Gas & $\begin{array}{c}\text { Results } \\
\text { Microscope }\end{array}$ & 4-point probe & \% Variation \\
\hline 50.54 & $\mathrm{He}$ & 50 & 44 & $13.4 \%$ \\
\hline 25.27 & $\mathrm{He}$ & 50 & 50 & $0 \%$ \\
\hline 25.27 & $\mathrm{He}$ & 50 & 41 & $18.8 \%$ \\
\hline 24.85 & $\mathrm{O}_{2}$ & 50 & 49 & $2.6 \%$ \\
\hline Average & & 50 & 46 & $8.7 \%$ \\
\hline
\end{tabular}

Table 14: Copper film thickness measurement 


\section{SEM ANALYSIS}

This is a two step process:

1) Gold Sputter: To make the coupon conductive

2) SEM Analysis

\section{DENTON VACUUM DESK-1 SPUTTER}

Denton vacuum desk-l sputterer is used for sputter deposition of gold films on the surface of non-conductive samples to be observed by SEM. The deposition consists of two stages: a) Cleaning of the substrate by etch mode, b) Deposition of gold film on the surface by sputter mode. In this experiment Step a) was not followed since the substrate was already etched and there was a possibility of having a false reading.

The vacuum gauge built into the desk-1 is broken. We need to monitor the pressure using the vacuum gauge just to the right of desk-1. If this gauge is not already on, then you must turn the dial on the lower left hand corner to "WarmUp" position for about 5 to 10 minutes. After the warm-up period, turn the dial to "On" position. At this point set the dial in the top center position to " 1 " position. You will be reading the chamber pressure using the left-hand side gauge. Now you are ready to sputter.

1) Open the main valve of the argon tank cylinder.

2) Place your substrate in the chamber 
3) Move the shutter inside the chamber over the substrate

4) Close the chamber. Be careful not to chip the edge of the glass cylinder. You may occasionally need to put a very light coating of vacuum grease on the lid from time to time.

5) Turn the vacuum pump on by flipping "Pump" switch to "On" position.

6) Turn "Gas Selector" switch to "Sputter" position. Wait until the chamber pressure is pumped down to 50 mtorr.

7) Slightly open "Sputter Valve" located on the top of desk-1 until the vacuum gage shows 75 mtorr.

8) Check timer switch for timed or manual, and sputter time.

9) Press "High Voltage On" button and turn the power adjust knob to the desired position. The desk-1 deposits about $100^{\circ} \mathrm{A}$ in 25 seconds if the current is set at $40 \mathrm{~mA}$. This will vary with the quantity of vacuum.

10) After the sputter time is complete, turn off the high voltage switch by pressing "High Voltage Off" button.

11) Close "Sputter Valve". Turn the "Gas Selector" switch to "Off" position.

12) Flip the "Pump Switch" to "Off" position. The Chamber vents automatically. Open chamber carefully and remove coated substrate.

13) Close argon gas tank main valve tightly. If the sputter step was proper, the surface of the substrate shows gold color. 


\section{SEM ANALYSIS}

A) To turn on the SEM machine (assuming that there is a specimen in the chamber) follow the procedure listed below.

1) Turn on the Nitrogen cylinder main valve

2) Turn on the "Display Power" switch.

3) When green "Ready / Off" light turns on, depress "HVON" button.

4) Set "Invert/Manual/Auto" switch to "Manual".

5) Set "Bias" control to 2 .

6) Depress "Waveform" button. This is to enable measurement of saturation current of the filament. If the bright horizontal line does not appear on the CRT, turn "Brightness" knob until the line appears.

7) Turn the "Filament" control clockwise until wave peaks ( at this point the wave form goes up and down rapidly). At the peak value, back down the "Filament" knob $1 / 16^{\text {th }}$ of an inch. This step makes sure that the filament is fully saturated. "Emission Current" meter should read about $80 \mu \mathrm{A}$.

8) Depress "Waveform" again, this turns off the waveform function.

9) Set "Invert/Manual/Auto" switch to "Auto".

B) To change specimen from the chamber follow the procedure listed below.

1) There is no need to turn off the "Display Power" if the machine has been in operation. Turn down "Filament" control and depress "Ready/Off" button. This lowers the magnification. 
2) Set controls of the specimen stage as follows:

$$
\mathrm{X}=20, \mathrm{Y}=20, \mathrm{~T}=0 \text { and } \mathrm{Z} \text {-control knob }=\mathrm{EX}-\mathrm{EX}
$$

3) Depress "Air" button. This starts the de-vacuum process of the chamber.

4) Upon completion of the de-vacuum process, pull out the specimen stage.

5) Change the specimen.

6) Push the specimen stage back, hold in place and depress "EVAC" button. This starts the chamber evacuation.

7) After the "High Vacuum" light turns on and the green "Ready/Off" light turns on, the system is ready to view the new specimen via procedure 3-9 in procedure $\mathbf{A}$.

C) To turn off the SEM machine follow this procedure.

1) Lower the magnification.

2) Turn down the "Filament" control knob. This step is vital to preserve the filament life.

3) Depress the "Ready/Off" button.

4) Set controls of the specimen as stated in procedure B-2 above.

5) Turn of the "Display Power" switch.

If you encounter problems, play it safe......See Dr. Pizzo.

Refer to the Figure 24 for HV, Video, Electron Probe, and Magnification controls - front panel display. The critical settings used for the SEM micrographs for this experiment were: 
Bias

Filament current

Aperture

Nitrogen

Working Distance

Dual Magnification

Contrast and Brightness

Film
2

$40 \mu \mathrm{A}$

2

To keep the chamber cleaner under pressure 10

Off

Set at the center of the scale for photographs

Type 53 film 


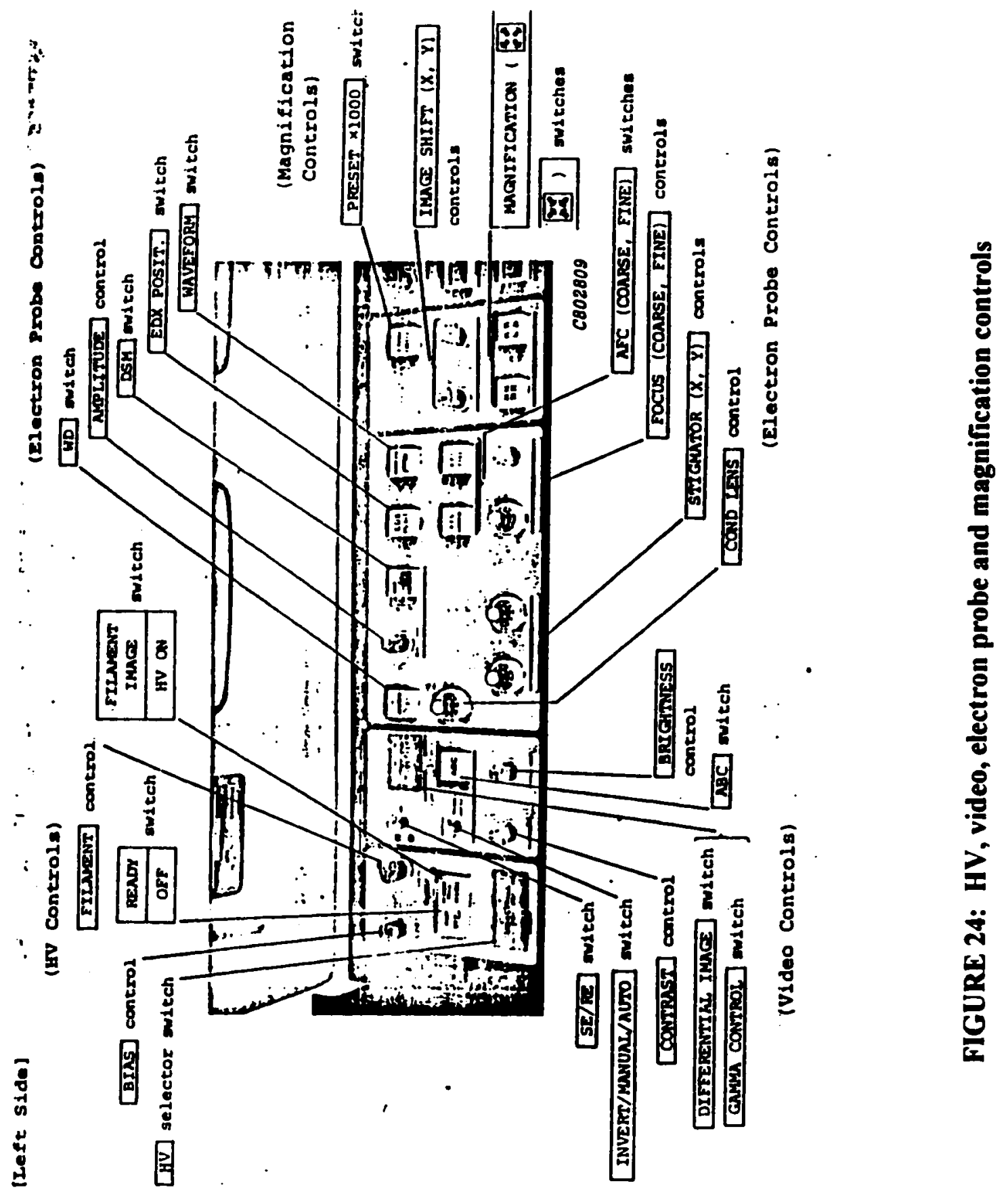




\section{APPENDIX C}

SEM traces of coupons etched with oxygen at $25 \mathrm{ml} / \mathrm{min}$. and $92 \mathrm{ml} / \mathrm{min}$. and helium at $25 \mathrm{ml} / \mathrm{min}$. and $100 \mathrm{ml} / \mathrm{min}$. 


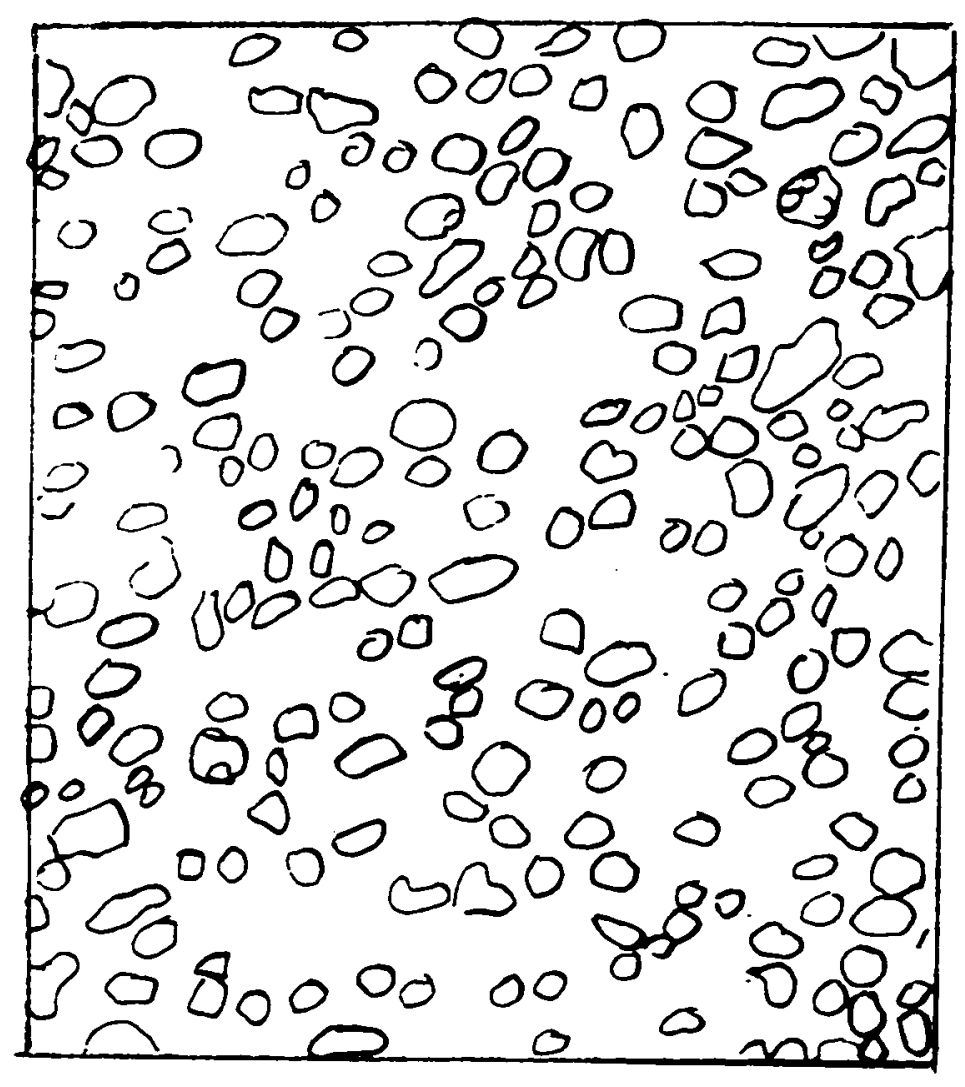

a)

b)

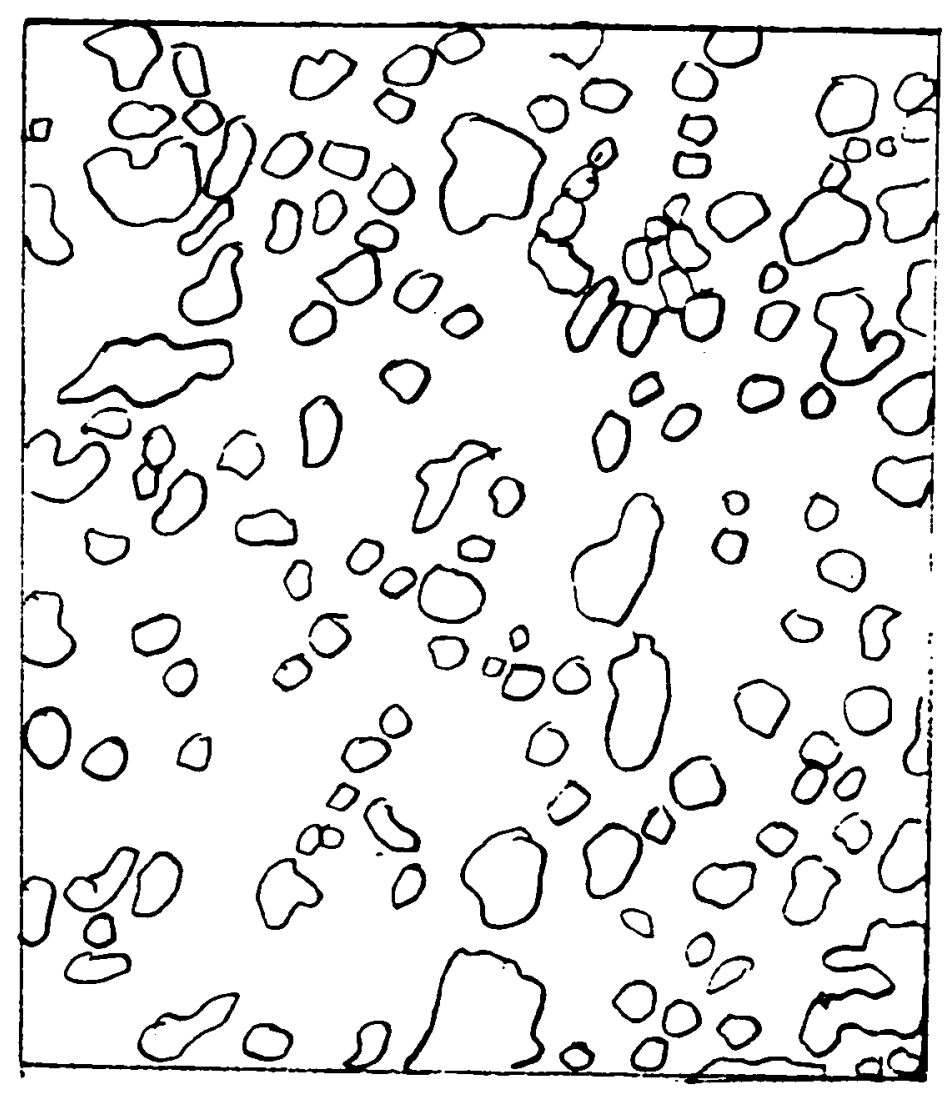

Figure 25: SEM trace of coupon etched with oxygen at a) $25 \mathrm{ml} / \mathrm{min}$. b) $92 \mathrm{ml} / \mathrm{min}$. 

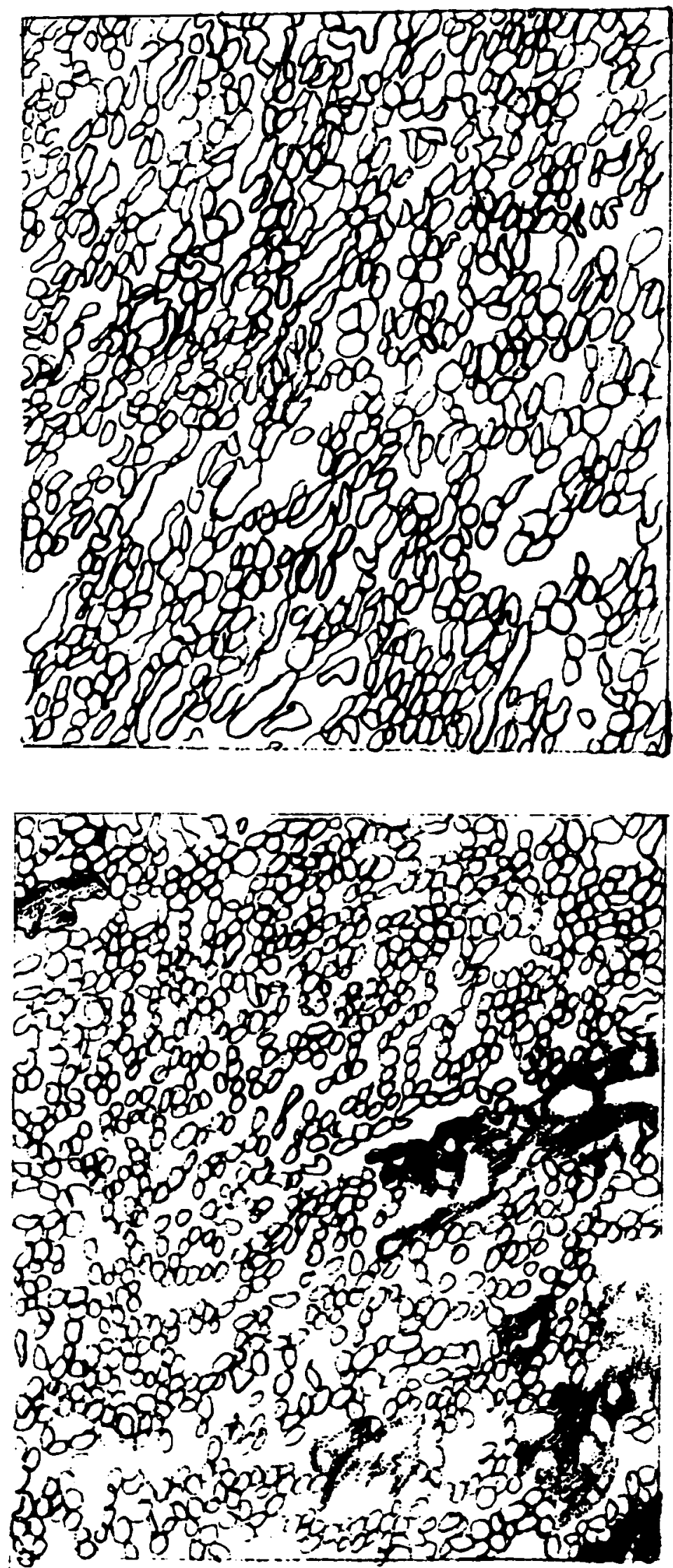

Figure 26: SEM trace of coupon etched with helium at a) $25 \mathrm{ml} / \mathrm{min}$. b) $100 \mathrm{ml} / \mathrm{min}$. 


\section{APPENDEX D}

SEM data for coupons etched with oxygen at $25 \mathrm{ml} / \mathrm{min}$. and $92 \mathrm{ml} / \mathrm{min}$. and helium at $25 \mathrm{ml} / \mathrm{min}$. and $100 \mathrm{ml} / \mathrm{min}$. 


\begin{tabular}{|ll|}
\hline Gas: & Oxygen \\
Flow Rate: & $25 \mathrm{ml} / \mathrm{min}$ \\
Photo Number: & 980110 \\
Magnification: & $15.1 \mathrm{~K}$ \\
& $20 \mathrm{KV}$ \\
Number of Pores: & $214+/-5$ \\
\hline
\end{tabular}

\begin{tabular}{|c|c|c|c|c|c|c|}
\hline Pore\# & $\begin{array}{l}D_{\min }(\mathrm{mm}) \\
+/-0.5 \mathrm{~mm}\end{array}$ & $\begin{array}{l}D_{\max }(\mathrm{mm}) \\
+/-0.5 \mathrm{~mm}\end{array}$ & $\begin{array}{c}D_{\min }(\mathrm{um}) \\
+1-0.03 \mathrm{um} \\
\end{array}$ & \begin{tabular}{|c|}
$D_{\max }(\mathrm{um})$ \\
$+1-0.03 \mathrm{um}$ \\
\end{tabular} & $\mathrm{D}_{\text {avg }}$ & $A_{\text {avg }}$ \\
\hline 1 & 2 & 2 & 0.133 & 0.133 & |0.133 & 0.014 \\
\hline 2 & 5 & 6 & 0.333 & 0.400 & 0.367 & 0.106 \\
\hline 3 & 2 & 4 & 0.133 & 0.267 & 0.200 & 0.031 \\
\hline 4 & 2 & 2 & 0.133 & 0.133 & 0.133 & 0.014 \\
\hline 5 & 4 & 5 & 0.267 & 0.333 & 0.300 & 0.071 \\
\hline 6 & 3 & 3 & 0.200 & 0.200 & 0.200 & 0.031 \\
\hline 7 & 3 & 3 & 0.200 & 0.200 & 0.200 & 0.031 \\
\hline 8 & 3 & 4 & 0.200 & 0.267 & 0.233 & 0.043 \\
\hline 9 & 2 & 2 & 0.133 & 0.133 & 0.133 & 0.014 \\
\hline 10 & 2 & 5 & 0.133 & 0.333 & 0.233 & 0.043 \\
\hline 11 & 4 & 4 & 0.267 & 0.267 & 0.267 & 0.056 \\
\hline 12 & 2 & 3 & 0.133 & 0.200 & 0.167 & 0.022 \\
\hline 13 & 2 & 4 & 0.133 & 0.267 & 0.200 & 0.031 \\
\hline 14 & 3 & 4 & 0.200 & 0.267 & 0.233 & 0.043 \\
\hline 15 & 2 & 2 & 0.133 & 0.133 & 0.133 & 0.014 \\
\hline 16 & 2 & 5 & 0.133 & 0.333 & 0.233 & 0.043 \\
\hline 17 & 3 & 6 & 0.200 & 0.400 & 0.300 & 0.071 \\
\hline 18 & 4 & 4 & 0.267 & 0.267 & 0.267 & 0.056 \\
\hline 19 & 3 & 5 & 0.200 & 0.333 & 0.267 & 0.056 \\
\hline 20 & 3 & 5 & 0.200 & 0.333 & 0.267 & 0.056 \\
\hline 21 & 3 & 3 & 0.200 & 0.200 & 0.200 & 0.031 \\
\hline 22 & 3 & 5 & 0.200 & 0.333 & 0.267 & 0.056 \\
\hline 23 & 2 & 2 & 0.133 & 0.133 & 0.133 & 0.014 \\
\hline 24 & 2 & 3 & 0.133 & 0.200 & 0.167 & 0.022 \\
\hline 25 & 2 & 2 & 0.133 & 0.133 & 0.133 & 0.014 \\
\hline 26 & 5 & 7 & 0.333 & 0.467 & 0.400 & 0.126 \\
\hline 27 & 3 & 3 & 0.200 & 0.200 & 0.200 & 0.031 \\
\hline 28 & 3 & 8 & 0.200 & 0.533 & 0.367 & 0.106 \\
\hline 29 & 2 & 2 & 0.133 & 0.133 & 0.133 & 0.014 \\
\hline 30 & 3 & 5 & 0.200 & 0.333 & 0.267 & 0.056 \\
\hline
\end{tabular}




\begin{tabular}{|c|c|c|c|c|c|c|}
\hline Pore \# $\left[\begin{array}{l}\mathrm{I} \\
+\end{array}\right.$ & $\begin{array}{l}D_{\min }(\mathrm{mm}) \\
+/-0.5 \mathrm{~mm}\end{array}$ & $\begin{array}{r}D_{\max }(\mathrm{mm}) \\
+/-0.5 \mathrm{~mm} \\
\end{array}$ & $\begin{array}{c}D_{\min }(\mathrm{um}) \\
+/-0.03 \mathrm{um} \\
\end{array}$ & \begin{tabular}{|c|}
$D_{\max }(\mathrm{um})$ \\
$+/-0.03 \mathrm{um}$
\end{tabular} & $D_{\text {avg }}$ & $A_{\text {avg }}$ \\
\hline 31 & 3 & 5 & 0.200 & 0.333 & 0.267 & 0.056 \\
\hline 32 & 3 & 3 & 0.200 & 0.200 & 0.200 & 0.031 \\
\hline 33 & 4 & 4 & 0.267 & 0.267 & 0.267 & 0.056 \\
\hline 34 & 3 & 3 & 0.200 & 0.200 & 0.200 & 0.031 \\
\hline 35 & 3 & 3 & 0.200 & 0.200 & 0.200 & 0.031 \\
\hline 36 & 3 & 7 & 0.200 & 0.467 & 0.333 & 0.087 \\
\hline 37 & 3 & 3 & 0.200 & 0.200 & 0.200 & 0.031 \\
\hline 38 & 3 & 3 & 0.200 & 0.200 & 0.200 & 0.031 \\
\hline 39 & 3 & 3 & 0.200 & 0.200 & 0.200 & 0.031 \\
\hline 40 & 3 & 3 & 0.200 & 0.200 & 0.200 & 0.031 \\
\hline 41 & 3 & 3 & 0.200 & 0.200 & 0.200 & 0.031 \\
\hline 42 & 5 & 5 & 0.333 & 0.333 & 0.333 & 0.087 \\
\hline 43 & 3 & 4 & 0.200 & 0.267 & 0.233 & 0.043 \\
\hline 44 & 2 & 2 & 0.133 & 0.133 & 0.133 & 0.014 \\
\hline 45 & 2 & 3 & 0.133 & 0.200 & 0.167 & 0.022 \\
\hline 46 & 4 & 4 & 0.267 & 0.267 & 0.267 & 0.056 \\
\hline 47| & 3 & 3 & 0.200 & 0.200 & 0.200 & 0.031 \\
\hline 48 & 3 & 6 & 0.200 & 0.400 & 0.300 & 0.071 \\
\hline 49 & 3 & 5 & 0.200 & 0.333 & 0.267 & 0.056 \\
\hline 50 & 2 & 6 & 0.133 & 0.400 & 0.267 & 0.056 \\
\hline 51 & 3 & 6 & 0.200 & 0.400 & 0.300 & 0.071 \\
\hline 52 & 3 & 4 & 0.200 & 0.267 & 0.233 & 0.043 \\
\hline 53 & 3 & 5 & 0.200 & 0.333 & 0.267 & 0.056 \\
\hline 54 & 2 & 4 & 0.133 & 0.267 & 0.200 & 0.031 \\
\hline 55 & 2 & 4 & 0.133 & 0.267 & 0.200 & 0.031 \\
\hline 56 & 3 & 4 & 0.200 & 0.267 & 0.233 & 0.043 \\
\hline 57. & 4 & 5 & 0.267 & 0.333 & 0.300 & 0.071 \\
\hline 58 & 2 & 2 & 0.133 & 0.133 & 0.133 & 0.014 \\
\hline 59 & 2 & 2 & 0.133 & 0.133 & 0.133 & 0.014 \\
\hline 60 & 2 & 4 & 0.133 & 0.267 & 0.200 & 0.031 \\
\hline 61 & 2 & 3 & 0.133 & 0.200 & 0.167 & 0.022 \\
\hline 62 & 2 & 2 & 0.133 & 0.133 & 0.133 & 0.014 \\
\hline 63 & 3 & 3 & 0.200 & 0.200 & 0.200 & 0.031 \\
\hline 64 & 3 & 4 & 0.200 & 0.267 & 0.233 & 0.043 \\
\hline 65 & 3 & 6 & 0.200 & 0.400 & 0.300 & 0.071 \\
\hline 66 & 3 & 3 & 0.200 & 0.200 & 0.200 & 0.031 \\
\hline 67 & 3 & 31 & 0.200 & 0.200 & 0.200 & 0.031 \\
\hline
\end{tabular}




\begin{tabular}{|c|c|c|c|c|c|c|}
\hline Pore\# & $\begin{array}{l}D_{\min }(\mathrm{mm}) \\
+/-0.5 \mathrm{~mm}\end{array}$ & \begin{tabular}{|l|} 
\\
$D_{\max }(m m)$ \\
$+/-0.5 m m$ \\
\end{tabular} & $\begin{array}{r}D_{\min }(\mathrm{um}) \\
+/-0.03 \text { um }\end{array}$ & \begin{tabular}{|c|}
$D_{\max }$ (um) \\
$+/-0.03$ um \\
\end{tabular} & $D_{\text {avg }}$ & $A_{\text {avg }}$ \\
\hline 68 & 4 & 7 & 0.267 & 0.467 & 0.367 & 0.106 \\
\hline 69 & 2 & 3 & 0.133 & 0.200 & 0.167 & 0.022 \\
\hline 70 & 3 & 3 & 0.200 & 0.200 & 0.200 & 0.031 \\
\hline 71 & 3 & 3 & 0.200 & 0.200 & 0.200 & 0.031 \\
\hline 72 & 4 & 7 & 0.267 & 0.467 & 0.367 & 0.106 \\
\hline 73 & 3 & 5 & 0.200 & 0.333 & 0.267 & 0.056 \\
\hline 74 & 2 & 5 & 0.133 & 0.333 & 0.233 & 0.043 \\
\hline 75 & 2 & 3 & 0.133 & 0.200 & 0.167 & 0.022 \\
\hline 76 & 3 & 3 & 0.200 & 0.200 & 0.200 & 0.031 \\
\hline 77 & 3 & 5 & 0.200 & 0.333 & 0.267 & 0.056 \\
\hline 78 & 3 & 3 & 0.200 & 0.200 & 0.200 & 0.031 \\
\hline 79 & 3 & 3 & 0.200 & 0.200 & 0.200 & 0.031 \\
\hline 80 & 3 & 3 & 0.200 & 0.200 & 0.200 & 0.031 \\
\hline 81 & 2 & 2 & 0.133 & 0.133 & 0.133 & 0.014 \\
\hline 82 & 2 & 4 & 0.133 & 0.267 & 0.200 & 0.031 \\
\hline 83 & 3 & 3 & 0.200 & 0.200 & 0.200 & 0.031 \\
\hline 84 & 4 & 4 & 0.267 & 0.267 & 0.267 & 0.056 \\
\hline 85 & 4 & 4 & 0.267 & 0.267 & 0.267 & 0.056 \\
\hline 86 & 5 & 5 & 0.333 & 0.333 & 0.333 & 0.087 \\
\hline 87 & 1 & 1 & 0.067 & 0.067 & 0.067 & 0.003 \\
\hline 88 & 4 & 7 & 0.267 & 0.467 & 0.367 & 0.106 \\
\hline 89 & 2 & 4 & 0.133 & 0.267 & 0.200 & 0.031 \\
\hline 90 & 3 & 4 & 0.200 & 0.267 & 0.233 & 0.043 \\
\hline 91 & 3 & 4 & 0.200 & 0.267 & 0.233 & 0.043 \\
\hline 92 & 4 & 4 & 0.267 & 0.267 & 0.267 & 0.056 \\
\hline 93 & 6 & 6 & 0.400 & 0.400 & 0.400 & 0.126 \\
\hline 94 & 4 & 5 & 0.267 & 0.333 & 0.300 & 0.071 \\
\hline 95 & 3 & 3 & 0.200 & 0.200 & 0.200 & 0.031 \\
\hline 96 & 4 & 4 & 0.267 & 0.267 & 0.267 & 0.056 \\
\hline 97 & 5 & 5 & 0.333 & 0.333 & 0.333 & 0.087 \\
\hline 98 & 4 & 4 & 0.267 & 0.267 & 0.267 & 0.056 \\
\hline 99 & 2 & 3 & 0.133 & 0.200 & 0.167 & 0.022 \\
\hline 100 & 4 & 3 & 0.267 & 0.200 & 0.233 & 0.043 \\
\hline 101 & 2 & 2 & 0.133 & 0.133 & 0.133 & 0.014 \\
\hline 102 & 3 & 4 & 0.200 & 0.267 & 0.233 & 0.043 \\
\hline 103 & 2 & 3 & 0.133 & 0.200 & 0.167 & 0.022 \\
\hline 104 & 3 & 31 & 0.200 & 0.200 & 0.200 & 0.031 \\
\hline
\end{tabular}




\begin{tabular}{|c|c|c|c|c|c|c|}
\hline Pore \# & \begin{tabular}{|l|}
$D_{\min }(\mathrm{mm})$ \\
$+1-0.5 \mathrm{~mm}$ \\
\end{tabular} & $\begin{array}{l}D_{\max }(\mathrm{mm}) \\
+1-0.5 \mathrm{~mm} \\
\end{array}$ & $\begin{array}{c}D_{\min } \text { (um) } \\
+/-0.03 \text { um } \\
\end{array}$ & \begin{tabular}{|}
$D_{\max }(\mathrm{um})$ \\
$+/-0.03 \mathrm{um}$ \\
\end{tabular} & $D_{\text {avg }}$ & $A_{\text {avg }}$ \\
\hline 105 & 3 & 4 & 0.200 & 0.267 & 0.233 & 0.043 \\
\hline 106 & 4 & 5 & 0.267 & 0.333 & 0.300 & 0.071 \\
\hline 107 & 4 & 4 & 0.267 & 0.267 & 0.267 & 0.056 \\
\hline 108 & 4 & 5 & 0.267 & 0.333 & 0.300 & 0.071 \\
\hline 109 & 4 & 8 & 0.267 & 0.533 & 0.400 & 0.126 \\
\hline 110 & 3 & 3 & 0.200 & 0.200 & 0.200 & 0.031 \\
\hline 111 & 3 & 3 & 0.200 & 0.200 & 0.200 & 0.031 \\
\hline 112 & 3 & 4 & 0.200 & 0.267 & 0.233 & 0.043 \\
\hline 113 & 3 & 3 & 0.200 & 0.200 & 0.200 & 0.031 \\
\hline 114 & 3 & 3 & 0.200 & 0.200 & 0.200 & 0.031 \\
\hline 115 & 5 & 5 & 0.333 & 0.333 & 0.333 & 0.087 \\
\hline 116 & 2 & 4 & 0.133 & 0.267 & 0.200 & 0.031 \\
\hline 117 & 5 & 6 & 0.333 & 0.400 & 0.367 & 0.106 \\
\hline 118 & 3 & 4 & 0.200 & 0.267 & 0.233 & 0.043 \\
\hline 119 & 3 & 3 & 0.200 & 0.200 & 0.200 & 0.031 \\
\hline 120 & 4 & 5 & 0.267 & 0.333 & 0.300 & 0.071 \\
\hline 121 & 5 & 5 & 0.333 & 0.333 & 0.333 & 0.087 \\
\hline 122 & 2 & 5 & 0.133 & 0.333 & 0.233 & 0.043 \\
\hline 123 & 3 & 3 & 0.200 & 0.200 & 0.200 & 0.031 \\
\hline 124 & 3 & 3 & 0.200 & 0.200 & 0.200 & 0.031 \\
\hline 125 & 3 & 3 & 0.200 & 0.200 & 0.200 & 0.031 \\
\hline 126 & 3 & 3 & 0.200 & 0.200 & 0.200 & 0.031 \\
\hline 127 & 2 & 4 & 0.133 & 0.267 & 0.200 & 0.031 \\
\hline 128 & 2 & 2 & 0.133 & 0.133 & 0.133 & 0.014 \\
\hline 129 & 3 & 3 & 0.200 & 0.200 & 0.200 & 0.031 \\
\hline 130 & 2 & 2 & 0.133 & 0.133 & 0.133 & 0.014 \\
\hline 131 & 2 & 2 & 0.133 & 0.133 & 0.133 & 0.014 \\
\hline 132 & 3 & 4 & 0.200 & 0.267 & 0.233 & 0.043 \\
\hline 133 & 3 & 3 & 0.200 & 0.200 & 0.200 & 0.031 \\
\hline 134 & 4 & 5 & 0.267 & 0.333 & 0.300 & 0.071 \\
\hline 135 & 2 & 3 & 0.133 & 0.200 & 0.167 & 0.022 \\
\hline 136 & 2 & 3 & 0.133 & 0.200 & 0.167 & 0.022 \\
\hline 137 & 4 & 7 & 0.267 & 0.467 & 0.367 & 0.106 \\
\hline 138 & 4 & 4 & 0.267 & 0.267 & 0.267 & 0.056 \\
\hline 139 & 3 & 4 & 0.200 & 0.267 & 0.233 & 0.043 \\
\hline 140 & 3 & 5 & 0.200 & 0.333 & 0.267 & 0.056 \\
\hline 141 & 3 & 3 & 0.200 & 0.200 & 0.200 & 0.031 \\
\hline
\end{tabular}




\begin{tabular}{|c|c|c|c|c|c|c|}
\hline Pore \# & $\begin{array}{l}D_{\min }(\mathrm{mm}) \\
+1-0.5 \mathrm{~mm} \\
\end{array}$ & $\begin{array}{l}D_{\max }(\mathrm{mm}) \\
+/-0.5 \mathrm{~mm} \\
\end{array}$ & $\begin{array}{c}D_{\min }(\mathrm{um}) \\
+/-0.03 \text { um }\end{array}$ & $\begin{array}{c}D_{\max } \text { (um) } \\
+/-0.03 \text { um }\end{array}$ & $D_{\text {avg }}$ & $A_{\text {avg }}$ \\
\hline 142 & 3 & 4 & 0.200 & 0.267 & 0.233 & 0.043 \\
\hline 143 & 4 & 5 & 0.267 & 0.333 & 0.300 & 0.071 \\
\hline 144 & 2 & 5 & 0.133 & 0.333 & 0.233 & 0.043 \\
\hline 145 & 2 & 3 & 0.133 & 0.200 & 0.167 & 0.022 \\
\hline 146 & 2 & 3 & 0.133 & 0.200 & 0.167 & 0.022 \\
\hline 147 & 3 & 6 & 0.200 & 0.400 & 0.300 & 0.071 \\
\hline 148 & 3 & 4 & 0.200 & 0.267 & 0.233 & 0.043 \\
\hline 149 & 3 & 5 & 0.200 & 0.333 & 0.267 & 0.056 \\
\hline 150 & 3 & 3 & 0.200 & 0.200 & 0.200 & 0.031 \\
\hline 151 & 4 & 5 & 0.267 & 0.333 & 0.300 & 0.071 \\
\hline 152 & 4 & 4 & 0.267 & 0.267 & 0.267 & 0.056 \\
\hline 153 & 2 & 4 & 0.133 & 0.267 & 0.200 & 0.031 \\
\hline 154 & 3 & 5 & 0.200 & 0.333 & 0.267 & 0.056 \\
\hline 155 & 3 & 4 & 0.200 & 0.267 & 0.233 & 0.043 \\
\hline 156 & 4 & 8 & 0.267 & 0.533 & 0.400 & 0.126 \\
\hline 157 & 4 & 5 & 0.267 & 0.333 & 0.300 & 0.071 \\
\hline 158 & 3 & 7 & 0.200 & 0.467 & 0.333 & 0.087 \\
\hline 159 & 2 & 2 & 0.133 & 0.133 & 0.133 & 0.014 \\
\hline 160 & 3 & 6 & 0.200 & 0.400 & 0.300 & 0.071 \\
\hline 161 & 4 & 4 & 0.267 & 0.267 & 0.267 & 0.056 \\
\hline 162 & 1 & 3 & 0.067 & 0.200 & 0.133 & 0.014 \\
\hline 163 & 3 & 3 & 0.200 & 0.200 & 0.200 & 0.031 \\
\hline 164 & 3 & 4 & 0.200 & 0.267 & 0.233 & 0.043 \\
\hline 165 & 2 & 3 & 0.133 & 0.200 & 0.167 & 0.022 \\
\hline 166 & 2 & 2 & 0.133 & 0.133 & 0.133 & 0.014 \\
\hline 167 & 4 & 5 & 0.267 & 0.333 & 0.300 & 0.071 \\
\hline 168 & 5 & 12 & 0.333 & 0.800 & 0.567 & 0.252 \\
\hline 169 & 3 & 5 & 0.200 & 0.333 & 0.267 & 0.056 \\
\hline 170 & 3 & 3 & 0.200 & 0.200 & 0.200 & 0.031 \\
\hline 171 & 4 & 5 & 0.267 & 0.333 & 0.300 & 0.071 \\
\hline 172 & 3 & 4 & 0.200 & 0.267 & 0.233 & 0.043 \\
\hline 173 & 2 & 2 & 0.133 & 0.133 & 0.133 & 0.014 \\
\hline 174 & 3 & 7 & 0.200 & 0.467 & 0.333 & 0.087 \\
\hline 175 & 2 & 2 & 0.133 & 0.133 & 0.133 & 0.014 \\
\hline 176 & 2 & 2 & 0.133 & 0.133 & 0.133 & 0.014 \\
\hline 177 & 4 & 5 & 0.267 & 0.333 & 0.300 & 0.071 \\
\hline 178 & 5 & 8 & 0.333 & 0.533 & 0.433 & 0.147 \\
\hline
\end{tabular}




\begin{tabular}{|c|c|c|c|c|c|c|}
\hline Pore \# & $\begin{array}{l}D_{\min }(\mathrm{mm}) \\
+1-0.5 \mathrm{~mm}\end{array}$ & $\begin{array}{l}D_{\max }(\mathrm{mm}) \\
+/-0.5 \mathrm{~mm}\end{array}$ & $\begin{array}{c}D_{\min } \text { (um) } \\
+/-0.03 \text { um }\end{array}$ & $\begin{array}{c}D_{\max }(\mathrm{um}) \\
+/-0.03 \mathrm{um}\end{array}$ & $D_{\text {avg }}$ & $A_{\text {avg }}$ \\
\hline 179 & 4 & 4 & 0.267 & 0.267 & 0.267 & 0.056 \\
\hline 180 & 2 & 3 & 0.133 & 0.200 & 0.167 & 0.022 \\
\hline 181 & 3 & 3 & 0.200 & 0.200 & 0.200 & 0.031 \\
\hline 182 & 2 & 2 & 0.133 & 0.133 & 0.133 & 0.014 \\
\hline 183 & 2 & 2 & 0.133 & 0.133 & 0.133 & 0.014 \\
\hline 184 & 2 & 3 & 0.133 & 0.200 & 0.167 & 0.022 \\
\hline 185 & 3 & 3 & 0.200 & 0.200 & 0.200 & 0.031 \\
\hline 186 & 3 & 4 & 0.200 & 0.267 & 0.233 & 0.043 \\
\hline 187| & 2 & 4 & 0.133 & 0.267 & 0.200 & 0.031 \\
\hline 188 & 3 & 4) & 0.200 & 0.267 & 0.233 & 0.043 \\
\hline 189 & 3 & 3 & 0.200 & 0.200 & 0.200 & 0.031 \\
\hline 190 & 3 & 5 & 0.200 & 0.333 & 0.267 & 0.056 \\
\hline 191 & 3 & 4 & 0.200 & 0.267 & 0.233 & 0.043 \\
\hline 192 & 3 & 4 & 0.200 & 0.267 & 0.233 & 0.043 \\
\hline 193 & 3 & 3 & 0.200 & 0.200 & 0.200 & 0.031 \\
\hline 194 & 2 & 3 & 0.133 & 0.200 & 0.167 & 0.022 \\
\hline 195 & 3 & 3 & 0.200 & 0.200 & 0.200 & 0.031 \\
\hline 196 & 2 & 2 & 0.133 & 0.133 & 0.133 & 0.014 \\
\hline 197 & 3 & 4 & 0.200 & 0.267 & 0.233 & 0.043 \\
\hline 198 & 3 & 3 & 0.200 & 0.200 & 0.200 & 0.031 \\
\hline 199 & 4 & 4 & 0.267 & 0.267 & 0.267 & 0.056 \\
\hline 200 & 4 & 5 & 0.267 & 0.333 & .0 .300 & 0.071 \\
\hline 201 & 2 & 3 & 0.133 & 0.200 & 0.167 & 0.022 \\
\hline 202 & 3 & 3 & 0.200 & 0.200 & 0.200 & 0.031 \\
\hline 203 & 3 & 4 & 0.200 & 0.267 & 0.233 & 0.043 \\
\hline 204 & 4 & 4 & 0.267 & 0.267 & 0.267 & 0.056 \\
\hline 205 & 2.5 & 2.5 & 0.167 & 0.167 & 0.167 & 0.022 \\
\hline 206 & 3 & 3 & 0.200 & 0.200 & 0.200 & 0.031 \\
\hline 207 & 2 & 3 & 0.133 & 0.200 & 0.167 & 0.022 \\
\hline 208 & 3 & 4 & 0.200 & 0.267 & 0.233 & 0.043 \\
\hline 209 & 2.5 & 2.5 & 0.167 & 0.167 & 0.167 & 0.022 \\
\hline 210 & 3 & 4 & 0.200 & 0.267 & 0.233 & 0.043 \\
\hline 211 & 5 & 6 & 0.333 & 0.400 & 0.367 & 0.106 \\
\hline 212 & 1 & 1 & 0.067 & 0.067 & 0.067 & 0.003 \\
\hline 213 & 1 & 1 & 0.067 & 0.067 & 0.067 & 0.003 \\
\hline 214 & 1 & 2 & 0.067 & 0.133 & 0.100 & 0.008 \\
\hline
\end{tabular}




\begin{tabular}{|c|c|c|c|c|c|c|}
\hline Pore \# & $\begin{array}{l}D_{\min }(\mathrm{mm}) \\
+1-0.5 \mathrm{~mm}\end{array}$ & $\begin{array}{l}D_{\max }(\mathrm{mm}) \\
+/-0.5 \mathrm{~mm}\end{array}$ & $\begin{array}{c}D_{\min } \text { (um) } \\
+/-0.03 \text { um }\end{array}$ & $\begin{array}{c}D_{\max }(\mathrm{um}) \\
+/-0.03 \mathrm{um}\end{array}$ & $\mathbf{D}_{\text {avg }}$ & $A_{\text {avg }}$ \\
\hline \multicolumn{3}{|l|}{ Average } & 0.198 & 0260 & 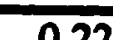 & \\
\hline \multicolumn{3}{|c|}{ Avearge Total etched area $\left(u^{2}{ }^{2}\right)$} & & & 0.26 & 9.660 \\
\hline \multicolumn{3}{|c|}{ Avearge Total etched area $\left(u^{2}{ }^{2}\right)$} & & 9.660 & & \\
\hline \multicolumn{3}{|c|}{ Total Surface Area $\left(u^{2}\right)$} & & 41.60 & & \\
\hline \multirow{2}{*}{\multicolumn{3}{|c|}{$\begin{array}{l}\text { Pore density (pores } / \mathrm{cm}^{2} \text { ) } \\
\text { Avg. Fractional Etched Area }\end{array}$}} & & 2.29 & & \\
\hline & & & & 0.232 & & \\
\hline
\end{tabular}




\begin{tabular}{ll|}
\hline Gas: & Oxygen \\
Flow Rate: & $92 \mathrm{mV} / \mathrm{min}$ \\
Photo Number: & 980110 \\
Magnification: & $15.1 \mathrm{~K}$ \\
& $20 \mathrm{KV}$ \\
& $135+1-4$ \\
\hline
\end{tabular}

\begin{tabular}{|r|r|r|r|r|r|r|}
\hline Pore \# & $\begin{array}{r}\mathrm{D}_{\min }(\mathrm{mm}) \\
+/-0.5 \mathrm{~mm}\end{array}$ & $\begin{array}{r}\mathrm{D}_{\max }(\mathrm{mm}) \\
+/-0.5 \mathrm{~mm}\end{array}$ & $\begin{array}{c}\mathrm{D}_{\min }(\mathrm{um}) \\
+1-0.03 \mathrm{um}\end{array}$ & $\begin{array}{r}\mathrm{D}_{\max }(\mathrm{um}) \\
+1-0.03 \mathrm{um}\end{array}$ & $\mathrm{D}_{\text {avg }}$ & $\mathrm{A}_{\text {avg }}$ \\
\hline 1 & 5 & 7 & 0.333 & 0.467 & 0.400 & 0.126 \\
2 & 2 & 5 & 0.133 & 0.333 & 0.233 & 0.043 \\
3 & 3 & 6 & 0.200 & 0.400 & 0.300 & 0.071 \\
4 & 2 & 2 & 0.133 & 0.133 & 0.133 & 0.014 \\
5 & 6 & 11 & 0.400 & 0.733 & 0.567 & 0.252 \\
6 & 3 & 4 & 0.200 & 0.267 & 0.233 & 0.043 \\
7 & 3 & 8 & 0.200 & 0.533 & 0.367 & 0.106 \\
8 & 1 & 7 & 0.067 & 0.467 & 0.267 & 0.056 \\
9 & 2 & 9 & 0.133 & 0.600 & 0.367 & 0.106 \\
10 & 7 & 17 & 0.467 & 1.133 & 0.800 & 0.503 \\
11 & 3 & 4 & 0.200 & 0.267 & 0.233 & 0.043 \\
12 & 3 & 3 & 0.200 & 0.200 & 0.200 & 0.031 \\
13 & 2 & 3 & 0.133 & 0.200 & 0.167 & 0.022 \\
14 & 3 & 7 & 0.200 & 0.467 & 0.333 & 0.087 \\
15 & 4 & 4 & 0.267 & 0.267 & 0.267 & 0.056 \\
16 & 3 & 4 & 0.200 & 0.267 & 0.233 & 0.043 \\
17 & 3 & 5 & 0.200 & 0.333 & 0.267 & 0.056 \\
18 & 3 & 6 & 0.200 & 0.400 & 0.300 & 0.071 \\
19 & 2 & 3.5 & 0.133 & 0.233 & 0.183 & 0.026 \\
20 & 4 & 4 & 0.267 & 0.267 & 0.267 & 0.056 \\
21 & 3 & 4 & 0.200 & 0.267 & 0.233 & 0.043 \\
22 & 3 & 3 & 0.200 & 0.200 & 0.200 & 0.031 \\
23 & 3 & 3 & 0.200 & 0.200 & 0.200 & 0.031 \\
24 & 3 & 4 & 0.200 & 0.267 & 0.233 & 0.043 \\
25 & 5 & 6 & 0.333 & 0.400 & 0.367 & 0.106 \\
26 & 3 & 8 & 0.200 & 0.533 & 0.367 & 0.106 \\
27 & 4 & 6 & 0.267 & 0.400 & 0.333 & 0.087 \\
28 & 2 & 2 & 0.133 & 0.133 & 0.133 & 0.014 \\
29 & 3 & 6 & 0.200 & 0.400 & 0.300 & 0.071 \\
30 & 2 & 11 & 0.133 & 0.733 & 0.433 & 0.147 \\
\hline
\end{tabular}




\begin{tabular}{|c|c|c|c|c|c|c|}
\hline Pore \# & $\begin{array}{r}D_{\min }(\mathrm{mm}) \\
+1-0.5 \mathrm{~mm} \\
\end{array}$ & $\begin{array}{l}D_{\max }(\mathrm{mm}) \\
+/-0.5 \mathrm{~mm}\end{array}$ & $\begin{array}{r}D_{\min } \text { (um) } \\
+/-0.03 \text { um } \\
\end{array}$ & $\begin{array}{r}D_{\max }(\mathrm{um}) \\
+/-0.03 \mathrm{um} \\
\end{array}$ & $D_{\text {avg }}$ & $A_{\text {avg }}$ \\
\hline 31 & 3 & 4 & 0.200 & 0.267 & 0.233 & 0.043 \\
\hline 32 & 2 & 4 & 0.133 & 0.267 & 0.200 & 0.031 \\
\hline 33 & 6 & 7 & 0.400 & 0.467 & 0.433 & 0.147 \\
\hline 34 & 2 & 2 & 0.133 & 0.133 & 0.133 & 0.014 \\
\hline 35 & 2 & 2 & 0.133 & 0.133 & 0.133 & 0.014 \\
\hline 36 & 2 & 2 & 0.133 & 0.133 & 0.133 & 0.014 \\
\hline 37 & 2 & 4 & 0.133 & 0.267 & 0.200 & 0.031 \\
\hline 38 & 2 & 2 & 0.133 & 0.133 & 0.133 & 0.014 \\
\hline 39 & 2 & 5 & 0.133 & 0.333 & 0.233 & 0.043 \\
\hline 40 & 3 & 4 & 0.200 & 0.267 & 0.233 & 0.043 \\
\hline 41 & 7 & 10 & 0.467 & 0.667 & 0.567 & 0.252 \\
\hline 42 & 2 & 3 & 0.133 & 0.200 & 0.167 & 0.022 \\
\hline 43 & 3 & 3 & 0.200 & 0.200 & 0.200 & 0.031 \\
\hline 44 & 4 & 4 & 0.267 & 0.267 & 0.267 & 0.056 \\
\hline 45 & 2 & 3 & 0.133 & 0.200 & 0.167 & 0.022 \\
\hline 46 & 5 & 7 & 0.333 & 0.467 & 0.400 & 0.126 \\
\hline 47 & 3 & 4 & 0.200 & 0.267 & 0.233 & 0.043 \\
\hline 48 & 4 & 4 & 0.267 & 0.267 & 0.267 & 0.056 \\
\hline 49 & 3 & 3 & 0.200 & 0.200 & 0.200 & 0.031 \\
\hline 50 & 1 & 1 & 0.067 & 0.067 & 0.067 & 0.003 \\
\hline 51 & 1 & 1 & 0.067 & 0.067 & 0.067 & 0.003 \\
\hline 52 & 3 & 4 & 0.200 & 0.267 & 0.233 & 0.043 \\
\hline 53 & 3 & 3 & 0.200 & 0.200 & 0.200 & 0.031 \\
\hline 54 & 6 & 6 & 0.400 & 0.400 & 0.400 & 0.126 \\
\hline 55 & 2 & 3 & 0.133 & 0.200 & 0.167 & 0.022 \\
\hline 56 & 3 & 3 & 0.200 & 0.200 & 0.200 & 0.031 \\
\hline 57 & 3 & 11 & 0.200 & 0.733 & 0.467 & 0.171 \\
\hline 58 & 2 & 3 & 0.133 & 0.200 & 0.167 & 0.022 \\
\hline 59 & 3 & 4 & 0.200 & 0.267 & 0.233 & 0.043 \\
\hline 60 & 4 & 7 & 0.267 & 0.467 & 0.367 & 0.106 \\
\hline 61 & 4 & 4 & 0.267 & 0.267 & 0.267 & 0.056 \\
\hline 62 & 3 & 3 & 0.200 & 0.200 & 0.200 & 0.031 \\
\hline 63 & 4 & 4.5 & 0.267 & 0.300 & 0.283 & 0.063 \\
\hline 64 & 5 & 5 & 0.333 & 0.333 & 0.333 & 0.087 \\
\hline 65 & 4 & 5 & 0.267 & 0.333 & 0.300 & 0.071 \\
\hline 66 & 2.5 & 4 & 0.167 & 0.267 & 0.217 & 0.037 \\
\hline 67 & 4 & 4 & 0.267 & 0.267 & 0.267 & 0.056 \\
\hline
\end{tabular}




\begin{tabular}{|c|c|c|c|c|c|c|}
\hline Pore \# & \begin{tabular}{|}
$D_{\min }(\mathrm{mm})$ \\
$+1-0.5 \mathrm{~mm}$ \\
\end{tabular} & $\begin{array}{l}D_{\max }(\mathrm{mm}) \\
+/-0.5 \mathrm{~mm} \\
\end{array}$ & $\begin{array}{r}D_{\min }(\mathrm{um}) \\
+/-0.03 \mathrm{um} \\
\end{array}$ & \begin{tabular}{|r|}
$D_{\max }$ (um) \\
$+/-0.03$ um \\
\end{tabular} & $D_{\text {avg }}$ & $\mathbf{A}_{\text {avg }}$ \\
\hline 68 & 3 & 3 & 0.200 & 0.200 & 0.200 & 0.031 \\
\hline 69 & 2 & 5 & 0.133 & 0.333 & 0.233 & 0.043 \\
\hline 70 & 3 & 5 & 0.200 & 0.333 & 0.267 & 0.056 \\
\hline 71 & 3 & 7 & 0.200 & 0.467 & 0.333 & 0.087 \\
\hline 72 & 3 & 3 & 0.200 & 0.200 & 0.200 & 0.031 \\
\hline 73 & 3 & 4 & 0.200 & 0.267 & 0.233 & 0.043 \\
\hline 74 & 3 & 5 & 0.200 & 0.333 & 0.267 & 0.056 \\
\hline 75 & 3 & 4 & 0.200 & 0.267 & 0.233 & 0.043 \\
\hline 76 & 11 & 11 & 0.733 & 0.733 & 0.733 & 0.422 \\
\hline 77 & 3 & 4 & 0.200 & 0.267 & 0.233 & 0.043 \\
\hline 78 & 3 & 5 & 0.200 & 0.333 & 0.267 & 0.056 \\
\hline 79 & 2 & 2 & 0.133 & 0.133 & 0.133 & 0.014 \\
\hline 80 & 3 & 3 & 0.200 & 0.200 & 0.200 & 0.031 \\
\hline 81 & 4 & 4 & 0.267 & 0.267 & 0.267 & 0.056 \\
\hline 82 & 4 & 7 & 0.267 & 0.467 & 0.367 & 0.106 \\
\hline 83 & 3 & 8 & 0.200 & 0.533 & 0.367 & 0.106 \\
\hline 84 & 4 & 5 & 0.267 & 0.333 & 0.300 & 0.071 \\
\hline 85 & 4 & 4 & 0.267 & 0.267 & 0.267 & 0.056 \\
\hline 86 & 3 & 3 & 0.200 & 0.200 & 0.200 & 0.031 \\
\hline 87 & 3 & 5 & 0.200 & 0.333 & 0.267 & 0.056 \\
\hline 88 & 4 & 5 & 0.267 & 0.333 & 0.300 & 0.071 \\
\hline 89 & 2 & 2 & 0.133 & 0.133 & 0.133 & 0.014 \\
\hline 90 & 2 & 2 & 0.133 & 0.133 & 0.133 & 0.014 \\
\hline 91 & 2 & 4) & 0.133 & 0.267 & 0.200 & 0.031 \\
\hline 92 & 2 & 3 & 0.133 & 0.200 & 0.167 & 0.022 \\
\hline 93 & 3 & 3 & 0.200 & 0.200 & 0.200 & 0.031 \\
\hline 94 & 4 & 4 & 0.267 & 0.267 & 0.267 & 0.056 \\
\hline 95 & 5 & 5 & 0.333 & 0.333 & 0.333 & 0.087 \\
\hline 96 & 4 & 4 & 0.267 & 0.267 & 0.267 & 0.056 \\
\hline 97 & 1 & 1 & 0.067 & 0.067 & 0.067 & 0.003 \\
\hline 98 & 2 & 2 & 0.133 & 0.133 & 0.133 & 0.014 \\
\hline 99 & 2 & 3 & 0.133 & 0.200 & 0.167 & 0.022 \\
\hline 100 & 6 & 9 & 0.400 & 0.600 & 0.500 & 0.196 \\
\hline 101 & 2 & 2 & 0.133 & 0.133 & 0.133 & 0.014 \\
\hline 102 & 3 & 4 & 0.200 & 0.267 & 0.233 & 0.043 \\
\hline 103 & 4 & 9 & 0.267 & 0.600 & 0.433 & 0.147 \\
\hline 104] & 5 & 5 & 0.333 & 0.333 & 0.333 & 0.087 \\
\hline
\end{tabular}




\begin{tabular}{|c|c|c|c|c|c|c|}
\hline Pore \# & $\begin{array}{l}D_{\min }(\mathrm{mm}) \\
+/-0.5 \mathrm{~mm}\end{array}$ & $\begin{array}{l}D_{\operatorname{mex}}(\mathrm{mm}) \\
+/-0.5 \mathrm{~mm}\end{array}$ & $\begin{array}{c}D_{\min }(\mathrm{um}) \\
+/-0.03 \mathrm{um} \\
\end{array}$ & $\begin{array}{r}D_{\max }(\mathrm{um}) \\
+/-0.03 \mathrm{um} \\
\end{array}$ & $D_{\text {avg }}$ & $A_{\text {avg }}$ \\
\hline 105 & 5 & 6 & 0.333 & 0.400 & 0.367 & 0.106 \\
\hline 106 & 3 & 3 & 0.200 & 0.200 & 0.200 & 0.031 \\
\hline 107 & 3 & 4 & 0.200 & 0.267 & 0.233 & 0.043 \\
\hline 108 & 3 & 4 & 0.200 & 0.267 & 0.233 & 0.043 \\
\hline 109 & 2 & 3 & 0.133 & 0.200 & 0.167 & 0.022 \\
\hline 110 & 3 & 5 & 0.200 & 0.333 & 0.267 & 0.056 \\
\hline 111 & 8 & 14 & 0.533 & 0.933 & 0.733 & 0.422 \\
\hline 112 & 2 & 2 & 0.133 & 0.133 & 0.133 & 0.014 \\
\hline 113 & 3 & 3 & 0.200 & 0.200 & 0.200 & 0.031 \\
\hline 114 & 3 & 3 & 0.200 & 0.200 & 0.200 & 0.031 \\
\hline 115 & 4 & 4 & 0.267 & 0.267 & 0.267 & 0.056 \\
\hline 116 & 3 & 5 & 0.200 & 0.333 & 0.267 & 0.056 \\
\hline 117 & 3 & 4) & 0.200 & 0.267 & 0.233 & 0.043 \\
\hline 118 & 5 & 13 & 0.333 & 0.867 & 0.600 & 0.283 \\
\hline 119 & 5 & 5 & 0.333 & 0.333 & 0.333 & 0.087 \\
\hline 120 & 5 & 5 & 0.333 & 0.333 & 0.333 & 0.087 \\
\hline 121 & 3 & 3 & 0.200 & 0.200 & 0.200 & 0.031 \\
\hline 122 & 4 & 6 & 0.267 & 0.400 & 0.333 & 0.087 \\
\hline 123 & 3 & 3 & 0.200 & 0.200 & 0.200 & 0.031 \\
\hline 124 & 3 & 3 & 0.200 & 0.200 & 0.200 & 0.031 \\
\hline 125 & 4 & 4 & 0.267 & 0.267 & 0.267 & 0.056 \\
\hline 126 & 5 & 5 & 0.333 & 0.333 & 0.333 & 0.087 \\
\hline 127 & 2 & 3 & 0.133 & 0.200 & 0.167 & 0.022 \\
\hline 128 & 3 & 3 & 0.200 & 0.200 & 0.200 & 0.031 \\
\hline 129 & 4 & 6 & 0.267 & 0.400 & 0.333 & 0.087 \\
\hline 130 & 2 & 3 & 0.133 & 0.200 & 0.167 & 0.022 \\
\hline 131 & 2 & 2 & 0.133 & 0.133 & 0.133 & 0.014 \\
\hline 132 & 3 & 3 & 0.200 & 0.200 & 0.200 & 0.031 \\
\hline 133 & 2 & 5 & 0.133 & 0.333 & 0.233 & 0.043 \\
\hline 134 & 2 & 2 & 0.133 & 0.133 & 0.133 & 0.014 \\
\hline 135 & 3 & 3 & 0.200 & 0.200 & 0.200 & 0.031 \\
\hline \multirow{2}{*}{\multicolumn{3}{|c|}{$\begin{array}{l}\text { Average } \\
\text { Avearge Total etched area }\left(\mathrm{um}^{2}\right)\end{array}$}} & 0.217 & 0.309 & 0.263 & \\
\hline & & & & & & 8.902 \\
\hline \multicolumn{3}{|c|}{ Avearge Total etched area(um²) } & & 8.902 & & \\
\hline \multicolumn{3}{|c|}{ Total Surface Area (um²) } & & 41.60 & & \\
\hline \multicolumn{3}{|c|}{$\begin{array}{l}\text { Pore density ( pores } / \mathrm{cm}^{2} \text { ) } \\
\text { Avg. Fractional Etched Area }\end{array}$} & & $\begin{array}{r}1.44 \\
0.214\end{array}$ & & \\
\hline
\end{tabular}




\begin{tabular}{|ll|}
\hline Gas: & Helium \\
Flow Rate: & $25 \mathrm{mV} / \mathrm{min}$ \\
Photo Number: & 980100 \\
Magnification: & $15 \mathrm{~K}$ \\
& $20 \mathrm{KV}$ \\
& $668+/-15$ \\
\hline
\end{tabular}

\begin{tabular}{|c|c|c|c|c|c|c|}
\hline Pore \# & $\begin{array}{l}D_{\min }(\mathrm{mm}) \\
+/-0.5 \mathrm{~mm} \\
\end{array}$ & $\begin{array}{r}D_{\max }(\mathrm{mm}) \\
+1-0.5 \mathrm{~mm}\end{array}$ & $\begin{array}{c}D_{\min }(\mathrm{um}) \\
+/-0.03 \mathrm{um}\end{array}$ & \begin{tabular}{|c|}
$D_{\max }(\mathrm{um})$ \\
$+/-0.03 \mathrm{um}$ \\
\end{tabular} & $D_{\text {avg }}$ & $A_{\text {avg }}$ \\
\hline 1 & 1 & 1 & 0.067 & 0.067 & \begin{tabular}{|c|}
0.067 \\
\end{tabular} & 0.003 \\
\hline 2 & 2 & 2 & 0.133 & 0.133 & 0.133 & 0.014 \\
\hline 3 & 1 & 1 & 0.067 & 0.067 & 0.067 & 0.003 \\
\hline 4 & 2 & 3 & 0.133 & 0.200 & 0.167 & 0.022 \\
\hline 5 & 2 & 3 & 0.133 & 0.200 & 0.167 & 0.022 \\
\hline 6 & 2 & 3 & 0.133 & 0.200 & 0.167 & 0.022 \\
\hline 7 & 2 & 3 & 0.133 & 0.200 & 0.167 & 0.022 \\
\hline 8 & 15 & 3 & 1.000 & 0.200 & 0.600 & 0.283 \\
\hline 9 & 2 & 3 & 0.133 & 0.200 & 0.167 & 0.022 \\
\hline 10 & 1 & 2 & 0.067 & 0.133 & 0.100 & 0.008 \\
\hline 11 & 2 & 2 & 0.133 & 0.133 & 0.133 & 0.014 \\
\hline 12 & 2 & 4 & 0.133 & 0.267 & 0.200 & 0.031 \\
\hline 13 & 3 & 4 & 0.200 & 0.267 & 0.233 & 0.043 \\
\hline 14 & 2 & 5 & 0.133 & 0.333 & 0.233 & 0.043 \\
\hline 15 & 2 & 2 & 0.133 & 0.133 & 0.133 & 0.014 \\
\hline 16 & 2 & 2 & 0.133 & 0.133 & 0.133 & 0.014 \\
\hline 17 & 2 & 3 & 0.133 & 0.200 & 0.167 & 0.022 \\
\hline 18 & 2 & 3 & 0.133 & 0.200 & 0.167 & 0.022 \\
\hline 19 & 2 & 3 & 0.133 & 0.200 & 0.167 & 0.022 \\
\hline 20 & 15 & 3 & 1.000 & 0.200 & 0.600 & 0.283 \\
\hline 21 & 2 & 4 & 0.133 & 0.267 & 0.200 & 0.031 \\
\hline 22 & 2 & 5 & 0.133 & 0.333 & 0.233 & 0.043 \\
\hline 23 & 2 & 4 & 0.133 & 0.267 & 0.200 & 0.031 \\
\hline 24 & 2 & 3 & 0.133 & 0.200 & 0.167 & 0.022 \\
\hline 25 & 2 & 3 & 0.133 & 0.200 & 0.167 & 0.022 \\
\hline 26 & 2 & 2 & 0.133 & 0.133 & 0.133 & 0.014 \\
\hline 27 & 2 & 2 & 0.133 & 0.133 & 0.133 & 0.014 \\
\hline 28 & 2 & 2 & 0.133 & 0.133 & 0.133 & 0.014 \\
\hline 29 & 2 & 4) & 0.133 & 0.267 & 0.200 & 0.031 \\
\hline 30 & 31 & 12 & 0.200 & 0.800 & 0.500 & 0.196 \\
\hline
\end{tabular}




\begin{tabular}{|r|r|r|r|r|r|r|}
\hline Pore \# & $\mathrm{D}_{\min }(\mathrm{mm})$ & $\mathrm{D}_{\max }(\mathrm{mm})$ & $\mathrm{D}_{\min }(\mathrm{um})$ & $\mathrm{D}_{\max }(\mathrm{um})$ & $\mathrm{D}_{\text {avg }}$ & $\mathrm{A}_{\text {avg }}$ \\
\hline$+1-0.5 \mathrm{~mm}$ & $+/-0.5 \mathrm{~mm}$ & $+1-0.03 \mathrm{um}$ & $+1-0.03 \mathrm{um}$ & & \\
\hline 31 & 1 & 1 & 0.067 & 0.067 & 0.067 & 0.003 \\
32 & 2 & 4 & 0.133 & 0.267 & 0.200 & 0.031 \\
33 & 1.5 & 4 & 0.100 & 0.267 & 0.183 & 0.026 \\
34 & 2 & 3 & 0.133 & 0.200 & 0.167 & 0.022 \\
35 & 2 & 2 & 0.133 & 0.133 & 0.133 & 0.014 \\
36 & 1.5 & 4 & 0.100 & 0.267 & 0.183 & 0.026 \\
37 & 2 & 2 & 0.133 & 0.133 & 0.133 & 0.014 \\
38 & 0.5 & 0.5 & 0.033 & 0.033 & 0.033 & 0.001 \\
39 & 2 & 2 & 0.133 & 0.133 & 0.133 & 0.014 \\
40 & 2 & 3 & 0.133 & 0.200 & 0.167 & 0.022 \\
41 & 2 & 3 & 0.133 & 0.200 & 0.167 & 0.022 \\
42 & 0.5 & 1 & 0.033 & 0.067 & 0.050 & 0.002 \\
43 & 1 & 9 & 0.067 & 0.600 & 0.333 & 0.087 \\
44 & 1 & 4 & 0.067 & 0.267 & 0.167 & 0.022 \\
45 & 2 & 3 & 0.133 & 0.200 & 0.167 & 0.022 \\
46 & 2 & 3 & 0.133 & 0.200 & 0.167 & 0.022 \\
47 & 2 & 3 & 0.133 & 0.200 & 0.167 & 0.022 \\
48 & 2 & 7 & 0.133 & 0.467 & 0.300 & 0.071 \\
49 & 2 & 3 & 0.133 & 0.200 & 0.167 & 0.022 \\
50 & 2 & 5 & 0.133 & 0.333 & 0.233 & 0.043 \\
51 & 3 & 5 & 0.200 & 0.333 & 0.267 & 0.056 \\
52 & 5 & 10 & 0.333 & 0.667 & 0.500 & 0.196 \\
53 & 2 & 4 & 0.133 & 0.267 & 0.200 & 0.031 \\
54 & 2 & 3 & 0.133 & 0.200 & 0.167 & 0.022 \\
55 & 2 & 3 & 0.200 & 0.200 & 0.200 & 0.031 \\
56 & 2 & 5 & 0.133 & 0.333 & 0.233 & 0.043 \\
57 & 1.5 & 3 & 0.100 & 0.200 & 0.150 & 0.018 \\
58 & 2 & 3 & 0.133 & 0.200 & 0.167 & 0.022 \\
59 & 2 & 3 & 0.133 & 0.200 & 0.167 & 0.022 \\
60 & 2 & 2 & 0.133 & 0.133 & 0.133 & 0.014 \\
61 & 2 & 3.5 & 0.133 & 0.233 & 0.183 & 0.026 \\
62 & 1.5 & 6 & 0.100 & 0.400 & 0.250 & 0.049 \\
63 & 2 & 6 & 0.133 & 0.400 & 0.267 & 0.056 \\
64 & 2 & 4 & 0.133 & 0.267 & 0.200 & 0.031 \\
65 & 1 & 2 & 0.067 & 0.133 & 0.100 & 0.008 \\
66 & 1 & 2 & 0.067 & 0.133 & 0.100 & 0.008 \\
67 & 1 & 1.5 & 0.067 & 0.100 & 0.083 & 0.005 \\
\hline & & & & & \\
\hline
\end{tabular}




\begin{tabular}{|c|c|c|c|c|c|c|}
\hline Pore \# & $\begin{array}{r}D_{\min }(\mathrm{mm}) \\
+1-0.5 \mathrm{~mm}\end{array}$ & \begin{tabular}{|}
$D_{\max }(\mathrm{mm})$ \\
$+/-0.5 \mathrm{~mm}$ \\
\end{tabular} & $\begin{array}{r}D_{\min }(\mathrm{um}) \\
+/-0.03 \text { um } \\
\end{array}$ & \begin{tabular}{|}
$D_{\max }(\mathrm{um})$ \\
$+/-0.03 \mathrm{um}$ \\
\end{tabular} & $D_{\text {avg }}$ & $A_{\text {avg }}$ \\
\hline 68 & 2 & 2 & 0.133 & 0.133 & 0.133 & 0.014 \\
\hline 69 & 2 & 3 & 0.133 & 0.200 & 0.167 & 0.022 \\
\hline 70 & 2 & 3 & 0.133 & 0.200 & 0.167 & 0.022 \\
\hline 71 & 1 & 3 & 0.067 & 0.200 & 0.133 & 0.014 \\
\hline 72 & 1 & 2 & 0.067 & 0.133 & 0.100 & 0.008 \\
\hline 73 & 2 & 3 & 0.133 & 0.200 & 0.167 & 0.022 \\
\hline 74 & 2 & 2 & 0.133 & 0.133 & 0.133 & 0.014 \\
\hline 75 & 0.5 & 6 & 0.033 & 0.400 & 0.217 & 0.037 \\
\hline 76 & 2 & 9 & 0.133 & 0.600 & 0.367 & 0.106 \\
\hline 77 & 2 & 7 & 0.133 & 0.467 & 0.300 & 0.071 \\
\hline 78 & 1.5 & 2 & 0.100 & 0.133 & 0.117 & 0.011 \\
\hline 79 & 2 & 4 & 0.133 & 0.267 & 0.200 & 0.031 \\
\hline 80 & 2 & 3 & 0.133 & 0.200 & 0.167 & 0.022 \\
\hline 81 & 1 & 3 & 0.067 & 0.200 & 0.133 & 0.014 \\
\hline 82 & 2 & 5 & 0.133 & 0.333 & 0.233 & 0.043 \\
\hline 83 & 1 & 5 & 0.067 & 0.333 & 0.200 & 0.031 \\
\hline 84 & 3 & 6 & 0.200 & 0.400 & 0.300 & 0.071 \\
\hline 85 & 2 & 5 & 0.133 & 0.333 & 0.233 & 0.043 \\
\hline 86 & 2 & 4 & 0.133 & 0.267 & 0.200 & 0.031 \\
\hline 87 & 3 & 4 & 0.200 & 0.267 & 0.233 & 0.043 \\
\hline 88 & 1 & 1 & 0.067 & 0.067 & 0.067 & 0.003 \\
\hline 89 & 2 & 3 & 0.133 & 0.200 & 0.167 & 0.022 \\
\hline 90 & 1 & 2 & 0.067 & 0.133 & 0.100 & 0.008 \\
\hline 91 & 3 & 4) & 0.200 & 0.267 & 0.233 & 0.043 \\
\hline 92 & 2 & 2 & 0.133 & 0.133 & 0.133 & 0.014 \\
\hline 93 & 2 & 4 & 0.133 & 0.267 & 0.200 & 0.031 \\
\hline 94 & 2 & 4 & 0.133 & 0.267 & 0.200 & 0.031 \\
\hline 95 & 1 & 3 & 0.067 & 0.200 & 0.133 & 0.014 \\
\hline 96 & 1 & 2 & 0.067 & 0.133 & 0.100 & 0.008 \\
\hline 97 & 2 & 4 & 0.133 & 0.267 & 0.200 & 0.031 \\
\hline 98 & 1 & 1 & 0.067 & 0.067 & 0.067 & 0.003 \\
\hline 99 & 1 & 2 & 0.067 & 0.133 & 0.100 & 0.008 \\
\hline 100 & 2 & 4 & 0.133 & 0.267 & 0.200 & 0.031 \\
\hline 101 & 2 & 8 & 0.133 & 0.533 & 0.333 & 0.087 \\
\hline 102 & 3 & 3 & 0.200 & 0.200 & 0.200 & 0.031 \\
\hline 103 & 2 & 3 & 0.133 & 0.200 & 0.167 & 0.022 \\
\hline 104 & 2 & 3 & 0.133 & 0.200 & 0.167 & 0.022 \\
\hline
\end{tabular}




\begin{tabular}{|c|c|c|c|c|c|c|}
\hline Pore \# & $\begin{array}{l}D_{\min }(\mathrm{mm}) \\
+/-0.5 \mathrm{~mm}\end{array}$ & $\begin{array}{l}D_{\max }(\mathrm{mm}) \\
+/-0.5 \mathrm{~mm}\end{array}$ & $\begin{array}{r}D_{\min } \text { (um) } \\
+/-0.03 \text { um } \\
\end{array}$ & \begin{tabular}{|}
$D_{\max }$ (um) \\
$+/-0.03$ um
\end{tabular} & $D_{\text {avg }}$ & $A_{\text {avg }}$ \\
\hline 105 & 1 & 1 & 0.067 & 0.067 & 0.067 & 0.003 \\
\hline 106 & 1 & 2 & 0.067 & 0.133 & 0.100 & 0.008 \\
\hline 107 & 1 & 1 & 0.067 & 0.067 & 0.067 & 0.003 \\
\hline 108 & 1 & 1 & 0.067 & 0.067 & 0.067 & 0.003 \\
\hline 109 & 2 & 7 & 0.133 & 0.467 & 0.300 & 0.071 \\
\hline 110 & 3 & 3 & 0.200 & 0.200 & 0.200 & 0.031 \\
\hline 111 & 1 & 2 & 0.067 & 0.133 & 0.100 & 0.008 \\
\hline 112 & 3 & 3 & 0.200 & 0.200 & 0.200 & 0.031 \\
\hline 113 & 2.5 & 3 & 0.167 & 0.200 & 0.183 & 0.026 \\
\hline 114 & 3 & 3 & 0.200 & 0.200 & 0.200 & 0.031 \\
\hline 115 & 2 & 3 & 0.133 & 0.200 & 0.167 & 0.022 \\
\hline 116 & 2 & 4 & 0.133 & 0.267 & 0.200 & 0.031 \\
\hline 117 & 3 & 3 & 0.200 & 0.200 & 0.200 & 0.031 \\
\hline 118 & 2 & 3 & 0.133 & 0.200 & 0.167 & 0.022 \\
\hline 119 & 1.5 & 3 & 0.100 & 0.200 & 0.150 & 0.018 \\
\hline 120 & 1 & 2 & 0.067 & 0.133 & 0.100 & 0.008 \\
\hline 121 & 3 & 3 & 0.200 & 0.200 & 0.200 & 0.031 \\
\hline 122 & 2 & 6 & 0.133 & 0.400 & 0.267 & 0.056 \\
\hline 123 & 0.5 & 0.5 & 0.033 & 0.033 & 0.033 & 0.001 \\
\hline 124 & 2 & 3 & 0.133 & 0.200 & 0.167 & 0.022 \\
\hline 125 & 2 & 4 & 0.133 & 0.267 & 0.200 & 0.031 \\
\hline 126 & 2.5 & 3 & 0.167 & 0.200 & 0.183 & 0.026 \\
\hline 127 & 3 & 5 & 0.200 & 0.333 & 0.267 & 0.056 \\
\hline 128 & 2 & 4 & 0.133 & 0.267 & 0.200 & 0.031 \\
\hline 129 & 2 & 4 & 0.133 & 0.267 & 0.200 & 0.031 \\
\hline 130 & 2 & 3 & 0.133 & 0.200 & 0.167 & 0.022 \\
\hline 131 & 2 & 3 & 0.133 & 0.200 & 0.167 & 0.022 \\
\hline 132 & 4 & 5 & 0.267 & 0.333 & 0.300 & 0.071 \\
\hline 133 & 2 & 5 & 0.133 & 0.333 & 0.233 & 0.043 \\
\hline 134 & 2 & 4 & 0.133 & 0.267 & 0.200 & 0.031 \\
\hline 135 & 4 & 4 & 0.267 & 0.267 & 0.267 & 0.056 \\
\hline 136 & 3 & 4 & 0.200 & 0.267 & 0.233 & 0.043 \\
\hline 137 & 2 & 5 & 0.133 & 0.333 & 0.233 & 0.043 \\
\hline 138 & 2 & 5 & 0.133 & 0.333 & 0.233 & 0.043 \\
\hline 139 & 2 & 4 & 0.133 & 0.267 & 0.200 & 0.031 \\
\hline 140 & 1 & 2 & 0.067 & 0.133 & 0.100 & 0.008 \\
\hline 141 & 4 & 4 & 0.267 & 0.267 & 0.267 & 0.056 \\
\hline
\end{tabular}




\begin{tabular}{|c|c|c|c|c|c|c|}
\hline Pore \# & \begin{tabular}{|l|}
$D_{\min }(\mathrm{mm})$ \\
$+/-0.5 \mathrm{~mm}$ \\
\end{tabular} & $\begin{array}{l}D_{\max }(\mathrm{mm}) \\
+1-0.5 \mathrm{~mm}\end{array}$ & \begin{tabular}{|c|}
$D_{\min }(\mathrm{um})$ \\
$+/-0.03 \mathrm{um}$
\end{tabular} & \begin{tabular}{|r|}
$D_{\max }$ (um) \\
$+/-0.03$ um \\
\end{tabular} & $\mathrm{D}_{\text {avg }}$ & $\overline{A_{\text {avg }}}$ \\
\hline 142 & 2 & 4 & 0.133 & 0.267 & 0.200 & 0.03 \\
\hline 143 & 2 & 5 & 0.133 & 0.333 & 0.233 & 0.04 \\
\hline 144 & 2 & 4 & 0.133 & 0.267 & 0.200 & 0.031 \\
\hline 145 & 2 & 4 & 0.133 & 0.267 & 0.200 & 0.031 \\
\hline 146 & 2 & 3 & 0.133 & 0.200 & 0.167 & 0.022 \\
\hline 147 & 1.5 & 3 & 0.100 & 0.200 & 0.150 & 0.018 \\
\hline 148 & 2 & 4 & 0.133 & 0.267 & 0.200 & 0.031 \\
\hline 149 & 2 & 3 & 0.133 & 0.200 & 0.167 & 0.022 \\
\hline 150 & 2 & 2 & 0.133 & 0.133 & 0.133 & 0.014 \\
\hline 151 & 2 & 3 & 0.133 & 0.200 & 0.167 & 0.022 \\
\hline 152 & 2 & 3 & 0.133 & 0.200 & 0.167 & 0.022 \\
\hline 153 & 3 & 3 & 0.200 & 0.200 & 0.200 & 0.031 \\
\hline 154 & 3 & 7 & 0.200 & 0.467 & 0.333 & 0.087 \\
\hline 155 & 2 & 4 & 0.133 & 0.267 & 0.200 & 0.031 \\
\hline 156 & 3 & 5 & 0.200 & 0.333 & 0.267 & 0.056 \\
\hline 157 & 1 & 3 & 0.067 & 0.200 & 0.133 & 0.014 \\
\hline 158 & 1 & 4 & 0.067 & 0.267 & 0.167 & 0.022 \\
\hline 159 & 1 & 3 & 0.067 & 0.200 & 0.133 & 0.014 \\
\hline 160 & 2 & 3 & 0.133 & 0.200 & 0.167 & 0.022 \\
\hline 161 & 1 & 3 & 0.067 & 0.200 & 0.133 & 0.014 \\
\hline 162 & 1 & 3 & 0.067 & 0.200 & 0.133 & 0.014 \\
\hline 163 & 1.5 & 3 & 0.100 & 0.200 & 0.150 & 0.018 \\
\hline 164 & 2 & 2 & 0.133 & 0.133 & 0.133 & 0.014 \\
\hline 165 & 2.5 & 4 & 0.167 & 0.267 & 0.217 & 0.037 \\
\hline 166 & 1 & 4 & 0.067 & 0.267 & 0.167 & 0.022 \\
\hline 167 & 2 & 3 & 0.133 & 0.200 & 0.167 & 0.022 \\
\hline \multirow{2}{*}{\multicolumn{3}{|c|}{$\begin{array}{l}\text { Average } \\
\text { Avearge Total etched area }\left(\mathrm{um}^{2}\right)\end{array}$}} & 0.138 & 0.231 & 0.185 & \\
\hline & & & & & & 5.381 \\
\hline \multicolumn{3}{|c|}{ Avearge Total etched area $\left(\mathrm{um}^{2}\right)$} & & 5.381 & & \\
\hline \multicolumn{3}{|c|}{ Total Surface Area (um²) } & & 10.40 & & \\
\hline \multicolumn{3}{|c|}{$\begin{array}{l}\text { Pore density ( pores } / \mathrm{cm}^{2} \text { ) } \\
\text { Avg. Fractional Etched Area }\end{array}$} & & $\begin{array}{r}7.14 \\
0.517\end{array}$ & & \\
\hline
\end{tabular}




\begin{tabular}{ll|}
\hline Gas: & Helium \\
Flow Rate: & $100 \mathrm{ml} / \mathrm{min}$ \\
Photo Number: & 980103 \\
Magnification: & $14.9 \mathrm{~K}$ \\
& $20 \mathrm{KV}$ \\
Number of Pores: & $1216+/-20$ \\
\hline
\end{tabular}

\begin{tabular}{|c|c|c|c|c|c|c|}
\hline Pore \# & $\begin{array}{l}D_{\min }(\mathrm{mm}) \\
+/-0.5 \mathrm{~mm}\end{array}$ & $\begin{array}{l}D_{\max }(\mathrm{mm}) \\
+/-0.5 \mathrm{~mm}\end{array}$ & $\begin{array}{r}D_{\min } \text { (um) } \\
+/-0.03 \text { um } \\
\end{array}$ & \begin{tabular}{|c|}
$D_{\max }(\mathrm{um})$ \\
$+/-0.03 \mathrm{um}$
\end{tabular} & $D_{\text {avg }}$ & $A_{\text {avg }}$ \\
\hline 1 & 2 & 2 & 0.133 & 0.133 & 0.133 & 0.014 \\
\hline 2 & 2 & 3 & 0.133 & 0.200 & 0.167 & 0.022 \\
\hline 3 & 1 & 2 & 0.067 & 0.133 & 0.100 & 0.008 \\
\hline 4 & 1 & 1 & 0.067 & 0.067 & 0.067 & 0.003 \\
\hline 5 & 1 & 1.5 & 0.067 & 0.100 & 0.083 & 0.005 \\
\hline 6 & 1 & 1 & 0.067 & 0.067 & 0.067 & 0.003 \\
\hline 7 & 2 & 2 & 0.133 & 0.133 & 0.133 & 0.014 \\
\hline 8 & 2 & 3 & 0.133 & 0.200 & 0.167 & 0.022 \\
\hline 9 & 2 & 3 & 0.133 & 0.200 & 0.167 & 0.022 \\
\hline 10 & 3 & 3 & 0.200 & 0.200 & 0.200 & 0.031 \\
\hline 11 & 2 & 3 & 0.133 & 0.200 & 0.167 & 0.022 \\
\hline 12 & 3 & 3 & 0.200 & 0.200 & 0.200 & 0.031 \\
\hline 13 & 2 & 2 & 0.133 & 0.133 & 0.133 & 0.014 \\
\hline 14 & 1 & 1 & 0.067 & 0.067 & 0.067 & 0.003 \\
\hline 15 & 1.5 & 1.5 & 0.100 & 0.100 & 0.100 & 0.008 \\
\hline 16 & 2 & 2 & 0.133 & 0.133 & 0.133 & 0.014 \\
\hline 17 & 2 & 2 & 0.133 & 0.133 & 0.133 & 0.014 \\
\hline 18 & 2 & 2.5 & 0.133 & 0.167 & 0.150 & 0.018 \\
\hline 19 & 1 & 3 & 0.067 & 0.200 & 0.133 & 0.014 \\
\hline 20 & 2 & 2 & 0.133 & 0.133 & 0.133 & 0.014 \\
\hline 21 & 2 & 3 & 0.133 & 0.200 & 0.167 & 0.022 \\
\hline 22 & 2 & 2.5 & 0.133 & 0.167 & 0.150 & 0.018 \\
\hline 23 & 2 & 2 & 0.133 & 0.133 & 0.133 & 0.014 \\
\hline 24 & 2 & 3 & 0.133 & 0.200 & 0.167 & 0.022 \\
\hline 25 & 3 & 3 & 0.200 & 0.200 & 0.200 & 0.031 \\
\hline 26 & 1 & 1.5 & 0.067 & 0.100 & 0.083 & 0.005 \\
\hline 27 & 2 & 3 & 0.133 & 0.200 & 0.167 & 0.022 \\
\hline 28 & 2 & 2 & 0.133 & 0.133 & 0.133 & 0.014 \\
\hline 29 & 1 & 3 & 0.067 & 0.200 & 0.133 & 0.014 \\
\hline 30 & $1]$ & 2 & 0.067 & 0.133 & 0.100 & 0.008 \\
\hline
\end{tabular}




\begin{tabular}{|c|c|c|c|c|c|c|}
\hline Pore \# & $\begin{array}{r}D_{\min }(\mathrm{mm}) \\
+/-0.5 \mathrm{~mm}\end{array}$ & $\begin{array}{l}D_{\max }(\mathrm{mm}) \\
+/-0.5 \mathrm{~mm}\end{array}$ & \begin{tabular}{|c|}
$D_{\min }(\mathrm{um})$ \\
$+/-0.03 \mathrm{um}$
\end{tabular} & \begin{tabular}{|c|}
$D_{\max }(\mathrm{um})$ \\
$+/-0.03 \mathrm{um}$
\end{tabular} & $D_{\text {avg }}$ & $A_{\text {avg }}$ \\
\hline 31 & 1 & 1 & 0.067 & 0.067 & 0.067 & 0.003 \\
\hline 32 & 2 & 2 & 0.133 & 0.133 & 0.133 & 0.014 \\
\hline 33 & 2 & 3 & 0.133 & 0.200 & 0.167 & 0.022 \\
\hline 34 & 1 & 2 & 0.067 & 0.133 & 0.100 & 0.008 \\
\hline 35 & 1.5 & 2 & 0.100 & 0.133 & 0.117 & 0.011 \\
\hline 36 & 2 & 3 & 0.133 & 0.200 & 0.167 & 0.022 \\
\hline 37 & 2 & 3 & 0.133 & 0.200 & 0.167 & 0.022 \\
\hline 38 & 1 & 5 & 0.067 & 0.333 & 0.200 & 0.031 \\
\hline 39 & 2 & 2 & 0.133 & 0.133 & 0.133 & 0.014 \\
\hline 40 & 1 & 2 & 0.067 & 0.133 & 0.100 & 0.008 \\
\hline 41 & 2 & 2 & 0.133 & 0.133 & 0.133 & 0.014 \\
\hline 42 & 1 & 1 & 0.067 & 0.067 & 0.067 & 0.003 \\
\hline 43 & 1 & 1 & 0.067 & 0.067 & 0.067 & 0.003 \\
\hline 44| & 1 & 1 & 0.067 & 0.067 & 0.067 & 0.003 \\
\hline 45 & 1.5 & 3 & 0.100 & 0.200 & 0.150 & 0.018 \\
\hline 46 & 1.5 & 1.5 & 0.100 & 0.100 & 0.100 & 0.008 \\
\hline 47 & 1.5 & 2 & 0.100 & 0.133 & 0.117 & 0.011 \\
\hline 48 & 1.5 & 5 & 0.100 & 0.333 & 0.217 & 0.037 \\
\hline 49 & 3 & 3 & 0.200 & 0.200 & 0.200 & 0.031 \\
\hline $50 \mid$ & 1 & 1 & 0.067 & 0.067 & 0.067 & 0.003 \\
\hline 51 & 1 & 1 & 0.067 & 0.067 & 0.067 & 0.003 \\
\hline 52 & 1.5 & 1.5 & 0.100 & 0.100 & 0.100 & 0.008 \\
\hline 53 & 1 & 1 & 0.067 & 0.067 & 0.067 & 0.003 \\
\hline 54 & 1 & 1 & 0.067 & 0.067 & 0.067 & 0.003 \\
\hline 55 & 1 & 1 & 0.067 & 0.067 & 0.067 & 0.003 \\
\hline 56 & 1 & 1 & 0.067 & 0.067 & 0.067 & 0.003 \\
\hline 57 & 1 & 1 & 0.067 & 0.067 & 0.067 & 0.003 \\
\hline 58 & 1 & 2 & 0.067 & 0.133 & 0.100 & 0.008 \\
\hline 59 & 1 & 1 & 0.067 & 0.067 & 0.067 & 0.003 \\
\hline 60 & 1 & 1 & 0.067 & 0.067 & 0.067 & 0.003 \\
\hline 61 & 1 & 1 & 0.067 & 0.067 & 0.067 & 0.003 \\
\hline 62 & 1 & 1 & 0.067 & 0.067 & 0.067 & 0.003 \\
\hline 63 & 1 & 1 & 0.067 & 0.067 & 0.067 & 0.003 \\
\hline 64 & 1 & 2 & 0.067 & 0.133 & 0.100 & 0.008 \\
\hline 65 & 2 & 3 & 0.133 & 0.200 & 0.167 & 0.022 \\
\hline 66 & 1.5 & 2 & 0.100 & 0.133 & 0.117 & 0.011 \\
\hline 67| & 1.5 & 31 & 0.100 & 0.200 & 0.150 & 0.018 \\
\hline
\end{tabular}




\begin{tabular}{|c|c|c|c|c|c|c|}
\hline Pore \# & \begin{tabular}{|}
$D_{\min }(\mathrm{mm})$ \\
$+/-0.5 \mathrm{~mm}$ \\
\end{tabular} & $\begin{array}{l}D_{\max }(\mathrm{mm}) \\
+1-0.5 \mathrm{~mm} \\
\end{array}$ & $\begin{array}{r}D_{\min }(\mathrm{um}) \\
+/-0.03 \mathrm{um} \\
\end{array}$ & $\begin{array}{c}D_{\max }(\mathrm{um}) \\
+/-0.03 \mathrm{um} \\
\end{array}$ & $D_{\text {avg }}$ & $\overline{A_{\text {avg }}}$ \\
\hline 68 & 1.5 & 2.5 & 0.100 & 0.167 & 0.133 & 0.014 \\
\hline 69 & 1.5 & 2 & 0.100 & 0.133 & 0.117 & 0.011 \\
\hline 70 & 2 & 2 & 0.133 & 0.133 & 0.133 & 0.014 \\
\hline 71 & 2 & 2 & 0.133 & 0.133 & 0.133 & 0.014 \\
\hline 72 & 2 & 2 & 0.133 & 0.133 & 0.133 & 0.014 \\
\hline 73 & 2 & 2 & 0.133 & 0.133 & 0.133 & 0.014 \\
\hline 74 & 1 & 1.5 & 0.067 & 0.100 & 0.083 & 0.005 \\
\hline 75 & 1.5 & 1.5 & 0.100 & 0.100 & 0.100 & 0.008 \\
\hline 76 & 1.5 & 1.5 & 0.100 & 0.100 & 0.100 & 0.008 \\
\hline 77 & 1.5 & 1.5 & 0.100 & 0.100 & 0.100 & 0.008 \\
\hline 78 & 1.5 & 1.5 & 0.100 & 0.100 & 0.100 & 0.008 \\
\hline 79 & 1.5 & 1.5 & 0.100 & 0.100 & 0.100 & 0.008 \\
\hline 80 & 1.5 & 1.5 & 0.100 & 0.100 & 0.100 & 0.008 \\
\hline 81 & 1.5 & 1.5 & 0.100 & 0.100 & 0.100 & 0.008 \\
\hline 82 & 2. & 4 & 0.133 & 0.267 & 0.200 & 0.031 \\
\hline 83 & 3 & 3 & 0.200 & 0.200 & 0.200 & 0.031 \\
\hline 84 & 1 & 1 & 0.067 & 0.067 & 0.067 & 0.003 \\
\hline 85 & 1 & 1 & 0.067 & 0.067 & 0.067 & 0.003 \\
\hline 86 & 2 & 3 & 0.133 & 0.200 & 0.167 & 0.022 \\
\hline 87 & 2 & 3 & 0.133 & 0.200 & 0.167 & 0.022 \\
\hline 88 & 2 & 3 & 0.133 & 0.200 & 0.167 & 0.022 \\
\hline 89 & 1 & 1 & 0.067 & 0.067 & 0.067 & 0.003 \\
\hline 90 & 1 & 1 & 0.067 & 0.067 & 0.067 & 0.003 \\
\hline 91 & 1 & 1 & 0.067 & 0.067 & 0.067 & 0.003 \\
\hline 92 & 1 & 1 & 0.067 & 0.067 & 0.067 & 0.003 \\
\hline 93 & 1 & 1 & 0.067 & 0.067 & 0.067 & 0.003 \\
\hline 94 & 1 & 1 & 0.067 & 0.067 & 0.067 & 0.003 \\
\hline 95 & 1 & 1 & 0.067 & 0.067 & 0.067 & 0.003 \\
\hline 96 & 1 & 1 & 0.067 & 0.067 & 0.067 & 0.003 \\
\hline 97. & 1 & 1 & 0.067 & 0.067 & 0.067 & 0.003 \\
\hline 98 & 1 & 1 & 0.067 & 0.067 & 0.067 & 0.003 \\
\hline 99 & 2 & 2 & 0.133 & 0.133 & 0.133 & 0.014 \\
\hline 100 & 2 & 2 & 0.133 & 0.133 & 0.133 & 0.014 \\
\hline 101 & 2 & 3 & 0.133 & 0.200 & 0.167 & 0.022 \\
\hline 102 & 2 & 3 & 0.133 & 0.200 & 0.167 & 0.022 \\
\hline 103 & 2 & 2.5 & 0.133 & 0.167 & 0.150 & 0.018 \\
\hline 104 & 2 & 2.5 & 0.133 & 0.167 & 0.150 & 0.018 \\
\hline
\end{tabular}




\begin{tabular}{|c|c|c|c|c|c|c|}
\hline Pore \# & \begin{tabular}{|l|} 
\\
$D_{\min }(\mathrm{mm})$ \\
$+1-0.5 \mathrm{~mm}$
\end{tabular} & $\begin{array}{r}D_{\max }(\mathrm{mm}) \\
+/-0.5 \mathrm{~mm} \\
\end{array}$ & \begin{tabular}{|c|}
$D_{\min }(\mathrm{um})$ \\
$+/-0.03 \mathrm{um}$ \\
\end{tabular} & $\begin{array}{c}D_{\max }(\mathrm{um}) \\
+1-0.03 \mathrm{um} \\
\end{array}$ & $D_{\text {avg }}$ & $\overline{A_{\text {avg }}}$ \\
\hline 105 & 1 & 1 & 0.067 & 0.067 & 0.067 & 0.003 \\
\hline 106 & 2 & 2 & 0.133 & 0.133 & 0.133 & 0.014 \\
\hline 107 & 2 & 2 & 0.133 & 0.133 & 0.133 & 0.014 \\
\hline 108 & 2 & 2 & 0.133 & 0.133 & 0.133 & 0.014 \\
\hline 109 & 2 & 2 & 0.133 & 0.133 & 0.133 & 0.014 \\
\hline 110 & 2 & 2 & 0.133 & 0.133 & 0.133 & 0.014 \\
\hline 111 & 2 & 3 & 0.133 & 0.200 & 0.167 & 0.022 \\
\hline 112 & 2 & 2 & 0.133 & 0.133 & 0.133 & 0.014 \\
\hline 113 & 2 & 2 & 0.133 & 0.133 & 0.133 & 0.014 \\
\hline 114 & 2 & 2 & 0.133 & 0.133 & 0.133 & 0.014 \\
\hline 115 & 2 & 2 & 0.133 & 0.133 & 0.133 & 0.014 \\
\hline 116 & 2 & 2 & 0.133 & 0.133 & 0.133 & 0.014 \\
\hline 117 & 1 & 1 & 0.067 & 0.067 & 0.067 & 0.003 \\
\hline 118 & 2 & 3 & 0.133 & 0.200 & 0.167 & 0.022 \\
\hline 119 & 2 & 2 & 0.133 & 0.133 & 0.133 & 0.014 \\
\hline 120 & 2 & 2 & 0.133 & 0.133 & 0.133 & 0.014 \\
\hline 121 & 2 & 2 & 0.133 & 0.133 & 0.133 & 0.014 \\
\hline 122 & 2 & 2 & 0.133 & 0.133 & 0.133 & 0.014 \\
\hline 123 & 1 & 1.5 & 0.067 & 0.100 & 0.083 & 0.005 \\
\hline 124 & 1 & 1.5 & 0.067 & 0.100 & 0.083 & 0.005 \\
\hline 125 & 1.5 & 2 & 0.100 & 0.133 & 0.117 & 0.011 \\
\hline 126 & 1 & 1 & 0.067 & 0.067 . & 0.067 & 0.003 \\
\hline 127 & 1 & 1 & 0.067 & 0.067 & 0.067 & 0.003 \\
\hline 128 & 1 & 1 & 0.067 & 0.067 & 0.067 & 0.003 \\
\hline 129 & 1 & 1 & 0.067 & 0.067 & 0.067 & 0.003 \\
\hline 130 & 1 & 1 & 0.067 & 0.067 & 0.067 & 0.003 \\
\hline 131 & 1 & 1 & 0.067 & 0.067 & 0.067 & 0.003 \\
\hline 132 & 1 & 1 & 0.067 & 0.067 & 0.067 & 0.003 \\
\hline 133 & 1 & 1 & 0.067 & 0.067 & 0.067 & 0.003 \\
\hline 134 & 1 & 1 & 0.067 & 0.067 & 0.067 & 0.003 \\
\hline 135 & 1 & 1 & 0.067 & 0.067 & 0.067 & 0.003 \\
\hline 136 & 1.5 & 2 & 0.100 & 0.133 & 0.117 & 0.011 \\
\hline 137 & 1 & 2 & 0.067 & 0.133 & 0.100 & 0.008 \\
\hline 138 & 1 & 2 & 0.067 & 0.133 & 0.100 & 0.008 \\
\hline 139 & 1 & 2 & 0.067 & 0.133 & 0.100 & 0.008 \\
\hline 140 & 2 & 3 & 0.133 & 0.200 & 0.167 & 0.022 \\
\hline 141 & 21 & 3 & 0.133 & 0.200 & 0.167 & 0.022 \\
\hline
\end{tabular}




\begin{tabular}{|c|c|c|c|c|c|c|}
\hline Pore \# & $\begin{array}{r}D_{\min }(\mathrm{mm}) \\
+1-0.5 \mathrm{~mm} \\
\end{array}$ & $\begin{array}{l}D_{\max }(\mathrm{mm}) \\
+/-0.5 \mathrm{~mm} \\
\end{array}$ & \begin{tabular}{|}
$D_{\min }(u m)$ \\
$+/-0.03$ um \\
\end{tabular} & $\begin{array}{r}D_{\max } \text { (um) } \\
+/-0.03 \text { um } \\
\end{array}$ & $D_{\text {avg }}$ & $A_{\text {avg }}$ \\
\hline 142 & 1.5 & 2 & 0.100 & 0.133 & 0.117 & 0.011 \\
\hline 143 & 2 & 3 & 0.133 & 0.200 & 0.167 & 0.022 \\
\hline 144 & 2 & 2 & 0.133 & 0.133 & 0.133 & 0.014 \\
\hline 145 & 3 & 3 & 0.200 & 0.200 & 0.200 & 0.031 \\
\hline 146 & 1 & 2 & 0.067 & 0.133 & 0.100 & 0.008 \\
\hline 147 & 1 & 2 & 0.067 & 0.133 & 0.100 & 0.008 \\
\hline 148 & 1 & 2 & 0.067 & 0.133 & 0.100 & 0.008 \\
\hline 149 & 2 & 2.5 & 0.133 & 0.167 & 0.150 & 0.018 \\
\hline 150 & 1 & 1 & 0.067 & 0.067 & 0.067 & 0.003 \\
\hline 151 & 2 & 3 & 0.133 & 0.200 & 0.167 & 0.022 \\
\hline 152 & 1.5 & 3 & 0.100 & 0.200 & 0.150 & 0.018 \\
\hline 153 & 1 & 1 & 0.067 & 0.067 & 0.067 & 0.003 \\
\hline 154 & 1.5 & 1.5 & 0.100 & 0.100 & 0.100 & 0.008 \\
\hline 155 & 2 & 2 & 0.133 & 0.133 & 0.133 & 0.014 \\
\hline 156 & 1 & 2 & 0.067 & 0.133 & 0.100 & 0.008 \\
\hline 157 & 1 & 1 & 0.067 & 0.067 & 0.067 & 0.003 \\
\hline 158 & 1 & 1 & 0.067 & 0.067 & 0.067 & 0.003 \\
\hline 159 & 1 & 1 & 0.067 & 0.067 & 0.067 & 0.003 \\
\hline 160 & 1 & 1 & 0.067 & 0.067 & 0.067 & 0.003 \\
\hline 161 & 1 & 1 & 0.067 & 0.067 & 0.067 & 0.003 \\
\hline 162 & 1.5 & 1.5 & 0.100 & 0.100 & 0.100 & 0.008 \\
\hline 163 & 1.5 & 1.5 & 0.100 & 0.100 & 0.100 & 0.008 \\
\hline 164 & 2 & 2 & 0.133 & 0.133 & 0.133 & 0.014 \\
\hline 165 & 2 & 2 & 0.133 & 0.133 & 0.133 & 0.014 \\
\hline 166 & 2 & 2 & 0.133 & 0.133 & 0.133 & 0.014 \\
\hline 167 & 2 & 3 & 0.133 & 0.200 & 0.167 & 0.022 \\
\hline 168 & 2 & 2 & 0.133 & 0.133 & 0.133 & 0.014 \\
\hline 169 & 2 & 2 & 0.133 & 0.133 & 0.133 & 0.014 \\
\hline 170 & 2 & 2 & 0.133 & 0.133 & 0.133 & 0.014 \\
\hline 171 & 2 & 2 & 0.133 & 0.133 & 0.133 & 0.014 \\
\hline 172 & 2 & 2.5 & 0.133 & 0.167 & 0.150 & 0.018 \\
\hline 173 & 2 & 2 & 0.133 & 0.133 & 0.133 & 0.014 \\
\hline 174 & 1 & 2 & 0.067 & 0.133 & 0.100 & 0.008 \\
\hline 175 & 1.5 & 2 & 0.100 & 0.133 & 0.117 & 0.011 \\
\hline 176 & 1.5 & 1.5 & 0.100 & 0.100 & 0.100 & 0.008 \\
\hline 177 & 2 & 2 & 0.133 & 0.133 & 0.133 & 0.014 \\
\hline 178 & 21 & 2 & 0.133 & 0.133 & 0.133 & 0.014 \\
\hline
\end{tabular}




\begin{tabular}{|c|c|c|c|c|c|c|}
\hline Pore \# & $\begin{array}{r}D_{\min }(\mathrm{mm}) \\
+/-0.5 \mathrm{~mm} \\
\end{array}$ & $\begin{array}{r}D_{\operatorname{mex}}(\mathrm{mm}) \\
+/-0.5 \mathrm{~mm}\end{array}$ & $\begin{array}{c}D_{\min } \text { (um) } \\
+1-0.03 \text { um }\end{array}$ & $\begin{array}{c}D_{\max }(\mathrm{um}) \\
+/-0.03 \mathrm{um}\end{array}$ & $D_{\text {avg }}$ & $A_{\text {avg }}$ \\
\hline 179 & 2 & 2 & 0.133 & 0.133 & 0.133 & 0.014 \\
\hline 180 & 2 & 2 & 0.133 & 0.133 & 0.133 & 0.014 \\
\hline 181 & 2 & 2 & 0.133 & 0.133 & 0.133 & 0.014 \\
\hline 182 & 2 & 2 & 0.133 & 0.133 & 0.133 & 0.014 \\
\hline 183 & 1 & 1 & 0.067 & 0.067 & 0.067 & 0.003 \\
\hline 184 & 1 & 2 & 0.067 & 0.133 & 0.100 & 0.008 \\
\hline 185 & 1 & 2 & 0.067 & 0.133 & 0.100 & 0.008 \\
\hline 186 & 1 & 1 & 0.067 & 0.067 & 0.067 & 0.003 \\
\hline 187 & 1 & 2 & 0.067 & 0.133 & 0.100 & 0.008 \\
\hline 188 & 2 & 2 & 0.133 & 0.133 & 0.133 & 0.014 \\
\hline 189 & 2 & 2 & 0.133 & 0.133 & 0.133 & 0.014 \\
\hline 190 & 1.5 & 2 & 0.100 & 0.133 & 0.117 & 0.011 \\
\hline 191 & 1.5 & 2 & 0.100 & 0.133 & 0.117 & 0.011 \\
\hline 192 & 1.5 & 2 & 0.100 & 0.133 & 0.117 & 0.011 \\
\hline 193 & 1.5 & 3 & 0.100 & 0.200 & 0.150 & 0.018 \\
\hline 194 & 1 & 1.5 & 0.067 & 0.100 & 0.083 & 0.005 \\
\hline 195 & 1 & 1 & 0.067 & 0.067 & 0.067 & 0.003 \\
\hline 196 & 1 & 1 & 0.067 & 0.067 & 0.067 & 0.003 \\
\hline 197 & 1 & 1 & 0.067 & 0.067 & 0.067 & 0.003 \\
\hline 198 & 2 & 3 & 0.133 & 0.200 & 0.167 & 0.022 \\
\hline 199 & 0.5 & 0.5 & 0.033 & 0.033 & 0.033 & 0.001 \\
\hline 200 & 1 & 1 & 0.067 & 0.067 & 0.067 & 0.003 \\
\hline 201 & 1 & 1 & 0.067 & 0.067 & 0.067 & 0.003 \\
\hline 202 & 1 & 1 & 0.067 & 0.067 & 0.067 & 0.003 \\
\hline 203 & 2 & 2 & 0.133 & 0.133 & 0.133 & 0.014 \\
\hline 204 & 2 & 2 & 0.133 & 0.133 & 0.133 & 0.014 \\
\hline 205 & 2 & 2 & 0.133 & 0.133 & 0.133 & 0.014 \\
\hline 206 & 2 & 2 & 0.133 & 0.133 & 0.133 & 0.014 \\
\hline 207 & 2 & 2 & 0.133 & 0.133 & 0.133 & 0.014 \\
\hline 208 & 1 & 1 & 0.067 & 0.067 & 0.067 & 0.003 \\
\hline 209 & 1 & 1 & 0.067 & 0.067 & 0.067 & 0.003 \\
\hline 210 & 1 & 1 & 0.067 & 0.067 & 0.067 & 0.003 \\
\hline 211 & 1 & 1 & 0.067 & 0.067 & 0.067 & 0.003 \\
\hline 212 & 1 & 1 & 0.067 & 0.067 & 0.067 & 0.003 \\
\hline 213 & 1 & 1 & 0.067 & 0.067 & 0.067 & 0.003 \\
\hline 214 & 1 & 1 & 0.067 & 0.067 & 0.067 & 0.003 \\
\hline 215 & 2 & 21 & 0.133 & 0.133 & 0.133 & 0.014 \\
\hline
\end{tabular}




\begin{tabular}{|c|c|c|c|c|c|c|}
\hline Pore \# & $\begin{array}{l}D_{\min }(\mathrm{mm}) \\
+/-0.5 \mathrm{~mm}\end{array}$ & $\begin{array}{l}D_{\max }(\mathrm{mm}) \\
+/-0.5 \mathrm{~mm}\end{array}$ & $\begin{array}{c}D_{\min } \text { (um) } \\
+/-0.03 \text { um }\end{array}$ & $\begin{array}{c}D_{\max }(\mathrm{um}) \\
+/-0.03 \mathrm{um}\end{array}$ & $D_{\text {avg }}$ & $A_{\text {avg }}$ \\
\hline 216 & 2 & 2 & 0.133 & 0.133 & 0.133 & 0.014 \\
\hline 217 & 2 & 2 & 0.133 & 0.133 & 0.133 & 0.014 \\
\hline 218 & 2 & 2 & 0.133 & 0.133 & 0.133 & 0.014 \\
\hline 219 & 2 & 2 & 0.133 & 0.133 & 0.133 & 0.014 \\
\hline 220 & 1 & 1 & 0.067 & 0.067 & 0.067 & 0.003 \\
\hline 221 & 1 & 1 & 0.067 & 0.067 & 0.067 & 0.003 \\
\hline 222 & 1 & 1 & 0.067 & 0.067 & 0.067 & 0.003 \\
\hline 223 & 1 & 1 & 0.067 & 0.067 & 0.067 & 0.003 \\
\hline 224 & 1 & 1 & 0.067 & 0.067 & 0.067 & 0.003 \\
\hline 225 & 1 & 1 & 0.067 & 0.067 & 0.067 & 0.003 \\
\hline 226 & 1 & 1 & 0.067 & 0.067 & 0.067 & 0.003 \\
\hline 227| & 1 & 1 & 0.067 & 0.067 & 0.067 & 0.003 \\
\hline 228 & 2 & 2.5 & 0.133 & 0.167 & 0.150 & 0.018 \\
\hline 229 & 2 & 2 & 0.133 & 0.133 & 0.133 & 0.014 \\
\hline 230 & 1.5 & 1.5 & 0.100 & 0.100 & 0.100 & 0.008 \\
\hline 231 & 1.5 & 1.5 & 0.100 & 0.100 & 0.100 & 0.008 \\
\hline 232 & 2 & 2 & 0.133 & 0.133 & 0.133 & 0.014 \\
\hline 233 & 2 & 2 & 0.133 & 0.133 & 0.133 & 0.014 \\
\hline 234 & 1 & 1 & 0.067 & 0.067 & 0.067 & 0.003 \\
\hline 235 & 1 & 1 & 0.067 & 0.067 & 0.067 & 0.003 \\
\hline 236 & 1 & 1 & 0.067 & 0.067 & 0.067 & 0.003 \\
\hline 237 & 1 & 1 & 0.067 & 0.067 & 0.067 & 0.003 \\
\hline 238 & 1 & 1 & 0.067 & 0.067 & 0.067 & 0.003 \\
\hline 239 & 1 & 1 & 0.067 & 0.067 & 0.067 & 0.003 \\
\hline 240 & 2 & 2 & 0.133 & 0.133 & 0.133 & 0.014 \\
\hline 241 & 2 & 2 & 0.133 & 0.133 & 0.133 & 0.014 \\
\hline 242 & 2 & 2 & 0.133 & 0.133 & 0.133 & 0.014 \\
\hline 243 & 2 & 2 & 0.133 & 0.133 & 0.133 & 0.014 \\
\hline 244 & 1.5 & 1.5 & 0.100 & 0.100 & 0.100 & 0.008 \\
\hline 245 & 2 & 3 & 0.133 & 0.200 & 0.167 & 0.022 \\
\hline 246 & 2 & 3 & 0.133 & 0.200 & 0.167 & 0.022 \\
\hline 247 & 2 & 2 & 0.133 & 0.133 & 0.133 & 0.014 \\
\hline 248 & 2 & 2 & 0.133 & 0.133 & 0.133 & 0.014 \\
\hline 249 & 2 & 2 & 0.133 & 0.133 & 0.133 & 0.014 \\
\hline 250 & 1 & 2 & 0.067 & 0.133 & 0.100 & 0.008 \\
\hline 251 & 2 & 3 & 0.133 & 0.200 & 0.167 & 0.022 \\
\hline 252 & 1] & 1.5 & 0.067 & 0.100 & 0.083 & 0.005 \\
\hline
\end{tabular}




\begin{tabular}{|c|c|c|c|c|c|c|}
\hline Pore \# & $\begin{array}{l}D_{\min }(\mathrm{mm}) \\
+1-0.5 \mathrm{~mm} \\
\end{array}$ & $\begin{array}{l}D_{\max }(\mathrm{mm}) \\
+/-0.5 \mathrm{~mm}\end{array}$ & $\begin{array}{c}D_{\min } \text { (um) } \\
+/-0.03 \text { um }\end{array}$ & $\begin{array}{c}D_{\max }(\mathrm{um}) \\
+/-0.03 \text { um }\end{array}$ & $D_{\text {avg }}$ & $A_{\text {avg }}$ \\
\hline 253 & 1.5 & 1.5 & 0.100 & 0.100 & 0.100 & 0.008 \\
\hline 254 & 1.5 & 2 & 0.100 & 0.133 & 0.117 & 0.011 \\
\hline 255 & 2 & 2 & 0.133 & 0.133 & 0.133 & 0.014 \\
\hline 256 & 2 & 2 & 0.133 & 0.133 & 0.133 & 0.014 \\
\hline 257 & 2 & 2 & 0.133 & 0.133 & 0.133 & 0.014 \\
\hline 258 & 2 & 2 & 0.133 & 0.133 & 0.133 & 0.014 \\
\hline 259 & 2 & 2 & 0.133 & 0.133 & 0.133 & 0.014 \\
\hline 260 & 2 & 2 & 0.133 & 0.133 & 0.133 & 0.014 \\
\hline 261 & 2 & 2 & 0.133 & 0.133 & 0.133 & 0.014 \\
\hline 262 & 2 & 2 & 0.133 & 0.133 & 0.133 & 0.014 \\
\hline 263 & 2 & 3 & 0.133 & 0.200 & 0.167 & 0.022 \\
\hline 264 & 2.5 & 3 & 0.167 & 0.200 & 0.183 & 0.026 \\
\hline 265 & 1 & 1 & 0.067 & 0.067 & 0.067 & 0.003 \\
\hline 266 & 1 & 1 & 0.067 & 0.067 & 0.067 & 0.003 \\
\hline 267 & 1 & 2 & 0.067 & 0.133 & 0.100 & 0.008 \\
\hline 268 & 1.5 & 3 & 0.100 & 0.200 & 0.150 & 0.018 \\
\hline 269 & 1 & 1 & 0.067 & 0.067 & 0.067 & 0.003 \\
\hline 270 & 1 & 1 & 0.067 & 0.067 & 0.067 & 0.003 \\
\hline 271 & 1.5 & 2 & 0.100 & 0.133 & 0.117 & 0.011 \\
\hline 272 & 1.5 & 2 & 0.100 & 0.133 & 0.117 & 0.011 \\
\hline 273 & 1.5 & 2 & 0.100 & 0.133 & 0.117 & 0.011 \\
\hline 274 & 1.5 & 2 & 0.100 & 0.133 & 0.117 & 0.011 \\
\hline 275 & 1.5 & 2 & 0.100 & 0.133 & 0.117 & 0.011 \\
\hline 276 & 1 & 2 & 0.067 & 0.133 & 0.100 & 0.008 \\
\hline 277 & 2 & 3 & 0.133 & 0.200 & 0.167 & 0.022 \\
\hline 278 & 2 & 3 & 0.133 & 0.200 & 0.167 & 0.022 \\
\hline 279 & 2.5 & 3 & 0.167 & 0.200 & 0.183 & 0.026 \\
\hline 280 & 2 & 2 & 0.133 & 0.133 & 0.133 & 0.014 \\
\hline 281 & 2 & 2 & 0.133 & 0.133 & 0.133 & 0.014 \\
\hline 282 & 2 & 2 & 0.133 & 0.133 & 0.133 & 0.014 \\
\hline 283 & 2 & 2 & 0.133 & 0.133 & 0.133 & 0.014 \\
\hline 284 & 1.5 & 2 & 0.100 & 0.133 & 0.117 & 0.011 \\
\hline 285 & 1 & 1.5 & 0.067 & 0.100 & 0.083 & 0.005 \\
\hline 286 & 1.5 & 3 & 0.100 & 0.200 & 0.150 & 0.018 \\
\hline 287 & 1 & 1 & 0.067 & 0.067 & 0.067 & 0.003 \\
\hline 288 & 1.5 & 3 & 0.100 & 0.200 & 0.150 & 0.018 \\
\hline 289 & 2 & 2 & 0.133 & 0.133 & 0.133 & 0.014 \\
\hline
\end{tabular}




\begin{tabular}{|c|c|c|c|c|c|c|}
\hline Pore \# & \begin{tabular}{|l|}
$D_{\min }(\mathrm{mm})$ \\
$+1-0.5 \mathrm{~mm}$ \\
\end{tabular} & $\begin{array}{l}D_{\max }(\mathrm{mm}) \\
+/-0.5 \mathrm{~mm}\end{array}$ & $\begin{array}{r}D_{\min }(\text { um) } \\
+/-0.03 \text { um } \\
\end{array}$ & $\begin{array}{c}D_{\max } \text { (um) } \\
+/-0.03 \text { um } \\
\end{array}$ & $D_{\text {avg }}$ & $A_{\text {avg }}$ \\
\hline 289 & 2 & 2 & 0.133 & 0.133 & 0.133 & 0.014 \\
\hline 290 & 2 & 2 & 0.133 & 0.133 & 0.133 & 0.014 \\
\hline 291 & 2 & 2 & 0.133 & 0.133 & 0.133 & 0.014 \\
\hline 292 & 2 & 2 & 0.133 & 0.133 & 0.133 & 0.014 \\
\hline 293 & 1.5 & 1.5 & 0.100 & 0.100 & 0.100 & 0.008 \\
\hline 294 & 1.5 & 1.5 & 0.100 & 0.100 & 0.100 & 0.008 \\
\hline 295 & 2 & 3 & 0.133 & 0.200 & 0.167 & 0.022 \\
\hline 296 & 2 & 4 & 0.133 & 0.267 & 0.200 & 0.031 \\
\hline 297 & 2 & 4 & 0.133 & 0.267 & 0.200 & 0.031 \\
\hline 298 & 2 & 4 & 0.133 & 0.267 & 0.200 & 0.031 \\
\hline 299 & 2 & 2 & 0.133 & 0.133 & 0.133 & 0.014 \\
\hline 300 & 2 & 5 & 0.133 & 0.333 & 0.233 & 0.043 \\
\hline 301 & 2 & 3 & 0.133 & 0.200 & 0.167 & 0.022 \\
\hline 302 & 3 & 4 & 0.200 & 0.267 & 0.233 & 0.043 \\
\hline 303 & 1.5 & 1.5 & 0.100 & 0.100 & 0.100 & 0.008 \\
\hline 304 & 1 & 1 & 0.067 & 0.067 & 0.067 & 0.003 \\
\hline \multirow{2}{*}{\multicolumn{3}{|c|}{$\begin{array}{l}\text { Average } \\
\text { Avearge Total etched area(um²) }\end{array}$}} & 0.104 & 0.127 & 0.116 & \\
\hline & & & & & & 3565 \\
\hline \multicolumn{3}{|c|}{ Avearge Total etched area $\left(u^{2}{ }^{2}\right)$} & & 3.565 & & \\
\hline \multicolumn{3}{|c|}{ Total Surface Area $\left(\mathrm{um}^{2}\right)$} & & 10.40 & & \\
\hline \multicolumn{3}{|c|}{$\begin{array}{l}\text { Pore density ( pores } / \mathrm{cm}^{2} \text { ) } \\
\text { Avg. Fractional Etched Area }\end{array}$} & & $\begin{array}{l}12.99 \\
0.343\end{array}$ & & \\
\hline
\end{tabular}



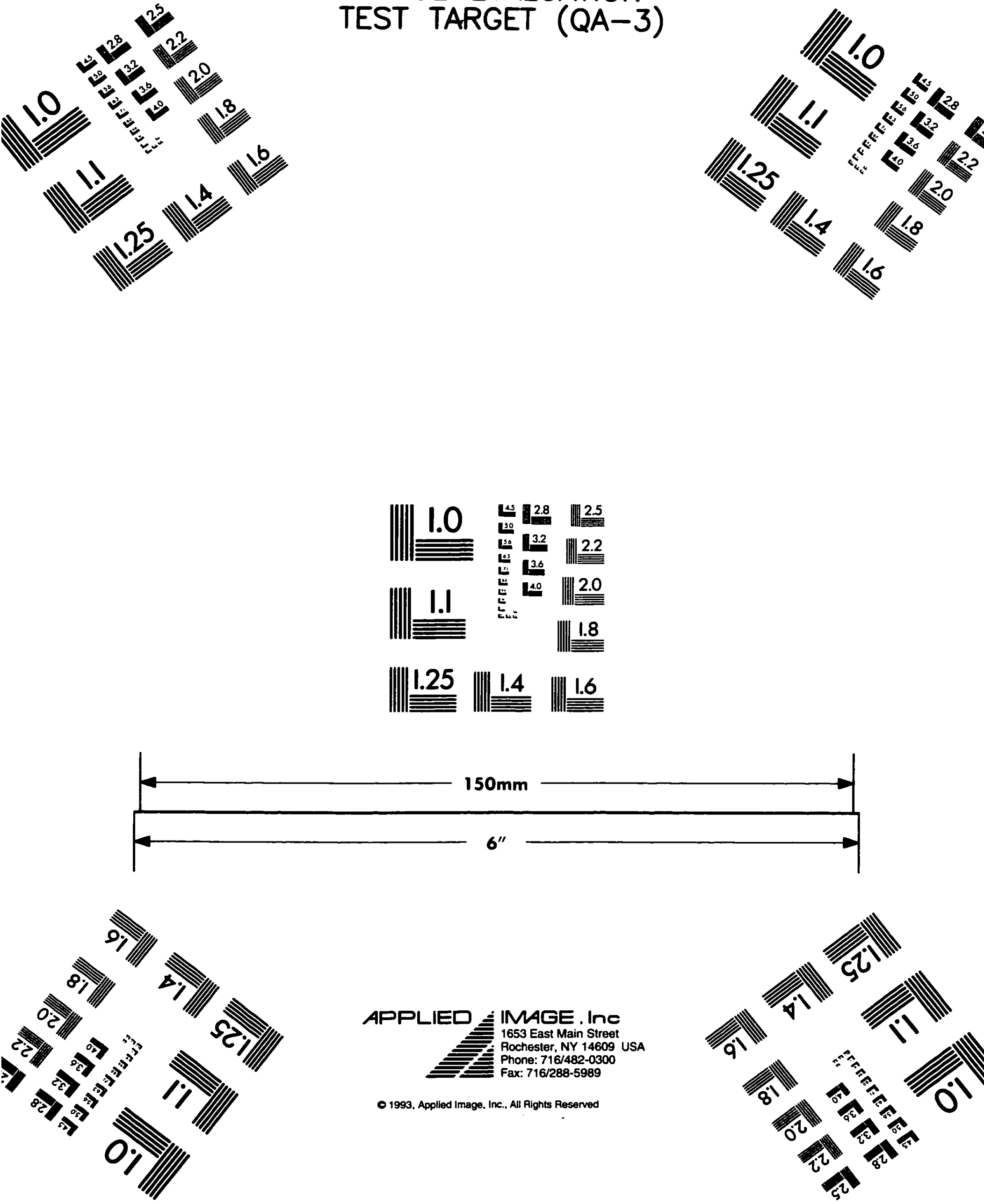

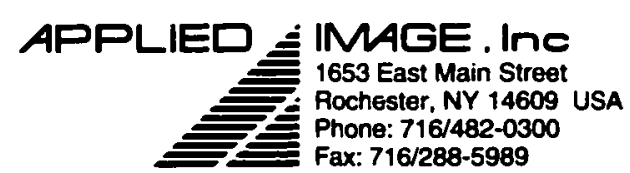

0 1993. Applied Image, Inc., All Rights Reserved

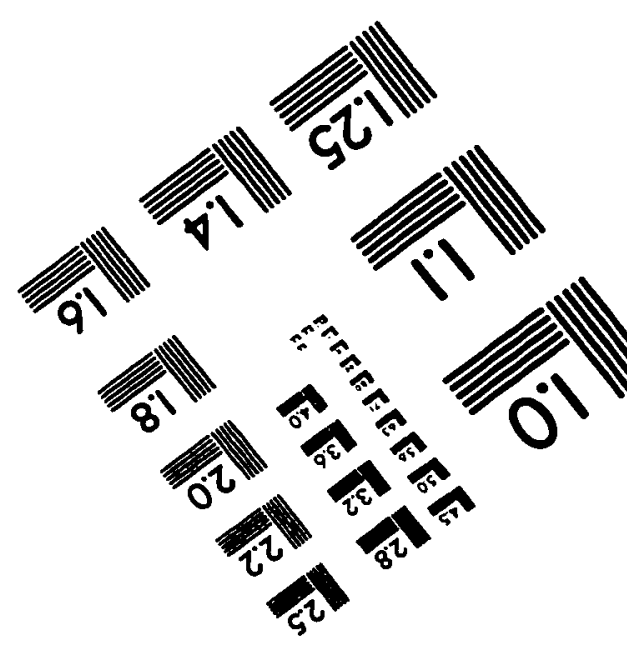

